\title{
MARCELO NISHIYAMA
}

Efeitos do treinamento físico e ingestão de vinho tinto na função cognitiva de indivíduos sem declínio cognitivo

Tese apresentada à Faculdade de Medicina da Universidade de São Paulo para obtenção do título de Doutor em Ciências

Programa de Cardiologia

Orientador: Francisco Rafael Martins Laurindo

SÃO PAULO 
Dados Internacionais de Catalogação na Publicação (CIP)

Preparada pela Biblioteca da

Faculdade de Medicina da Universidade de São Paulo

Creprodução autorizada pelo autor

Nishiyama, Marcelo

Efeitos do treinamento físico e ingestão de vinho tinto na função cognitiva de indivíduos sem declínio cognitivo / Marcelo Nishiyama. -- São Paulo, 2018. Tese (doutorado)--Faculdade de Medicina da Universidade de São Paulo.

Programa de Cardiologia.

Orientador: Francisco Rafael Martins Laurindo.

Descritores: 1.Exercício 2.Consumo de oxigênio 3. Cognição 4.Vinho 5. Imagem por ressonância magnética funcional 6. Testes neuropsicológicos

$\mathrm{USP} / \mathrm{FM} / \mathrm{DBD}-468 / 18$ 
Dedicatória 
Para meus amados pais, Alberto Choiti (in memorian) e Rosa Maria, por minha formação como homem e cidadão.

Aos meus irmãos Simoni e Fábio, que sempre me ajudaram e tornaram tudo tão mais fácil.

Para minha esposa Aline, por compartilhar a vida.

Para meu filho Max, pelo maravilhoso e surpreendente futuro! 
Agradecimentos 
Agradeço ao Prof. Dr. Protásio Lemos da Luz, meu professor, meu mestre, a quem tive a honra, o privilégio e o prazer de acompanhar na ciência e no dia-adia. Um grande incentivador, que com trabalho e exemplo me ensinou uma Nova Face da Medicina! Muito obrigado!

Agradeço a todos que colaboraram para a realização desta tese, e de modo especial:

Ao meu orientador, Prof. Dr. Francisco Rafael Martins Laurindo, por todo apoio e suporte acadêmico, e por emprestar sua excelência em pesquisa e ciência para esta tese. Obrigado.

- Ao Prof. Dr. Edson Amaro Júnior

- Ao Prof. Dr. Desidério Favarato

- Ao Prof. Dr. Carlos Eduardo Negrão

Agradeço aos Institutos e seus muitos colaboradores, sem os quais este trabalho, que é multidisciplinar, não seria possível:

- Instituto do Coração do HCFMUSP- InCor

- Laboratório do Incor

- Reabilitação Cardiovascular do InCor

- Instituto de Radiologia do HCFMUSP - InRad

- Instituto de Psiquiatria do HCFMUSP - IPq

Agradeço às Instituições:

- Fundação Zerbini - pelo amparo administrativo

- Banco Bradesco - pelo apoio financeiro à equipe de Pesquisa do Prof. Protásio Lemos da Luz

Agradeço com especial carinho:

Os co-autores:

- Meu bom amigo Dr. Lucas Zoppi Campane, por todos os anos de companheirismo

- Dra. Mariana Penteado Nucci, pois o seu auxílio foi essencial em todos os momentos

- Dra. Marina Von Zuben

- Dra. Ivani Credidio Trombetta

Às Enfermeiras:

- Enf. Juliana Cecília Pereto Rocha

- Enf. Natacia Sabina Pereto Rocha 
$\grave{A}$ assistente de pesquisa

Dra. Michelle Aparecida Pereira, por toda sua dedicação e competência durante todo meu curso de pós-graduação.

Agradeço aos 97 voluntários desta pesquisa.

Quero ainda agradecer aos amigos que juntos sofreram e se alegraram com este trabalho, e aos professores inspiradores que passaram por minha vida:

- Dra. Maria Zenaide Soares Fichino

- Prof. Dr. Romeu Sérgio Meneghelo 
Epígrafe 
"Combati o bom combate, terminei a corrida, guardei a fé" 
Normatização adotada 
Esta tese está de acordo com as seguintes normas, em vigor no momento de sua publicação:

Referências: adaptado de International Committee of Medical Journals Editors (Vancouver).

Universidade de São Paulo. Faculdade de Medicina. Divisão de Biblioteca e Documentação. Guia de apresentação de dissertações, teses e monografias. Elaborado por Anneliese Carneiro da Cunha, Maria Julia de A.L.Freddi, Maria F.Crestana, Marinalva de Souza Aragão, Suely Campos Cardoso, Valéria Vilhena. $3^{\underline{a}}$ ed. São Paulo: Divisão de Biblioteca e Documentação; 2011.

Abreviatura dos títulos e periódicos de acordo com List of Journals Indexed in Index Medicus. 
Sumário 
Lista de siglas e abreviaturas

Lista de tabelas

Lista de figuras

Lista de gráficos

\section{Resumo}

Abstract

$1 \quad$ INTRODUÇÃO.......................................................................... 01

$1.1 \quad$ Envelhecimento normal e patológico ......................................... 03

1.2 Exercício físico e função cognitiva............................................ 06

1.3 Mecanismos e efeitos protetores do consumo regular de vinho

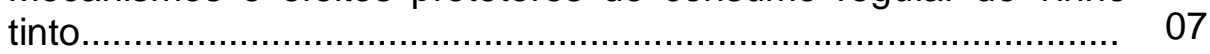

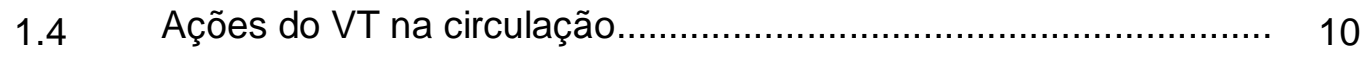

1.5 O eixo cérebro/coração........................................................... 13

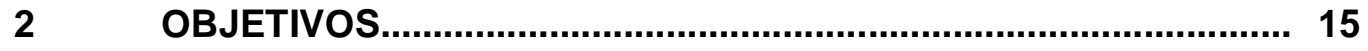

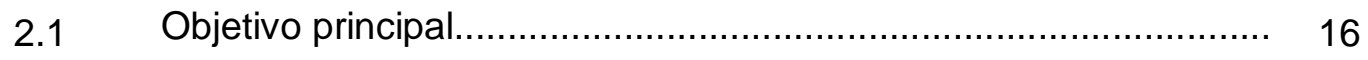

2.2 Objetivos secundários....................................................... 16

3 MATERIAL E MÉTODOS.......................................................... 17

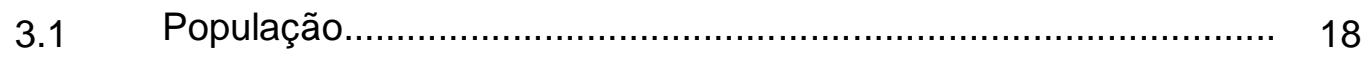

3.2 Recrutamento............................................................... 18

3.3 Critérios de inclusão................................................................... 19

3.4 Critérios de exclusão.......................................................... 20

3.5 Dinâmica do estudo.................................................................. 22

3.6 Randomização e alocação....................................................... 23

3.7 Avaliação clínica................................................................. 24

3.7.1 Dados pessoais e exame físico.............................................. 24

3.7.2 Escolaridade.................................................................... 24

3.7.3 Consumo de bebida alcoólica.................................................... 25

3.7.4 Teste de esforço cardiopulmonar.......................................... 25

3.7.5 Avaliação Neuropsicológica.................................................. 26

3.7.6 Ressonância Magnética Funcional (fMRI) …............................. 27

3.8 Sequências e parâmetros de aquisição das imagens por RM......... 28

3.8.1 Imagens estruturais............................................................... 28

3.8.2 Imagens funcionais................................................................... 29

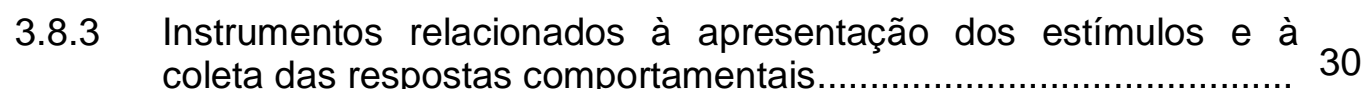

3.8.4 Paradigmas da RM funcional................................................ 32

3.8.5 Paradigma de função executiva.................................................. 32

3.8.6 Paradigma de memória operacional............................................. 34

3.9 Dinâmica do exame de RM funcional............................................ 36

3.9.1 Treino dos paradigmas......................................................... 36 
3.9.2 Posicionamento dos voluntários.................................................. 37

3.9.3 Realização do exame de RM funcional......................................... 37

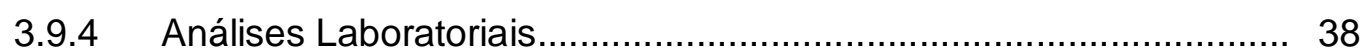

3.9.5 Programa de exercício supervisionado....................................... 38

3.9.6 Análise estatística.................................................................. 39

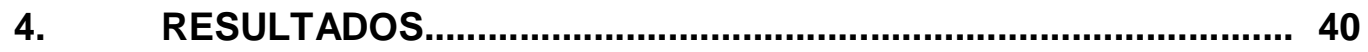

4.1 Característica da amostra........................................................ 41

4.2 Questionários e avaliação neuropsicológica................................. 42

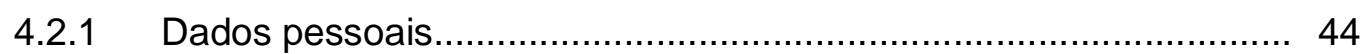

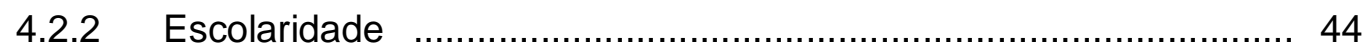

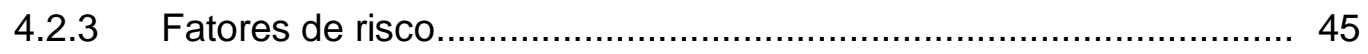

4.2.4 Consumo de vinho tinto.......................................................... 46

4.2.5 Teste de esforço cardiopulmonar.............................................. 47

4.2.6 Análises Laboratoriais........................................................... 49

4.3 Avaliação Neuropsicológica.................................................... 50

4.3.1 Rastreio do comprometimento cognitivo.................................... 50

4.4 Avaliação pré-exercício............................................................ 51

4.4.1 Testes Neuropsicológico.......................................................... 51

4.4.2 Ressonância Magnética Funcional.............................................. 52

$4.5 \quad$ Efeitos do treinamento físico..................................................... 57

4.5.1 Testes Neuropsicológicos......................................................... 57

4.5.2 Ressonância Magnética Funcional............................................... 61

4.6 Relação $\mathrm{VO}_{2}$ e Funções cerebrais............................................... 86

5. CONCLUSÃO.......................................................................... 91

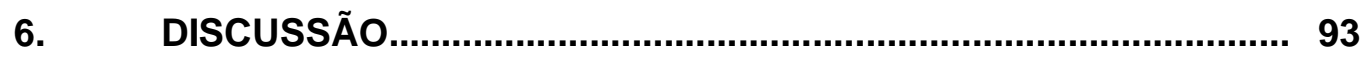

7. REFERÊNCIAS BIBLIOGRÁFICAS........................................... 101

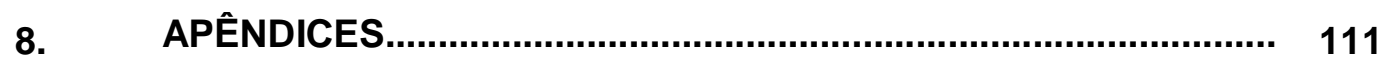




\section{Listas}




\begin{tabular}{ll} 
ANOVA & Análise de variância \\
AP & Anteroposterior \\
ABS & Abstêmios sem treinamento físico \\
ABST & Abstêmios com treinamento físico \\
AVC & Acidente vascular cerebral \\
b-FFE & Fast field echo \\
CAPPesq & Comissão de Ética para Análise de Projetos de Pesquisa \\
CC & Craniocaudal \\
CDT & Teste do Desenho do Relógio \\
CO2 & Dióxido de Carbono \\
DA & Doença de Alzheimer \\
DAC & Doença arterial coronariana \\
DP & Desvio padrão \\
DVC & Doença vascular cerebral \\
ENF & Emaranhados neurofibrilares \\
eNOS & Oxidonitrico-sintase endotelial \\
EPI & Echo-planar imaging- Técnica ecoplanar \\
EX & Exercício \\
\hline
\end{tabular}

FAPESP Fundação de Amparo à Pesquisa do Estado de São Paulo

FC Frequência cardíaca

FLAIR Fluid attenuation inversion recovery

fMRI Function magnetic resonance imaging

FMUSP Faculdade de Medicina da Universidade de São Paulo

FOV Field of View - Compo de Visão

HCFMUSP Hospital das Clínicas da Faculdade de Medicina da Universidade de São Paulo

HDL High density lipoproteins

IC Intervalo de confiança 


\begin{tabular}{|c|c|}
\hline IGF-1 & Fator de crescimento Insulina 1 \\
\hline IMC & Índice de Massa Corporal \\
\hline InCor & Instituto do Coração \\
\hline InRad & Instituto de Radiologia \\
\hline $\mathrm{IPq}$ & Instituto de Psiquiatria \\
\hline KO & Ratos knockout \\
\hline LDL & Low-density lipoproteins \\
\hline LL & Laterolateral \\
\hline MEM & Miniexame do Estado Mental \\
\hline mRNA & RNA mensageiro \\
\hline $\boldsymbol{N}$ & Número \\
\hline $\mathrm{PetCO}_{2}$ & Pressão parcial de $\mathrm{CO}_{2}$ no final da expiração \\
\hline $\mathrm{PetO}_{2}$ & Pressão parcial de oxigênio no final da expiração \\
\hline PNAV & Produtos não-alcoólicos do Vinho \\
\hline RER & Razão da Troca Respiratória \\
\hline RM & Ressonância magnética \\
\hline RMf & Ressonância magnética funcional \\
\hline RS & Resveratrol \\
\hline SIRT-1 & Sirtuína-1 \\
\hline TC & Tomografia computadorizada \\
\hline TCP & Teste de esforço cardiopulmonar \\
\hline TE & Tempo de Eco \\
\hline TFE & Turbo field echo \\
\hline $\mathrm{TI}$ & Tempo de inversão \\
\hline TR & Tempo de Repetição \\
\hline USP & Universidade de São Paulo \\
\hline VBM & (Voxel basic morphometry) \\
\hline $\mathrm{VE} / \mathrm{VCO}_{2}$ & Equivalente ventilatório de $\mathrm{CO}_{2}$ \\
\hline $\mathrm{VE} / \mathrm{VO}_{2}$ & Valor de equivalente ventilatório de $\mathrm{O}_{2}$ \\
\hline
\end{tabular}


$\mathrm{VO}_{2}$ pico Consumo de oxigênio de pico

VT

Vinho tinto

VT

Consumidores regulares de vinho tinto sem treinamento físico

VTT

Consumidores regulares de vinho tinto com treinamento físico

WHO

World health organization 
Tabela 1 Descrição da Idade e escolaridade segundo grupos ............ 45

Tabela $2 \quad$ Fatores de risco............................................................... 46

Tabela $3 \quad$ Parâmetros do Teste cardiopulmonar segundo grupos ........ 47

Tabela $4 \quad$ Exames laboratoriais..................................................... 49

Tabela 5 Descrição do minimental e CDT segundo grupos ............... 51

Tabela 6 Descrição dos tempos de execução dos testes neuropsicológicos .................................................... 52

Tabela 7 Dados comportamentais ABS X VT Stroop PRÉ ............... 55

Tabela 8 Dados comportamentais ABS X VT 2-Back PRÉ ............. 57

Tabela 9 Descrição dos tempos de execução dos testes

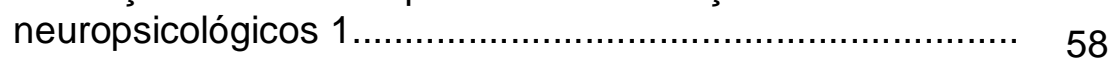

Tabela 10 Descrição dos tempos de execução dos testes 59 neuropsicológicos 2 .

Tabela 11 Dados comportamentais ABST PRÉ X ABST PÓS Stroop .. 62

Tabela 12 Dados comportamentais ABST PRÉ X ABST PÓS 2-Back . 64

Tabela 13 Dados comportamentais ABS PRÉ X ABS PÓS Stroop ..... 67

Tabela 14 Dados comportamentais ABS PRÉ X ABS PÓS 2-Back .... 69

Tabela 15 Dados comportamentais VTT PRÉ X VTT PÓS Stroop ....... 71

Tabela 16 Dados comportamentais VTT PRÉ X VTT PÓS 2-Back ...... 73

Tabela 17 Dados comportamentais VT PRÉ X VT PÓS Stroop ........... 75

Tabela 18 Dados comportamentais VT PRÉ X VT PÓS 2-Back ......... 77

Tabela 19 Dados comportamentais VTT PÓS X ABST PÓS Stroop .... 79

Tabela 20 Dados comportamentais VTT PÓS X ABST PÓS 2-Back .... 80

Tabela 21 Dados comportamentais VT PÓS X ABS PÓS Stroop ........ 81

Tabela 22 Dados comportamentais VT PÓS X ABS PÓS 2-Back ....... 83

Tabela 23 Dados comportamentais VTT PÓS X ABS PÓS Stroop ..... 84

Tabela 24 Dados comportamentais VTT PÓS X ABS PÓS 2-Back ...... 85 
Figura 1

Efeitos dos polifenóis do VT na circulação

Figura 2 Interferência do resveratrol na conformação da substância amiloide ${ }^{57}$

Figura 3

Fluxograma do estudo

Figura 4 Representação do paradigma de função executiva (Stroop Color Naming task), sendo mostrados a sequência de condições $A B C$, exemplos dos primeiros estímulos com seus respectivos períodos de resposta de cada condição e o sistema de resposta manual utilizado pelo voluntário

Figura 5 Representação do paradigma de memória operacional (2-Back task), sendo mostrados a sequência dos ciclos de condições $A B$, exemplos dos primeiros estímulos com seus respectivos períodos de resposta de cada condição e o sistema de resposta manual utilizado pelo voluntário

Figura 6 Tamanho da amostra e poder estatístico

Figura 7 Fluxograma de recrutamento dos voluntários.

Figura 8 A Mapa de grupo Abstêmios do paradigma Stroop (condição incongruente $>$ congruente $):(Z>2,3 ; p<0,05)$

Figura 8 B Mapa de grupo VT do paradigma Stroop (condição incongruente $>$ congruente): $(Z>2,3 ; p<0,05)$......

Figura 9

Mapa estatístico ABS X VT do paradigma Stroop (condição incongruente $>$ congruente): $(Z>2,3$ e $p<0,05)$.

Figura $10 \mathrm{~A}$

Mapa de grupo Abstêmios do teste 2-Back (condição ativa > neutra): $(Z>2,3 ; p<0,05)$.

Figura $10 \mathrm{~B}$

Mapa de grupo VT do paradigma 2-Back (condição ativa > neutra): $(Z>2,3 ; p<0,05)$

Figura 11 Mapa estatístico VT X ABS, VT > ABS: paradigma 2-Back (condição ativa $>$ neutra): $(Z>2,3 ; p<0,05)$.

Figura 12 Gráfico do desempenho dos sujeitos no tempo de execução do subteste 2 do Stroop Color-Word Test......

Figura 13

Figura $14 \mathrm{~A}$

Gráfico do desempenho dos sujeitos no tempo de execução do Rivermead Behavioral Memory Test 1

Mapa de grupo ABS PRÉ com treinamento físico: Stroop (condição incongruente $>$ congruente): $(Z>2,3 ; p<0,05)$.

Figura 14 B

Mapa de grupo ABS PÓS com treinamento físico: Stroop (condição incongruente $>$ congruente): $(Z>2,3 ; p<0,05)$.

Figura 15

Mapa estatístico ABS PRÉ com treinamento físico X ABS PÓS com treinamento físico: Stroop (condição incongruente > congruente): $(Z>2,3$ e $p<0,05)$. 
Figura 16 A Mapa de grupo ABS PRÉ com treinamento físico: 2-Back (condição ativa > neutra): $(Z>2,3$ e $p<0,05)$.....

Figura 16 B Mapa de grupo ABS PÓS com treinamento físico: 2-Back (condição ativa > neutra): $(Z>2,3$ e $p<0,05)$.

Figura 17 Mapa estatístico ABS PRÉ com treinamento físico X ABS PÓS com treinamento físico: 2-Back (condição ativa > neutra): $(Z>2,3$ e $p<0,05)$

Figura 18 A Mapa de grupo ABS PRÉ sem treinamento físico: Stroop (condição incongruente > congruente): $(Z>2,3$ e $p<0,05)$.

Figura 18 B Mapa de grupo ABS PÓS sem treinamento físico: STROOP (condição incongruente $>$ congruente): $(Z>2,3$ e $p<0,05)$..

Figura 19

Mapa estatístico ABS PRÉ sem treinamento físico X ABS PÓS sem treinamento físico: STROOP (condição incongruente > congruente): $(Z>2,3$ e $p<0,05)$.

Figura 20 A Mapa de grupo ABS PRÉ sem treinamento físico: 2-Back (condição ativa > neutra): $(Z>2,3$ e $p<0,05)$.

Figura 20 B Mapa de grupo ABS PÓS sem treinamento físico ( $N=20): 2$ Back (condição ativa $>$ neutra): $(Z>2,3$ e $p<0,05)$.

Figura 21

Mapa estatístico ABS PRÉ sem treinamento físico X ABS PÓS sem treinamento físico: paradigma 2-Back (condição ativa > neutra): $(Z>2,3$ e $p<0,05)$.

Figura $22 \mathrm{~A}$

Mapa de grupo VT PRÉ com treinamento físico: Stroop (condição incongruente > congruente): $(Z>2,3$ e $p<0,05)$...

Figura 22 B Mapa de grupo VT PÓS com treinamento físico: Stroop (condição incongruente $>$ congruente): $(Z>2,3$ e $p<0,05)$.

Figura 23

Mapa estatístico VT PRÉ com treinamento físico X VT PÓS com treinamento físico: paradigma Stroop (condição incongruente $>$ congruente $):(Z>2,3$ e $p<0,05)$

Figura 24 A Mapa de grupo VT PRÉ com treinamento físico: 2-Back (condição ativa > neutra): $(Z>2,3$ e $p<0,05)$.

Figura 24 B Mapa de grupo VT PÓS com treinamento físico: 2-Back (condição ativa > neutra): $(Z>2,3$ e $p<0,05)$

Figura 25 Mapa estatístico VT PRÉ com treinamento físico X VT PÓs com treinamento físico: paradigma 2-Back (condição ativa > neutra): $(Z>2,3$ e $p<0,05)$

Figura 26 A Mapa de grupo VT PRÉ sem treinamento físico: Stroop (condição incongruente $>$ congruente): $(Z>2,3$ e $p<0,05)$.

Figura 26 B Mapa de grupo VT PÓS sem treinamento físico: Stroop (condição incongruente $>$ congruente): $(Z>2,3$ e $p<0,05)$

Figura 27

Mapa estatístico VT PRÉ sem treinamento físico X VT PÓs sem treinamento físico: STROOP (condição incongruente > congruente $)$ : $(Z>2,3$ e $p<0,05)$ 
Figura 28 A Mapa de grupo VT PRÉ sem treinamento físico: 2-Back (condição ativa > neutra): $(Z>2,3$ e $p<0,05)$.

Figura 28 B Mapa de grupo VT PÓS sem treinamento físico: 2-Back (condição ativa > neutra): $(Z>2,3$ e $p<0,05)$.

Figura 29 Mapa estatístico VT PRÉ sem treinamento físico X VT PÓS sem treinamento físico: paradigma 2-Back (condição ativa > neutra): $(Z>2,3$ e $p<0,05)$.

Figura 30 Mapa estatístico VT PÓS com treinamento físico X ABS PÓS com treinamento físico: paradigma Stroop (condição incongruente $>$ congruente $):(Z>2,3$ e $p<0,05)$.

Figura 31 Mapa estatístico VT PÓS com treinamento físico X ABS PÓS com treinamento físico: paradigma 2-Back (condição ativa > neutra): $(Z>2,3$ e $p<0,05)$

Figura 32 Mapa estatístico VT PÓS sem treinamento físico X ABS PÓS sem treinamento físico: paradigma Stroop (condição incongruente $>$ congruente $):(Z>2,3$ e $p<0,05)$

Figura 33 Mapa estatístico VT PÓS sem treinamento físico X ABS PÓS sem treinamento físico: paradigma 2-Back (condição ativa > neutra): $(Z>2,3$ e $p<0,05)$

Figura 34 Mapa estatístico VT PÓS com treinamento físico X ABS PÓS sem treinamento físico: paradigma Stroop (condição incongruente $>$ congruente $(Z>2,3$ e $p<0,05)$...

Figura 35 Mapa estatístico VT PÓS sem treinamento físico X ABS PÓS sem treinamento físico: paradigma 2-Back (condição ativa > neutra): $(Z>2,3$ e $p<0,05)$ 
Gráficos 1 e 2 Potência máxima atingida nos ABS..................................... 47

Gráficos 3 e 4 Potência máxima atingida nos bebedores de VT................... 48

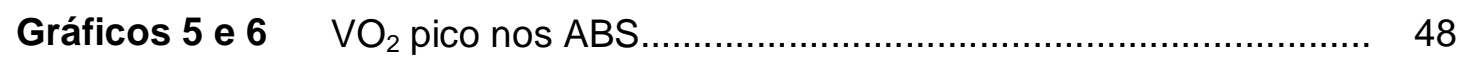

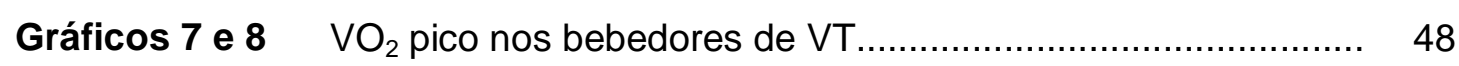


Nishiyama M. Efeitos do treinamento físico e ingestão de vinho tinto na função cognitiva de indivíduos sem declínio cognitivo [tese]. São Paulo: Faculdade de Medicina, Universidade de São Paulo; 2018.

Introdução: Embora vinho tinto (VT) e exercício (Ex) sejam potenciais protetores cardiovasculares, um possível efeito aditivo de ambos não é conhecido. Neste estudo investigamos se o Ex. Físico supervisionado poderia influenciar funções cognitivas (cognição) em homens bebedores habituais de VT em comparação a indivíduos abstêmios (ABS), ambos sem declínio cognitivo.

Objetivos: além do acima também comparamos os efeitos do treinamento físico supervisionado no desempenho cardiovascular de bebedores de VT e abstêmios. Métodos: Foram incluídos homens, de 50 a 75 anos, sem déficit cognitivo, consumidores regulares de VT e abstêmios, randomizados em 4 grupos: ABS com e sem treinamento físico, consumidores de VT com e sem treinamento físico. Estudamos função executiva (Stroop) e memória operacional (2-Back) por Ressonância Magnética Funcional (RMf-3T), assim como a acurácia e tempo de resposta. Igualmente foram utilizados testes neuropsicológicos clássicos nas condições pré e pós Ex. Foi realizado Teste de Esforço Cardiopulmonar (TECP). Os voluntários foram treinados durante 3 meses, com três sessões semanais de uma hora de duração. Avaliação cognitiva foi feita por instrumentos padronizados de avaliação neuropsicológica. Resultados: 73 pacientes, sendo 47 ABS com média de idade 58,4 $\pm 5,1$ (DP) anos e 50 VT com média de idade de $60.9 \pm 6$,4anos (DP). O consumo médio de VT foi de $19.8 \pm 10.3$ gramas de etanol/dia e o tempo de consumo médio de $26,1 \pm 15,7$ anos. Na fase pré, os consumidores de VT têm melhor desempenho que os ABS tanto nos testes neuropsicológicos (Trilhas A, B, e Stroop 1) quanto nas imagens cerebrais (2-Back). No pós, os bebedores com treinamento físico mostraram: nos testes neuropsicológicos redução no tempo de execução (Stroop 2); na imagem por ressonância magnética funcional não houve modificações nas áreas ativadas, mas registrou-se tendência a melhora da acurácia (Stroop). Houve aumento significativo na média do consumo de oxigênio pico $\left(\mathrm{VO}_{2}\right.$ pico) nos grupos que treinaram (VT $24.9 \pm 2.6$ vs $27.1 \pm 3.5 \mathrm{e}$ no grupo $A B S$ foi $27.1 \pm 4.9$ vs $29.7 \pm 4.1$ ). Houve correlação negativa entre $\mathrm{VO}_{2}$ pico e a resposta cerebral nos ABS e bebedores $\mathrm{VT}$ (quanto menor o $\mathrm{VO}_{2}$ pico maior a resposta cerebral).

Conclusão: Indivíduos consumidores regulares de VT tem melhor função cognitiva em testes de memória e atenção mesmo na fase pré-treinamento e respondem melhor ao exercício físico. Existe correlação negativa entre $\mathrm{o} \mathrm{VO}_{2}$ pico e a ativação cerebral, o que pode indicar que melhor desempenho físico pode induzir maior eficiência mental. Estes dados são sugestivos, embora não afirmativos, de que existe efeito aditivo do Ex físico sobre funções cognitivas em bebedores crônicos, moderados de VT, sem déficit cognitivo. Dadas as limitações do estudo consideramos que o mesmo deva ser visto como gerador de futuras hipóteses que deverão ser melhor avaliadas em pesquisas subsequentes.

Descritores: exercício; consumo de oxigênio; cognição; vinho; imagem por ressonância magnética funcional; testes neuropsicológicos. 
Abstract 
Nishiyama M. Effects of physical training and red wine consumption on cognitive function in individuals without cognitive decline [thesis]. São Paulo: "Faculdade de Medicina, Universidade de São Paulo"; 2018.

Introduction: Although red wine (RW) and exercise (Ex) have potential protective cardiovascular effects, a possible additive effect of both is not known. In this study, we investigated whether the supervised Physical Ex could influence cognitive functions in habitual men, RW drinkers, in comparison to abstainers (ABS), both without cognitive dysfunction. Objectives: in addition to the above we also compared the effects of Ex on the cardiovascular performance of drinkers and nondrinkers.

Methods: included were 73 men, 50 to 75 years, without cognitive deficit, regular RW consumers and abstainers, randomized into 4 groups: ABS with and without physical training, RW consumers with and without physical training. We studied executive function (Stroop) and working memory (2-back) through Functional Magnetic Resonance Imaging (fMRI) as well as accuracy and response time. Classical neuropsychological tests have also been performed pre and post Ex. Cardiopulmonary exercise Testing (TECP) was performed. The volunteers were trained during 3 months, with 3 weekly sessions of one hour duration. Cognitive assessment was performed by standardized instruments of neuropsychology assessment.

Results: 73 men, 47 (ABS) with a mean age 58,4 $\pm 5,1$ (SD) years and $50 \mathrm{RW}$ drinkers with a mean age of $60.9 \pm 6,4$ years (SD) were studied. The average RW consumption was $19.8 \pm 10.3$ grams of ethanol/day, and the average time of consumption was $26.1 \pm 15,7$ years. In the pre Ex the RW consumers had better performance than the $A B S$ both on neuropsychological tests (Trails $A, B$, and Stroop 1) as well as in brain imaging (2-back). In the post Ex drinkers with physical training showed: in the neuropsychological tests reduction in execution time (Stroop color word test); at fMRI there were no changes in the activated areas, but a trend towards improvement of accuracy (Stroop) was noted. There was a significant increase in the peak VO2 (oxygen consumption) in the groups that trained (RW $24.9 \pm 2.6$ vs $27.1 \pm 3.5$ and in the group of $A B S$ was $27.1 \pm 4.9$ vs 29.7 \pm 4.1$)$. There was a negative correlation between VO2 peak and the activated brain areas in the ABS and drinkers RW (the lower the VO2 peak the larger the response of the brain).

Conclusion: Regular RW consumers had better cognitive function on tests of memory and attention even in the pre-Ex and responded better to physical exercise. There was a negative correlation between VO2 peak and the brain activation, which may indicate that better physical performance can induce greater mental efficiency. These data are suggestive, though not affirmative, that there is additive effect of physical Ex on cognitive functions in chronic, moderate RW drinkers, without cognitive deficit.

Given protocol limitations, we think that the study should be considered as hypothesis generating that ought to be further evaluated in subsequent investigations.

Descriptors: exercise; oxygen consumption; cognition; wine; functional magnetic resonance imaging; neuropsychological tests. 
1. Introdução 
O envelhecimento populacional é fenômeno universal, característico tanto dos países desenvolvidos como nos países em desenvolvimento. No Brasil, o número de pessoas com mais de 60 anos passou de três milhões em 1960 para vinte milhões em 2010, um aumento de 600\% em cinquenta anos. Estima-se que em 2020 este número alcançará trinta e dois milhões ${ }^{1}$.

Um dos aspectos mais críticos do envelhecimento refere-se às funções cerebrais $^{2}$. O declínio das funções cognitivas e da capacidade funcional, comumente observados a partir de aproximadamente 65 anos de idade, são fatores limitantes para o envelhecimento saudável ${ }^{3}$. Ocorre deterioração progressiva da memória, orientação espacial e outros, devido ao envelhecimento celular e limitações na capacidade de divisão, renovação e regeneração celulares. Este processo é inevitável e orientado por regras biológicas não totalmente esclarecidas. Assim, processos primários são muito individuais e se referem a quando e como o envelhecimento se inicia na vida do indivíduo; já os processos secundários são dependentes da qualidade e estilo de vida, dieta e atividade física ${ }^{4}$.

Uma consequência do crescimento da população idosa e do aumento das doenças neurodegenerativas é seu alto custo. Hurd et $\mathrm{al}^{5}$ relataram os custos com demência nos Estados Unidos em 2010; eles estudaram 10.903 participantes do estudo Health and Retirement, no qual a prevalência de demência entre pessoas com mais de 70 anos era de 14.7\% nos Estados Unidos. O custo anual por pessoa variou entre 42.000 e 56.000 dólares, o que representou um gasto entre 157 e 215 bilhões de dólares em 2010. Esses dados permitiram concluir que a demência é um ônus econômico substancial para a sociedade, comparável à doença arterial coronariana e ao câncer. 
Segundo dados da Organização Mundial da Saúde (WHO), as mortes por demência mais que dobraram de 2000 a 2015, tornando esta doença em 2015 a sétima causa de óbitos no mundo ${ }^{6}$. No Brasil, em uma revisão sistemática, a prevalência estimada de demência foi de $11,9 \%$ entre os iletrados e de $4,5 \%$ entre os letrados ${ }^{7}$

Durante muito tempo a avaliação de transtornos cognitivos foi essencialmente clínica, e portanto subjetiva. Mais recentemente surgiram técnicas de avaliação psicológica e de imagem, como a ressonância magnética funcional cerebral (fMRI), que permitem localização e quantificação de áreas específicas relacionadas a distúrbios cognitivos ${ }^{8}$.

Por outro lado, estudos como The Hunty Study ${ }^{9}$, The Rottherdam Study $^{10}$, The Canadian Study of Health and Aging ${ }^{11}$, sugerem que funções cognitivas podem ser influenciadas por intervenções diversas, tanto farmacológicas quanto por estilos de vida.

Neste cenário, a proposta do presente estudo é avaliar efeitos do exercício físico sobre as funções cognitivas, em consumidores regular de vinho tinto e abstêmios.

Segue-se uma revisão sucinta das bases científicas que justificam esta proposta.

\subsection{Envelhecimento normal e patológico}

É importante diferenciar o declínio da capacidade cognitiva decorrente dos processos fisiológicos do envelhecimento normal, daquilo que representa a transição para as síndromes demenciais. Embora se tenham estabelecido 
critérios neuropsicológicos, patológicos e de neuroimagem para diferenciação entre o normal e o patológico, o diagnóstico dos problemas cognitivos leves continua desafiador ${ }^{12}$.

Em relação aos aspectos neuropsicológicos, o padrão de deterioração da memória no idoso normal assemelha-se ao encontrado nas fases iniciais da Doença de Alzheimer (DA), na qual observa-se declínio da memória "operacional" e da memória "secundária/recente", maior que o da memória "primária/imediata", e da memória "terciária/remota"13. No envelhecimento normal, a captação de situações ou informações novas, a evocação retardada e repetição de números em ordem inversa são as funções mais alteradas; por outro lado, o vocabulário, a repetição de números em ordem direta e a realização de tarefas rotineiras e automatizadas permanecem relativamente intactas. As dificuldades de memória relacionadas à idade são maiores para a memória episódica do que para a memória semântica e pioram em ordem crescente na seguinte sequência: memória de procedimentos, reaprendizado, memória de reconhecimento, evocação baseadas em pistas contextuais, evocação livre e memória prospectiva ("lembrar de lembrar") ${ }^{14}$. 0 envelhecimento afeta sobretudo a memória prospectiva e a evocação livre e retardada de material verbal aprendido, preservando-se a lembrança baseada em pistas contextuais ${ }^{15}$. O envelhecimento normal deixa relativamente intactos o vocabulário e o processamento sintático, enquanto altera a lembrança de palavras, como na conversação e em testes de fluência verbal, aparecendo raras parafasias semânticas ${ }^{16}$. No nível discursivo, ocorrem dificuldades narrativas e omissão de informações sobre a "situação" da estória; omissão de passos essenciais durante a descrição de procedimentos: conversação, notam- 
se dificuldade de compreensão, falta de clareza do enunciado, "parafasias narrativas" e problemas com inferências e pressuposições.

Com referência a neuropatologia, particularmente após a sexta década, acelera-se o processo de atrofia cerebral, com dilatação de sulcos e ventrículos, perda de neurônios, depósitos de proteína beta-amilóide e degeneração granulovacuolar; e a presença de placas neuríticas e emaranhados neurofibrilares (ENF), os quais aparecem precocemente nas regiões temporais mediais e espalham-se por todo o neocórtex ${ }^{17}$. Tais achados correlacionam-se com distúrbios precoces e proeminentes da memória factual ('secundária"). Na histopatologia, os limites entre o normal e o patológico são também imprecisos; daí a necessidade de estabelecer critérios consensuais, como o tipo de coloração, números de placas neuríticas e emaranhados neurofibrilares extraídos de determinadas regiões cerebrais, levando-se em conta a idade do sujeito. O diagnóstico neuropatológico deve levar em conta a gravidade dessas alterações, sua localização ou distribuição, a presença de lesões cumulativas decorrentes de traumas, neurotóxicas ou vasculares, e a história prévia demência ${ }^{18}$.

Finalmente, métodos de neuroimagem representam um instrumento valioso para diagnóstico não invasivo. A neuroimagem estruturada com tomografia computadorizada (TC) e ressonância nuclear magnética (RM) mostram redução do volume total do cérebro, com dilatação dos sulcos e sistema ventricular, especialmente dos ventrículos laterais e III ventrículo em idosos sadios $^{19}$. Estas alterações são mais acentuadas nos sujeitos dementes, mas há variações individuais, podendo estar ausentes em casos individuais 
com franca demência e presentes em outros cognitivamente intactos. Neste estudo analisamos pessoas normais, isto é, sem distúrbios mentais evidentes.

\subsection{Exercício físico e função cognitiva}

Sabe-se com o suporte de uma extensa literatura, a qual está baseada em estudos longitudinais e estudos clínicos randomizados, que a atividade física pode contribuir para o envelhecimento saudável, reduzindo os fatores de risco para doenças crônicas como a hipertensão arterial, o diabetes tipo 2 e a osteoporose $^{20,21,22,23,24,25,26,27}$. E mais recentemente, tem-se acumulado evidências de que o exercício e a atividade física podem influenciar para se ter um envelhecimento cerebral saudável ${ }^{3}$. Recentes pesquisas básicas e estudos epidemiológicos enfatizam que o sedentarismo pode afetar o declínio cognitivo relacionado com a idade e o desenvolvimento da $\mathrm{DA}^{28}$. Evidências sugerem que estilo de vida fisicamente ativo é uma estratégia preventiva que pode ajudar a retardar o início do declínio cognitivo e a progressão de doenças demenciais $^{29,30}$. Ainda não estão totalmente esclarecidos estes mecanismos, mas existem numerosas hipóteses. Pesquisas em animais sugerem que a atividade física pode modular diretamente a formação da proteína beta amilóide através de vários mecanismos ${ }^{31}$. Outra hipótese é que o exercício físico pode estimular a perfusão e a angiogênese cerebrais ${ }^{22}$. Outro possível efeito é a modulação das vias inflamatórias, reduzindo a produção de fator de

crescimento semelhante à insulina tipo 1 (IGF-1), um dos responsáveis por acelerar o processo de envelhecimento ${ }^{32}$. 
Numa meta-análise publicada em 2003, Colcombe e Kramer ${ }^{33}$ incluíram 18 estudos de intervenção, publicados entre 1966 e 2001, que demonstraram que o treinamento aeróbico produz melhorias em aspectos cognitivos como atenção, velocidade de processamento, função executiva e de memória e pouca influência na memória de trabalho. Observou-se também que a magnitude dos efeitos do exercício físico na cognição são dependentes do número fatores programáticos e metodológicos aplicados, como o tipo e a intensidade do treinamento físico, a duração das sessões e o gênero dos participantes dos estudos.

Em uma revisão publicada em 2008, Angevaren e colaboradores ${ }^{34}$ demonstraram a efetividade da atividade física na função cognitiva em pessoas com mais de 55 anos de idade e sem declínico cognitivo. Em 8 ensaios clínicos randomizados, que compararam programas de atividade física aeróbica com outras intervenções ou nenhum intervenção, foi observada melhora na capacidade cognitiva que coincidiu com aumento na capacidade cardiorespiratória no grupo submetido a intervenção. Os maiores efeitos na função cognitiva foram encontrados nas funções motoras e atenção auditiva. Moderado efeito também foi observado nas funções de velocidade de processamento e atenção visual.

\subsection{Mecanismos e efeitos protetores do consumo regular de vinho tinto}

O vinho tinto (VT) é uma bebida derivada da fermentação da uva. Numerosos estudos, clínicos e experimentais, demonstram que consumo de 
vinho tinto é associado à menor risco cardiovascular bem como redução da mortalidade global $^{35,36,37,38}$.

Em metanálise de 84 estudos de coorte prospectivos, em adultos, sem doença cardiovascular manifesta avaliou-se a associação entre consumo de álcool e incidência de eventos cardiovasculares maiores e mortalidade total ${ }^{39}$. Dentre os estudos, o tempo de seguimento mediano foi de 11 anos. Destacouse o efeito protetor do consumo de álcool em relação a eventos cardiovasculares maiores fatais, isto é, mortalidade cardiovascular, mortalidade por doença arterial coronária e mortalidade por acidente vascular cerebral, e não fatais (doença arterial coronária e acidente vascular cerebral) apresentando uma redução de risco de 14 a $25 \%$.

Nosso grupo vem realizando estudos sobre os efeitos do vinho tinto nos últimos anos. Por exemplo, avaliou-se a ação do vinho tinto e vinho sem álcool, produtos não alcóolicos do vinho (PNAV) sobre a formação de placas ateroscleróticas na aorta de coelhos alimentados com dieta hipercolesterolêmica ${ }^{40}$. Animais que receberam VT na água de beber junto com dieta gordurosa desenvolveram menos placas do que os controles; os que receberam PNAV também desenvolveram menos placas que os controles, porém este efeito foi menor que com VT. Curiosamente, a redução da formação de placas não se acompanhou da diminuição de lípides plasmáticos, sugerindo que ações protetoras do VT e PNAV independem dos lípides.

Avaliou-se também a ação do vinho tinto e do suco de uva na reatividade vascular de indivíduos jovens com hipercolesterolemia isolada ${ }^{41}$. Foi medida a reatividade da artéria braquial, lipídios plasmáticos, glicose e agregação plaquetária em 16 indivíduos com hipercolesterolemia isolada. 
Foram randomizados e numa primeira etapa um grupo recebeu $500 \mathrm{ml} / \mathrm{dia}$ de suco de uva e o outro $250 \mathrm{ml} / \mathrm{dia}$ de vinho tinto durante 14 dias. Depois de um período de mesma duração de washout, seguiu-se a segunda etapa do tratamento, sendo feito um crossover. Observou-se em ambos um aumento significante na dilatação da artéria braquial, para o suco de uva $(10.1 \pm 7.1$ antes vs $16.9 \pm 6.7 \%$ depois: $p<0.05)$ e vinho tinto $(10.1 \pm 6.4$ antes $v s 15.6 \pm$ 4.6\% depois: $p<0.05)$. Não foram observadas alterações significantes nos lipídios plasmáticos, glicose e na agregação plaquetária.

Posteriormente, avaliou-se a ação de resveratrol e VT sobre o envelhecimento celular, função vascular, e sobrevida em ratos normais ${ }^{42}$. Vinho tinto e resveratrol melhoraram o desempenho físico em relação ao grupocontrole, com consequente melhora da capacidade aeróbica; houve aumento de tolerância ao tempo de exercício e à distância percorrida. Houve também melhora da função endotelial; em tecido aórtico também observou-se, diminuição da expressão de P53 e P16, bem como preservação do comprimento de telômeros e aumento da expressão de telomerase. No entanto a sobrevida não aumentou. Portanto, vinho tinto e resveratrol melhoraram a função vascular e reduziram índices de envelhecimento.

Da Luz et al. conduziram um estudo observacional em 101 homens sadios, bebedores habituais de vinho tinto por 18 anos em média, comparandoos a 104 abstêmios, da mesma idade ${ }^{43}$. Contrariamente à expectativa, o grau de lesões nas artérias coronárias analisadas por angiotomografia computadorizada não foi diferente em relação aos abstêmios. Porém os bebedores de vinho tinto tinham $H D L$ mais alto $(46,9 \pm 10,9$ versus $39,5 \pm 9$ $\mathrm{mg} / \mathrm{dL})$ e glicemia mais baixa $(97,6 \pm 18,2$ versus $105,9 \pm 32,0 \mathrm{mg} / \mathrm{dL})$ além de 
menos história de diabetes (4,5\% vs $11,7 \%)$ curiosamente o escore de cálcio coronário era maior entre os consumidores de vinho tinto. A fim de esclarecer este achado, em estudo subsequente os autores analisaram o escore de cálcio coronário em relação a evolução clínica a longo prazo. Juntando populações do estudo acima com outra de Veranópolis (RS), com as mesmas carasterísticas de consumo de VT a longo prazo, os autores documentaram que os consumidores de VT têm maior escore de cálcio coronário, porém menos eventos cardiovasculares ${ }^{44}$. Assim, interpretou-se que isso indica que 0 VT causa estabilização das lesões, e portanto diminuiu eventos. Isso explicaria em parte as inúmeras documentações clínicas de que o consumo moderado a longo prazo de vinho tinto reduz eventos cardiovasculares.

Destaca-se na composição química do vinho tinto o álcool e os compostos polifenólicos. Ambos parecem ter efeitos benéficos, sendo que as evidências mecanísticas e clínicas apontam os polifenóis como principais responsáveis; mas um efeito coadjuvante do álcool não pode ser desprezado ${ }^{45}$. O efeito mais evidente do álcool é o aumento do $H D L$ colesterol, o qual tem efeitos protetores bem conhecidos ${ }^{46}$. Além disso álcool poderia aumentar a absorção intestinal de polifenóis do vinho tinto ${ }^{36}$.

A maioria dos efeitos benéficos do VT é atribuída a seus compostos polifenólicos, especialmente o resveratrol. Segue-se uma breve revisão dos mecanismos básicos da ação do vinho e dos polifenóis. 


\subsection{Ações do VT na circulação}

Em trabalhos anteriores nosso grupo demonstrou a eficácia do vinho tinto na melhora da dilatação mediada pelo fluxo em pacientes hipertensos ${ }^{47} \mathrm{e}$ hipercolesterolêmicos ${ }^{41}$. Outros investigadores obtiveram resultados semelhantes $^{48,49}$. A figura 1 mostra os vários efeitos dos polifenóis do VT na circulação ${ }^{50}$.

\section{Efeitos do consumo moderado de vinho tinto}

- Função endotelial:

$\downarrow$ Endotelina-1

- NO (óxido nítrico)

DMF (dilatação mediada pelo fluxo)

- Coagulação e plaquetas

Agregação plaquetária

Fator tissular

Fibrinogenio

Fator VII

$\checkmark$ Fator Von Willebrand

- Efeitos antioxidantes

4 Capacidade antioxidante do plasma

Paraoxanase-1

LDL oxidadas

Dano oxidativo do DNA

MDA (malonil-dialdeído)

- Efeitos anti-inflamatórios

PCR

Nos leucócitos

NF- $\mathrm{B}$

Moléculas de adesão

- Efeitos lipícos

A HDL

ApoA-I

- Efeitos no metabolismo da glicose

$\downarrow$ Glicemia de jejum

4 Sensibilidade à insulina

Figura 1- Efeitos dos polifenóis do VT na circulação 
Os mecanismos responsáveis por tais efeitos incluem ${ }^{51}$ :

a) diminuição da síntese da endotelina-1 (ET-1) em células endoteliais por supressão da transcrição do gene ET $-1^{52}$;

b) indução da expressão e a atividade da oxidonitrico-sintase endotelial (eNOS) e, assim, a liberação de óxido nítrico ${ }^{53}$;

c) aumento da atividade do promotor de eNOS (efeito transcricional) e estabilização do mRNA da eNOS (efeito pós-transcricional) pelo resveratrol ${ }^{54}$;

d) diminuição da atividade de NADPH oxidase nas paredes arteriais, também pelo resveratrol ${ }^{55}$;

e) estimulação do resveratrol sobre a sirtuína-1 (SIRT-1) em animais de experimentação KO para SIRT-1, observa-se degeneração neuronal; RS reduz significativamente tal degeneração, melhorando capacidade locomotora e memória dos animais ${ }^{56}$. A interferência do RS na alteração conformacional da substância amilóide é ilustrada na figura $2^{45}$ (Nesta figura preferimos manter o original em inglês, para fidelidade). 


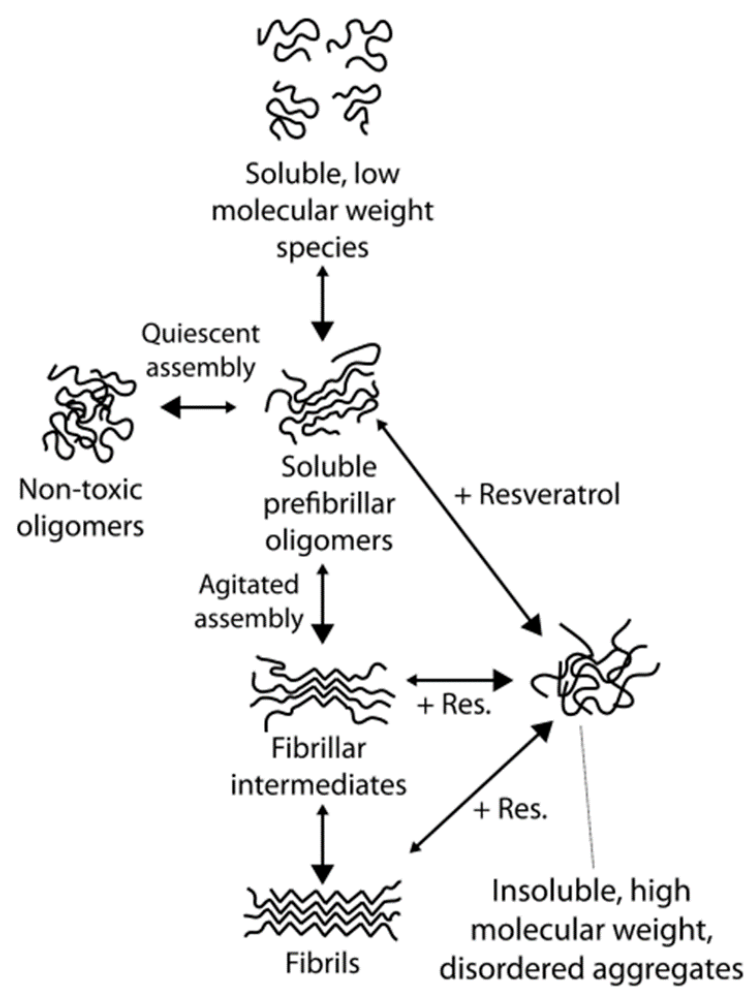

Figura 2- Interferência do resveratrol na conformação da substância amilóide ${ }^{57}$.

A importância deste tópico no trabalho atual refere-se ao fato de que as análises por RMf baseiam-se em alterações da circulação cerebral, que podem ser influenciadas pela ação vasodilatadora do VT.

\subsection{O eixo cérebro/coração}

Existem inúmeras evidências ligando o sistema cardiovascular e o cérebro $^{58}$. Por exemplo, a hipertensão arterial, a hipercolesterolemia e o diabetes são fatores de risco para enfermidades que comprometem os dois sistemas. Todos produzem lesões vasculares que afetam tanto o coração como o cérebro. Assim, a hipertensão arterial é causa de DAC e AVC. A hipercolesterolemia que causa DAC é a mesma que causa lesões carotídeas e 
eventuais isquemias cerebrais. O sedentarismo é fator de risco para doenças vasculares cerebrais e também para alterações da função cognitiva ${ }^{59,60}$. A influência entre os dois sistemas é recíproca, e se faz principalmente pelo sistema simpático e parassimpático, mediante a liberação de hormônios como o cortisol e produtos químicos com adrenalina e noradrenalina ${ }^{61}$. Além disso existem ações locais, que em tecidos específicos e seus respectivos receptores, modulam funções nos sistemas neurológico e cardiovascular. Assim, são bem conhecidas alterações eletrocardiográficas associadas a danos cerebrais, bem como arritmias causadas por estresse emocional. Por outro lado, déficits da função ventricular podem afetar nitidamente funções cerebrais, devido à redução do débito cardíaco.

Quanto à prevenção, medidas benéficas para o coração são as mesmas que protegem o cérebro, tais como estilo de vida saudável, tratamento da hipertensão, de hipercolesterolemia e do diabetes.

No entanto, vários aspectos desta inter-relação são pouco conhecidos, especialmente efeitos de intervenções simultâneas, como as consideradas aqui.

Diante do acima exposto procuramos investigar se o exercício físico controlado poderia influenciar funções cerebrais em indivíduos bebedores habituais de vinho tinto em comparação a indivíduos abstêmios, ambos sem declínio cognitivo. 
2. Objetivos 


\section{$2.1 \quad$ Objetivo principal}

Investigar os efeitos do exercício físico programado sobre funções cognitivas de adultos bebedores habituais de vinho tinto e abstêmios, sem declínio cognitivo.

\subsection{Objetivos secundários}

- Comparar os efeitos do treinamento físico no desempenho cardiovascular de bebedores habituais de vinho tinto e abstêmios.

- Investigar os efeitos do treinamento físico nos níveis séricos de glicose, triglicerídeos, colesterol total e suas frações. 
Este foi um estudo multidisciplinar que envolveu, além da Equipe de Pesquisa do Professor Protásio Lemos da Luz, coordenador geral, as equipes do InRad, IPq e Reabilitação Cardiovascular do Incor. Este estudo foi aprovado pela Fundação de Amparo à Pesquisa do Estado de São Paulo (FAPESP), processo número 2012/00329-0 e pela Comissão de Ética para Análise de Projetos de Pesquisa (CAPPesq) protocolo número 0100/09, da FMUSP.

Os participantes foram recrutados da população pesquisada no projeto intitulado "Coronary artery plaque burden and calcium scores in healthy men adhering to long-term wine drinking or alcohol abstinence" ${ }^{\prime 3}$, no qual foi estudado o estado da circulação coronária por meio de angiotomografia computadorizada, em indivíduos consumidores regulares de vinho tinto comparando-os a indivíduos abstêmios, publicado em 2014.

\subsection{População}

A população alvo deste estudo eram homens entre 50 a 75 anos, sem déficit cognitivo clínico e consumidores regulares de vinho tinto. Foram selecionados também voluntários abstêmios, sem déficit cognitivo e pertencentes ao mesmo grupo etário. O processo de inclusão durou de 2009 a 2014.

\subsection{Recrutamento}

A maioria (88\%) dos voluntários recrutados para o presente estudo participaram em 2009 do projeto acima referido, foram contactados por telefone 
por uma enfermeira treinada de nossa equipe de pesquisa do Instituto do Coração (InCor) do Hospital das Clínicas da Faculdade de Medicina da Universidade de São Paulo (HCFMUSP), sendo informados sobre os objetivos do estudo, a forma como o mesmo seria conduzido e, após essas informações, o convite para participação do estudo era feito.

Os interessados em participar eram agendados para uma entrevista, durante a qual a enfermeira lia e explicava o termo de esclarecimento livre e esclarecido (apêndice A) e aplicava os diferentes questionários. Após essa entrevista, os voluntários eram agendados para uma avaliação clínica inicial e uma triagem com a Equipe de Neuropsicologia do Instituto de Psiquiatria (IPq) do HFMUSP para rastreamento de comprometimento cognitivo por neuropsicólogas habilitadas, sob a supervisão da Psicóloga Marina Von Zuben.

A minoria (12\%) dos voluntários consumidores regulares de vinho tinto e abstêmios não fazia parte do projeto anterior e foi indicado por participantes previamente selecionados. Igualmente, foram contactados por telefone pela mesma enfermeira e passaram pelas mesmas etapas acima delineadas do processo de recrutamento.

\subsection{Critérios de inclusão}

- Homens;

- Idade entre 50 e 75 anos;

- Sem déficit cognitivo clínico. Foi definido como déficit cognitivo pontuação abaixo de 25 pontos para escolarizados e 20 pontos para analfabetos no 
Miniexame do Estado Mental ou pontuação abaixo de 3 pontos no Teste do Desenho do Relógio.

- Consumidores regulares e moderados de vinho tinto há pelo menos 5 anos. Como consumo moderado de vinho tinto foi considerada a ingestão média de até 2 taças por dia. Como consumo regular foi considerado ingestão superior a 3 vezes por semana nos 5 anos que precederam a entrada dos voluntários no estudo.

- Foram considerados abstêmios os indivíduos que não referissem passado de consumo regular de qualquer bebiba alcoólica e estavam pelo menos há mais de 10 anos sem ingerí-las.

\subsection{Critérios de exclusão}

- Contraindicação para o exame de RM (marcapasso cardíaco, neuroestimulador, implante coclear, entre outros);

- Déficit cognitivo e/ou antecedentes de acidente vascular encefálico, epilepsia, procedimentos neurocirúrgicos ou trauma cranioencefálico grave;

- Comportamentos e/ou sinais suspeitos para síndrome de abstinência alcoólica, os quais foram considerados presentes se houvesse respostas afirmativas às perguntas $9,10,11$ e 12 (todas as quatro) do questionário de consumo de bebida (apêndice B);

- Alteração do nível de consciência por uso de drogas ilícitas ou medicamentos; 
- Doenças sistêmicas graves não controladas que poderiam interferir na condução do estudo, isto é, insuficiência renal, insuficiência hepática, canceres, doença pulmonar crônica, diabetes não controlada, quaisquer condições limitantes que impedissem treinamento físico;

- Aparelhos ortodônticos, implantes ou próteses dentárias que causassem artefatos de suscetibilidade magnética significativos e que pudessem comprometer a análise das imagens;

- Aqueles que não comparecessem por mais de 5 aulas consecutivas ou não cumprissem um mínimo de 70\% do total de sessões previstas do programa de treinamento físico;

- Voluntários com qualquer outra condição que, na opinião do investigador responsável, tornasse problemática a inclusão do primeiro no presente estudo.

Para este estudo consideraram-se as seguintes definições:

a) Hipertensão arterial - pressão arterial sistólica maior ou igual a 140 $\mathrm{mmHg}$ e diastólica maior ou maior que $90 \mathrm{mmHg}$.

b) Diabetes - glicemia de jejum maior que $126 \mathrm{mg} / \mathrm{dl}$ ou ingestão regular de medicamentos anti-diabéticos.

c) Tabagismo - fumar 1 cigarro pelo menos 1 vez por semana.

d) Sedentarismo - prática de atividade física leve e inferior a 150 minutos por semana.

e) Obesidade - pacientes com IMC acima de 30.

f) Insuficiência renal, Insuficiência hepática, doenças pulmonares e canceres foram descartados com base em informações clínicas. 


\subsection{Dinâmica do estudo}

Após revisão dos critérios de inclusão e exclusão, os voluntários elegíveis eram submetidos a exame clínico, a coleta de sangue, ao teste de esforço cardiopulmonar, bateria de testes neuropsicológicos e ressonância magnética cerebral funcional. Em seguida os participantes foram randomizados em quatro grupos (Figura 1: fluxograma do estudo):

Abreviaturas:

- ABST: abstêmios com treinamento físico

- ABS: abstêmios sem treinamento físico

- VTT: consumidores regulares de vinho tinto com treinamento físico

- VT: consumidores regulares de vinho tinto sem treinamento físico 


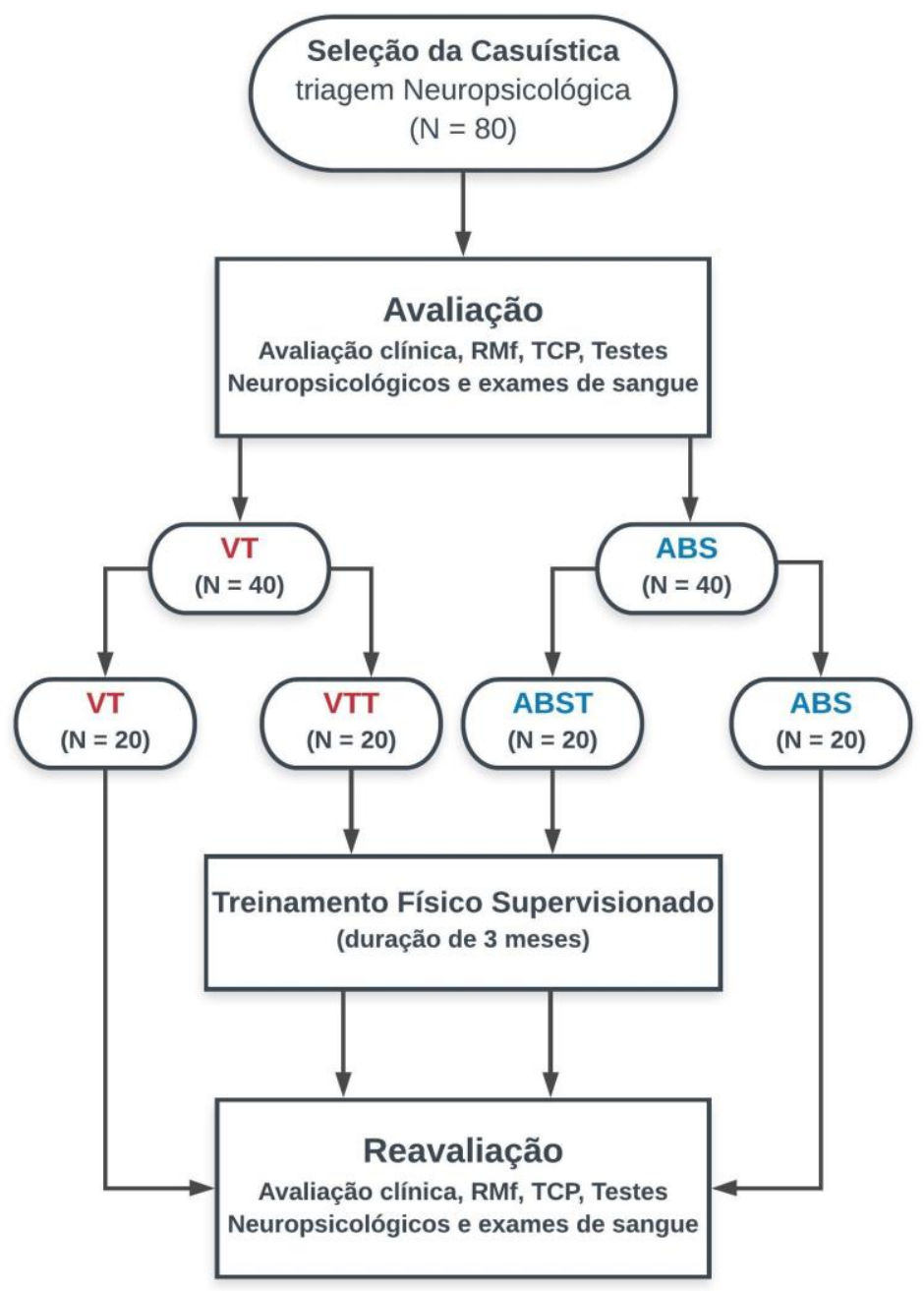

Figura 3- Fluxograma do estudo

\subsection{Randomização e alocação}

Foi realizada randomização simples. Os participantes foram divididos em consumidores regular de vinho tinto e abstêmios. Cada envelope, selado e opaco, continha na parte externa: número de randomização, grupo, data da randomização e iniciais do voluntário. Na parte interna estava escrito: sem treinamento físico ou com treinamento físico. 


\subsection{Avaliação clínica}

\subsubsection{Dados pessoais e exame físico}

A história clínica e o exame físico completos foram realizados pelo pósgraduando Marcelo Nishiyama. Registraram-se os seguintes parâmetros demográficos: idade, sexo, peso, altura, circunferência abdominal, índice de massa corpórea, pressão arterial, frequência cardíaca e os fatores de risco, preenchidos em um questionário formulado para esta pesquisa (apêndice $C$ ).

\subsubsection{Escolaridade}

Foi aplicado o questionário de escolaridade (apêndice D) para a obtenção da duração em anos da formação educacional (desde o ensino fundamental até a pós-graduação) e a distribuição dos anos de estudo durante as fases dos ensinos fundamental e médio em instituições escolares públicas e privadas.

O questionário foi elaborado pelos pesquisadores do presente estudo com a finalidade de dimensionar as variáveis acima apresentadas, as quais são potenciais variáveis de confusão e poderão ser usadas na análise de covariância. 


\subsubsection{Consumo de bebida alcoólica}

Foi aplicado o questionário de consumo de bebida alcoólica e triagem para síndrome de abstinência alcoólica (apêndice B). O questionário foi elaborado pelos pesquisadores com a finalidade de:1) estimar a quantidade média diária de etanol e vinho tinto consumidos; 2) identificar comportamentos e/ou sinais suspeitos da síndrome de abstinência alcoólica.

\subsubsection{Teste de esforço cardiopulmonar}

Os indivíduos foram submetidos ao teste cardiopulmonar em esforço (SensorMedics - Vmax Analyzer Assembly, Encore 29S), em cicloergômetro (Ergoline - Via Sprint 150 P), seguindo protocolo de rampa com aumento constante de carga e velocidade de 60 a 70 rotações por minuto até a exaustão, com incrementos de 10 a $35 \mathrm{~W} / \mathrm{min}$, dependendo da carga máxima predita para cada paciente, em ambiente com temperatura controlada (21 a $23^{\circ} \mathrm{C}$ ). Os pacientes foram orientados a realizar refeição leve pelo menos duas horas antes e evitar o consumo de bebidas contendo cafeína no dia do exame.

Após dois minutos de repouso, em posição sentada, os voluntários foram encorajados a realizar exercício progressivo até próximo a sua exaustão. Durante o teste de esforço, o comportamento cardiovascular foi continuamente avaliado através de eletrocardiógrafo (Micromed - Cardio PC 13), com as doze derivações simultâneas. A pressão arterial foi monitorizada manualmente a cada dois minutos durante todo o exame. A capacidade funcional máxima é 
determinada pelo consumo de oxigênio de pico $\left(\mathrm{VO}_{2}\right.$ pico) avaliado na intensidade máxima de exercício. Os critérios de interrupção do esforço foram os mesmos descritos nas diretrizes brasileiras de teste ergométrico ${ }^{62}$.

O limiar anaeróbio foi determinado no minuto em que o indivíduo apresentou o menor valor de equivalente ventilatório de $\mathrm{O}_{2}\left(\mathrm{VE} / \mathrm{VO}_{2}\right)$, a menor pressão parcial de oxigênio no final da expiração $\left(\mathrm{PetO}_{2}\right)$, antes que estes parâmetros iniciassem aumento progressivo e não linear da razão de troca respiratória (RER).

O ponto de compensação respiratória foi determinado no minuto em que o indivíduo apresentou menor valor de equivalente ventilatório de $\mathrm{CO}_{2}$ (VE/VCO $)_{2}$, antes que este parâmetro iniciasse aumento progressivo, com valor mais elevado de pressão parcial de $\mathrm{CO}_{2}$ no final da expiração $\left(\mathrm{PetCO}_{2}\right)$ e antes que iniciasse queda progressiva.

\subsubsection{Avaliação Neuropsicológica}

Foi realizada pela equipe de Neuropsicologia do Instituto de Psiquiatria do Hospital das Clínicas (IPq), sob a supervisão da Psicóloga Marina Von Zuben. As avaliações foram conduzidas por psicólogos devidamente treinados para a aplicação e correção dos instrumentos. As avaliações foram realizadas no Centro de Pesquisa do InCor.

Foi elaborado um protocolo de avaliação neuropsicológica visando incluir todas as funções cognitivas, com maior ênfase em aspectos da memória e funções executivas, em conformidade com os dados da literatura 
relacionados ao consumo de álcool e prática de atividades físicas. Sendo assim, o protocolo incluiu os seguintes instrumentos: O Rivermead Behavioral Memory Test (Wilson, 1985,1989) ${ }^{63}$ que é uma tarefa ecológica desenvolvida para a avaliação da memória e de aspectos dela tais como: memória prospectiva, memória episódica, memória visual, memória para faces, orientação temporal e espacial. O Trail Making Test (TMT, Army Individual Test Battery, 1944$)^{64}$ que é um instrumento utilizado para avaliação da sustentação da atenção e da atenção alternada. A versão brasileira do Rey-Osterrieth Complex Figure (Rey, 1999) ${ }^{65}$ foi utilizada como medida da capacidade de planejamento e organização visuoespacial e visuoconstrutiva. O Stroop ColorWord Test (Stroop, 1935) ${ }^{66}$ envolve tarefas de atenção visual -subteste I, e controle inibitório -subtestes II e III (apêndice E e F).

\subsubsection{Ressonância Magnética Funcional (RMf)}

Os exames de ressonância magnética foram realizados no Instituto de Radiologia (InRad) do Hospital das Clínicas da Faculdade de Medicina da Universidade de São Paulo, sob a supervisão do Professor Edson Amaro Junior e executado pelos pesquisadores Lucas Zoppi Campane e Mariana Penteado Nucci. Utilizou-se o equipamento série Achieva de 3.0T da empresa Philips (Eindhoven, Holanda), com sistema de gradiente Quasar Dual (amplitudes de gradiente de até $80 \mathrm{mT} / \mathrm{m}$ ), bobina receptora dedicada para crânio de 8 canais e versão Release 3.2.3.2 do software de operação do equipamento. Ao longo do período do estudo, o aparelho de RM teve o seu 
comportamento aferido, utilizando protocolo de controle de qualidade diário, bem como visitas técnicas de manutenção regulares, a fim de garantir qualidade adequada das imagens adquiridas.

Para cada voluntário foram adquiridas imagens estruturais e funcionais do encéfalo.

\subsection{Sequências e parâmetros de aquisição das imagens por RM}

\subsubsection{Imagens estruturais}

- Técnica Turbo Field Echo (TFE) ponderada em T1 com as imagens adquiridas nos 3 planos e sendo utilizados os seguintes parâmetros: tempo de repetição (TR): 9,8 s; tempo de eco (TE): 4,6 s; matriz: 256x128; número de fatias: 9; espessura: $10 \mathrm{~mm}$; espaçamento: $10 \mathrm{~mm}$. Essas imagens foram utilizadas no início do exame para a localização da cabeça.

- Técnica 3D-Balance Fast Field Echo (b-FFE) com as imagens adquiridas no plano sagital, sendo utilizados TR: 5,9 s; TE: 2,4 s; matriz $272 \times 273$; número de fatias: 20; campo de visão (FOV, do inglês Field of view):

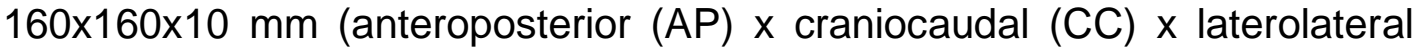
(LL)); flip angle: 45o; espessura: $1 \mathrm{~mm}$. Essas imagens foram utilizadas para adequar a orientação da prescrição das demais sequências, sendo que a determinação do plano axial foi orientanda pela linha que unia as comissuras anterior e posterior. 
- Técnica 3D-Turbo Field Echo ponderada em T1 com as imagens adquiridas no plano sagital e sendo utilizados os seguintes parâmetros: TR: 7 s; TE:

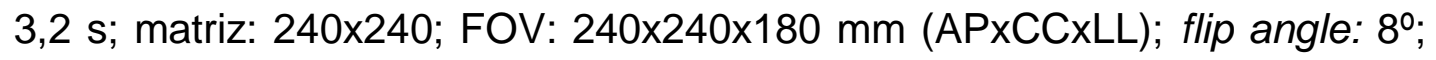
espessura: $1 \mathrm{~mm}$. Essas imagens volumétricas foram adquiridas para aplicação do VBM (Voxel Basic Morphometry).

- Técnica Fluid Attenuation Inversion Recovery (FLAIR) ponderada em T2 com as imagens adquiridas no plano axial e sendo utilizados os seguintes parâmetros: TR: $11 \mathrm{~s}$; TE: $130 \mathrm{~ms}$; tempo de inversão (TI): 2,8 s; matriz:

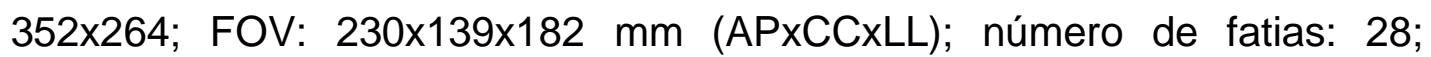
espessura: 4,5 mm; espaçamento: 0,5 mm. Essas imagens foram utilizadas para identificação de eventuais lesões no parênquima encefálico, bem como para avaliação e quantificação das alterações possivelmente de natureza microangiopáticas na substância branca.

\subsubsection{Imagens funcionais}

As aquisições das imagens funcionais foram realizadas por meio da técnica ecoplanar (EPI, do inglês Echo-planar imaging) gradiente eco ponderada em T2, com imagens adquiridas no plano axial e utilizando FOV envolvendo todo o cérebro. Antes da sincronização do equipamento da RM com a apresentação dos estímulos, foram realizadas 5 sequências de pulsos, porém sem aquisição de imagens com o objetivo de estabilização do sinal por meio de saturação da relaxação T1 (dummy scans). Os parâmetros otimizados das sequências das imagens funcionais foram: 
- Paradigma de função executiva (Stroop Color Naming task): TR: 3 s; TE: 30 ms; matriz: 72x71; FOV: 240x122x240 mm (APxCCxLL); espessura: 3,3 $\mathrm{mm}$, sem espaçamento entre as fatias; número de fatias: 37 fatias por volume cerebral. O número total de volumes cerebrais foi de 120 , o tempo total da sequência foi de 6 minutos e 0 tamanho do voxel foi $3,3 \times 3,3 \times 3,3$ mm (APXLLXCC).

- Paradigma de memória operacional (2-Back task): TR: 2 s; TE: 30 ms; matriz: 80x80; FOV: 240x117x240 mm (APxCCxLL); espessura: $3 \mathrm{~mm}$, sem espaçamento entre as fatias; número de fatias: 39 fatias por volume cerebral. O número total de volumes cerebrais foi de 100 , o tempo total da sequência foi de 3 minutos e o tamanho do voxel foi $3,0 \times 3,0 \times 3,0 \mathrm{~mm}$ (APXLLXCC).

- Estado de repouso (Resting state): TR:2 s; TE:30 ms; matriz:80x80; FOV:240x139x240 (APxCCxLL); espessura: $4 \mathrm{~mm}$; espaçamento:0,5 mm; número de fatias: 31 fatias por volume cerebral. O número total de volumes cerebrais foi de 200, o tempo total da sequência foi de 6 minutos e 40 segundos e o tamanho do voxel foi de $3 \times 3 \times 3 \mathrm{~mm}$ (APxCCxLL).

\subsubsection{Instrumentos relacionados à apresentação dos estímulos e à coleta das respostas comportamentais}

Todos os instrumentos utilizados no ambiente da RM foram produzidos por materiais compatíveis a esse local e, consequentemente, não determinavam artefatos ou interferências de qualquer natureza que pudessem prejudicar a formação ou interpretação das imagens. Foi utilizado um painel de 
penetração para que houvesse a comunicação dos equipamentos entre as salas do scanner e de controle da RM. Os principais instrumentos utilizados foram:

- Trigger: instrumento por meio do qual foi feito a sincronização com precisão das sequências de pulsos da RM com a apresentação dos estímulos dos paradigmas (Zurc \& Zurc, São Paulo - SP, Brasil). Por meio desse equipamento, era feito reconhecimento do pulso da $\mathrm{RM}$ e o envio subsequente de um pulso de sincronização para o computador responsável pela geração dos estímulos dos paradigmas, de forma que os últimos somente eram enviados para a tela de projeção após a identificação dos correspondentes pulsos da RM;

- Computador para geração dos estímulos dos paradigmas, o qual compõe o sistema de equipamentos da Invivo Eloquence ${ }^{\mathrm{TM}}$ (Gainesville - Florida, Estados Unidos);

- $\quad$ Sistema de resposta manual: instrumento composto por 3 botões por meio do qual as respostas comportamentais dos voluntários eram registradas (Zurc \& Zurc, São Paulo - São Paulo, Brasil) a partir do pressionamento digital desses botões nos momentos adequados;

- Tela de projeção: anteparo de acrílico posicionado perpendicularmente ao maior eixo da maca do scanner e a uma distância de $150 \mathrm{~cm}$ da entrada do gantry do equipamento da RM;

- Sistema de espelhos acoplados à bobina de crânio: conjunto de espelhos planos que permitiu a visualização dos estímulos apresentados na tela de projeção sem que os voluntários, na posição de decúbito dorsal horizontal, movessem a cabeça ou os olhos; 
- Projetor de vídeo: equipamento de multimídia (modelo 2400 mp, Dell, Estados Unidos), localizado na sala de controle da RM (fora do ambiente magnético) e que estava conectado ao computador gerador dos estímulos dos paradigmas.

\subsubsection{Paradigmas da RM funcional}

Todos os paradigmas foram programados e apresentados utilizando o programa E-prime® (versão 1.1, Psychology Software Tools, Inc, Sharpburg Pensilvânia, Estados Unidos) e a apresentação dos estímulos foi sincronizado com os pulsos da RM por meio do equipamento trigger (descrito no item anterior).

\subsubsection{Paradigma de função executiva}

Para avaliação da função executiva da cognição foi utilizado o paradigma Stroop Color Naming Task, por meio do qual uma sequência de palavras era projetada no centro da tela e o voluntário tinha que responder (pressionando um de três botões, cada um dos quais representando uma cor específica) a cor que a palavra estava escrita (vermelho, verde ou azul). 0 botão referente a cor vermelha era acionado pelo dedo indicador, o da cor verde pelo dedo médio e o da cor azul pelo dedo anelar. Seguindo o modelo utilizado por Carter e colaboradores ${ }^{67}$, os estímulos foram apresentados em 
três condições distintas: congruente, neutra e incongruente. O paradigma foi desenhado em forma de bloco do tipo $A B C$, sendo que na condição $A$ (congruente), o significado da palavra e a cor eram iguais (exemplo: palavra "AZUL" escrita com letras em cor azul); na condição B (neutra), as palavras não tinham denotação de cor (exemplo: CASA) e poderiam aparecer escritas com letras de cor azul, vermelho ou verde; e na condição $C$ (incongruente), 0 significado da palavra apresentada correspondia a uma cor diferente daquela das letras que a formava (exemplo: a palavra "VERDE" escrita com letras vermelhas). Em cada um dos ciclos $A B C$, as condições eram apresentadas sucessivamente na mesma ordem: congruente, depois a neutra e por último a incongruente. Cada uma das condições era formada por uma sequência de 10 palavras, as quais eram intercaladas entre si por um período de resposta, durante o qual era projetado na tela um sinal "+" (com mesmo tamanho que a das letras das palavras) e os voluntários eram orientados a pressionar o botão de resposta nesse momento. O tempo de apresentação de cada uma das palavras foi de 1 segundo e o tempo respectivo de resposta foi de $995 \mathrm{~ms}$ para as três condições, com exceção para o tempo de resposta da décima palavra da condição incongruente, que foi de 800 (ms). Assim, em um ciclo, as condições congruente e neutra duravam 19 s 95 ms, e a incongruente, 19 s 75 ms. Cada um dos ciclos ABC tinha uma duração de 1 minuto (59 s 65 ms de apresentação das palavras e períodos de respostas somado a um período de atraso de 0,35 ms para garantir a adequada sincronização do início do próximo ciclo de condições com a aquisição das imagens de RM). O ciclo de condições ABC foi apresentado 6 vezes para cada um dos voluntários e, portanto, 0 tempo total do paradigma foi de 6 minutos (Figura 4). 


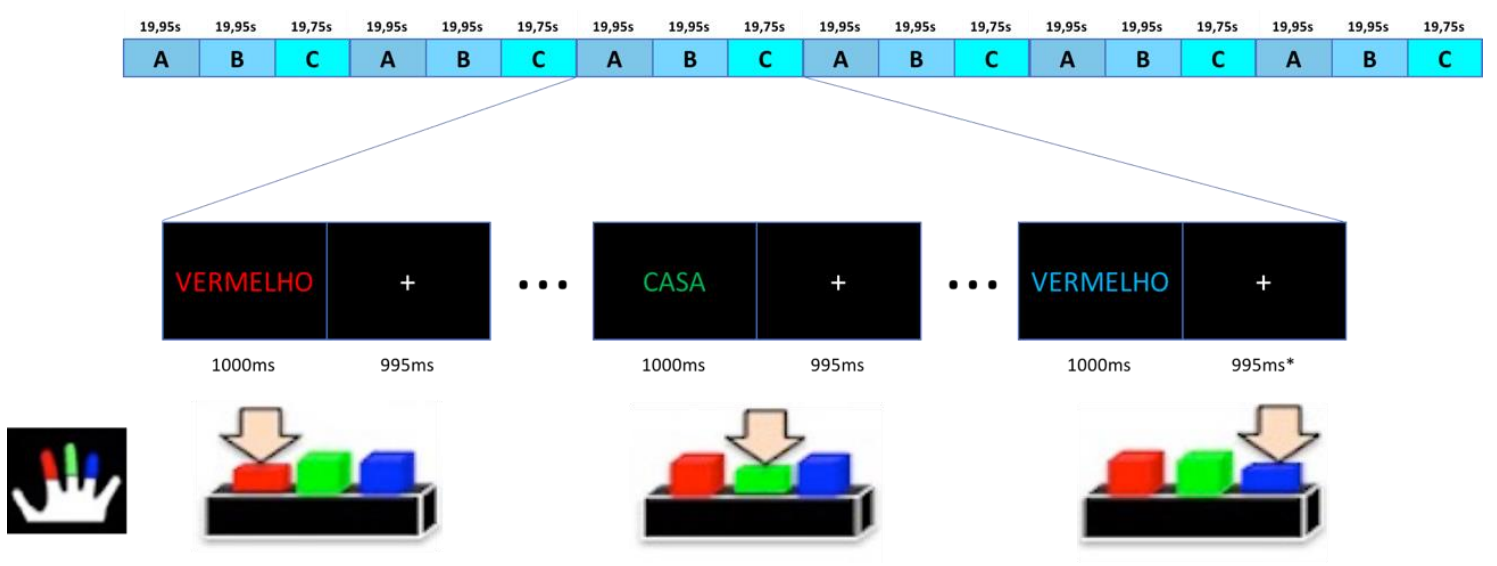

Figura 4- Representação do paradigma de função executiva (Stroop Color Naming task), sendo mostrados a sequência dos 6 ciclos de condições $A B C$ (entre um ciclo e outro existe um atraso de 0,35 s - não representado na figura), exemplos dos primeiros estímulos com seus respectivos períodos de resposta de cada condição do terceiro ciclo $A B C$, e o sistema de resposta manual utilizado pelo voluntário (os dedos indicador, médio e anelar posicionados, respectivamente, nos botões representativos das cores vermelha, verde e azul). O tempo de duração de cada condição é mostrado logo acima do retângulo representativo da mesma. Os tempos de duração do estímulo e do período de resposta são mostrados logo abaixo dos retângulos representativos dos mesmos. As setas de cor rosa clara indicam quais botões deveriam ser acionados nos exemplos de estímulos apresentados ( ${ }^{*} O$ último estímulo da condição incongruente de cada bloco tem duração de $800 \mathrm{~ms}$ ).

\subsubsection{Paradigma de memória operacional}

Para avaliação da função cognitiva de memória operacional, foi utilizado o paradigma 2-Back, por meio do qual uma sequência de letras foi projetada no centro da tela e o voluntário tinha que responder (pressionando com o dedo indicador apenas um botão) quando ele visse uma determinada letra. Os estímulos foram apresentados em duas condições distintas: ativa e neutra. O paradigma foi desenhado em forma de bloco do tipo $A B$, sendo que na condição A (ativa), o voluntário tinha que responder quando a letra que 
aparecesse na tela (atual) fosse igual à letra que foi apresentada antes da anterior, ou seja, 2 letras anteriores à atual (2-Back); na condição B (neutra), o voluntário tinha que responder quando a letra "X" aparecesse na tela. Em cada um dos ciclos $(A B)$, as condições eram apresentadas sucessivamente na mesma ordem: ativa e depois a neutra. Cada uma das condições era formada por uma sequência de 10 letras, as quais eram intercaladas entre si por um período de resposta, durante o qual era projetado na tela um sinal "+" (com mesmo tamanho que a das letras das palavras) e os voluntários eram orientados a pressionar o botão de resposta nesse momento. O tempo de apresentação de cada uma das palavras foi de 1 segundo e o tempo respectivo de resposta foi de 800 ms para as duas condições. Assim, em um ciclo, as duas condições duravam $18 \mathrm{~s}$ cada uma e, portanto, o ciclo AB tinha duração de 36 s. O ciclo de condições $A B$ foi apresentado 5 vezes para cada um dos voluntários e, portanto, o tempo total do paradigma foi de 3 minutos (Figura 5).

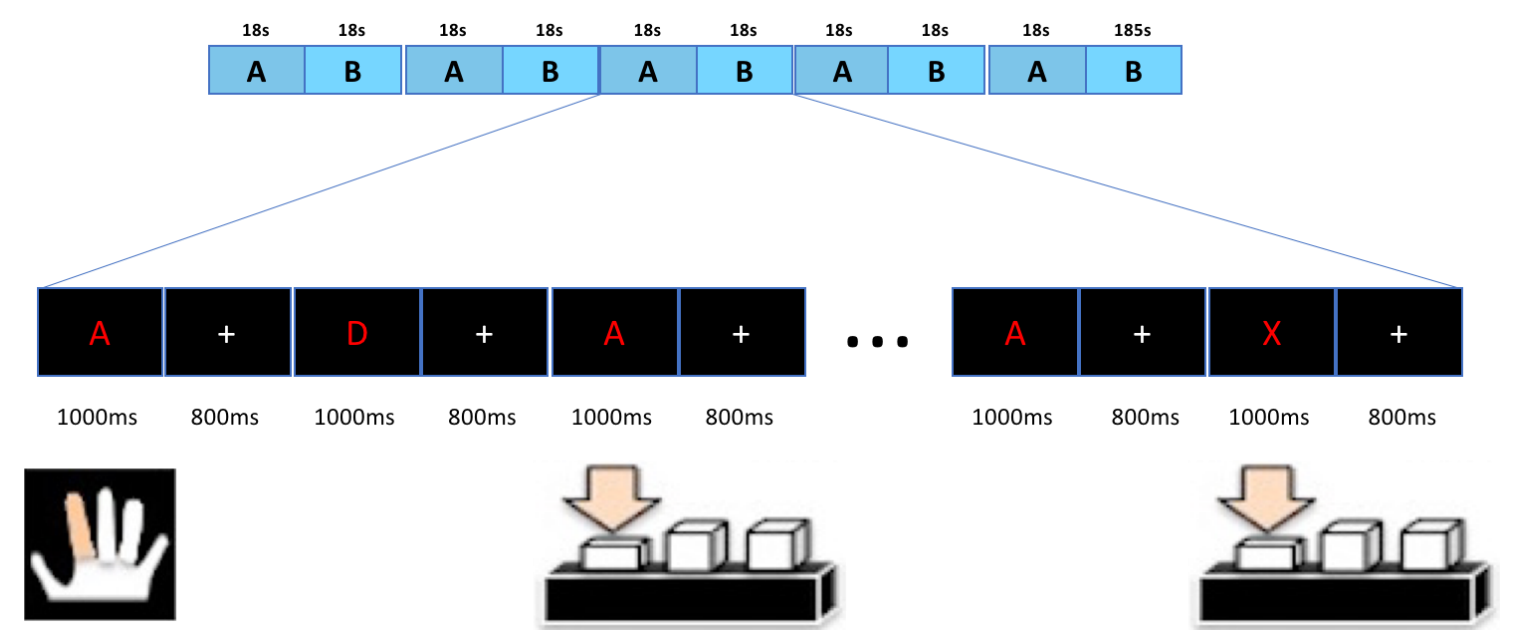

Figura 5- $\quad$ Representação do paradigma de memória operacional (2-Back task), sendo mostrados a sequência dos 5 ciclos de condições $A B$, exemplos dos primeiros estímulos com seus respectivos períodos de resposta de cada condição do terceiro ciclo $A B$, e 0 sistema de resposta manual utilizado pelo voluntário (o dedo 
indicador posicionado no primeiro botão). O tempo de duração de cada condição é mostrado logo acima do retângulo representativo da mesma. Os tempos de duração do estímulo e do período de resposta são mostrados logo abaixo dos retângulos representativos dos mesmos. As setas de cor rosa clara indicam em qual momento o primeiro botão do sistema de resposta manual deveria ser acionado.

\subsection{Dinâmica do exame de RM funcional}

\subsubsection{Treino dos paradigmas}

Todos os voluntários, no mesmo dia e imediatamente antes do exame de RMf, em uma sala do setor de RM do InRad, foram instruídos sobre a dinâmica dos dois paradigmas, bem como foram submetidos a uma sessão de treinamento. Por meio de um computador portátil e comando de resposta manual semelhante ao que seria utilizado no exame, os voluntários eram expostos a uma versão de treinamento dos dois paradigmas (organização sequencial diferente dos estímulos, mesma sequência de condições por ciclo e menor número de repetição dos ciclos). A sessão de treinamento era finalizada após um número suficiente de repetição dos paradigmas para que o voluntário se declarasse confortável com a dinâmica dos mesmos. Para os que tinham distúrbios visuais de refração, foram oferecidas lentes corretivas montadas em armação compatível com o ambiente do equipamento da RM. Após a finalização do treinamento, os voluntários eram encaminhados para o exame de RMf. 


\subsubsection{Posicionamento dos voluntários}

Todos os voluntários foram posicionados em decúbito dorsal horizontal na maca do equipamento de RM, com o corpo orientado de forma que a cabeça entrasse primeiro que os pés no interior do equipamento (head first). Para minimizar o incômodo do estímulo sonoro, era colocado um abafador do tipo concha. A cabeça do voluntário era apoiada em posição neutra no interior da bobina receptora, de forma que o centro do campo de visão do voluntário contivesse o espelho fixado na parte anterior da bobina, o qual fazia parte de um sistema óptico simples (formado por dois espelhos planos) que refletia os estímulos visuais projetados na tela. Eram utilizados coxins de espuma e faixas de fita adesiva para assegurar a manutenção do alinhamento da cabeça durante o exame. O comando de resposta era colocado na mão direita do voluntário, com os dedos indicador, médio e anelar posicionados sobre cada um dos três botões, da mesma forma como havia sido feito na sessão de treinamento. Avaliava-se se o voluntário estava visualizando adequadamente (por meio do sistema óptico) o conteúdo projetado na tela e, por último, colocava-se sobre o quadril do voluntário, no alcance da mão esquerda dele, um dispositivo mecânico de alarme de segurança, o qual o voluntário poderia acionar se sentisse qualquer desconforto.

\subsubsection{Realização do exame de RM funcional}

O exame de RMf era iniciado com aquisição das imagens de localização; posteriormente eram adquiridas as imagens funcionais durante a 
exposição sincronizada dos estímulos dos dois paradigmas e, por último, as imagens estruturais eram coletadas.

Eram feitos contatos com os voluntários por meio de microfone interno do equipamento de RM em três momentos: antes de iniciar o exame, antes do começo de cada um dos dois paradigmas e antes da aquisição das imagens estruturais. Os objetivos eram reforçar a importância da imobilidade da cabeça, relembrar resumidamente as instruções de cada um dos paradigmas e dar condições aos voluntários de expressar dúvidas ou desconfortos.

\subsubsection{Análises Laboratoriais}

As amostras de sangue foram obtidas através de venopunção após 20 minutos de repouso e jejum de 8 horas. Todos foram orientados a não realizar exercício 24 horas antes.

O colesterol total, $H D L$ colesterol, $L D L$ colesterol, triglicérideos e glicemia de jejum, foram avaliados pelos métodos adotados rotineiramente no laboratório de Análises Clínicas do InCor.

\subsubsection{Programa de exercício supervisionado}

Os voluntários selecionados para os grupos com treinamento físico, foram submetidos a 12 semanas de treinamento físico aeróbico supervisionado, incluindo três sessões semanais, com duração de 60 minutos, 
constituídos de: 5 minutos de aquecimento, 40 minutos de exercício aeróbio em cicloergômetro, com intensidade entre o limiar anaeróbio e o ponto de compensação respiratória, aferidos pela frequência cardíaca, 10 minutos de exercícios resistidos e 5 minutos de relaxamento.

Alguns dos voluntários submetidos ao treinamento físico supervisionado treinaram no setor de Reabilitação Cardiovascular do InCor e os outros na escola de Educação Física da USP, na cidade universitária, sob a supervisão da Equipe do Professor Carlos Eduardo Negrão.

\subsubsection{Análise estatística}

O tamanho da amostra foi calculado de acordo com o trabalho de Mumford e Nichols ${ }^{68}$, indicando que para estudos com ressonância magnética funcional, para um poder de $80 \%$, serão necessários de 18 a 20 indivíduos em cada grupo (Figura 6). 


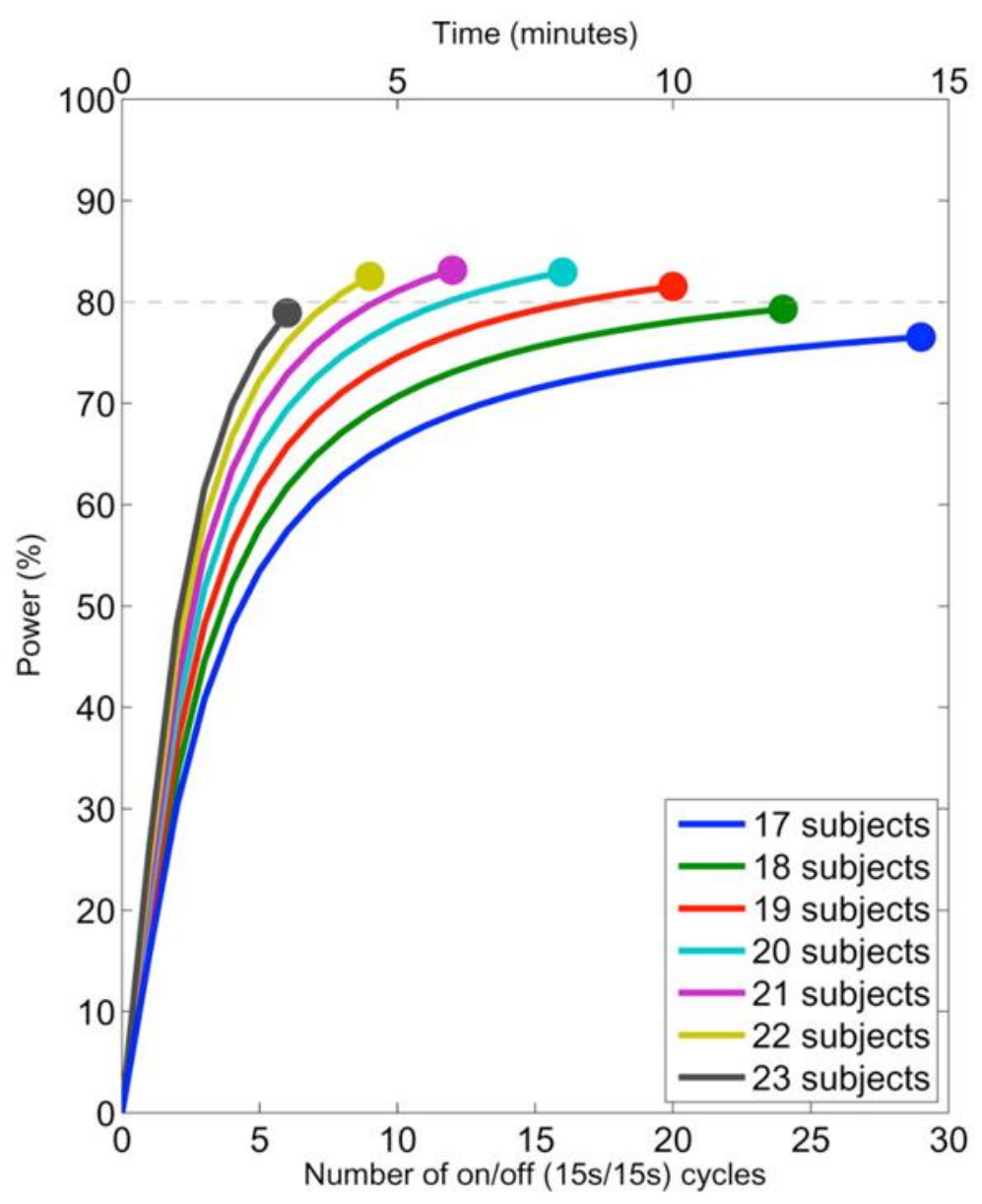

Figura 6- Tamanho da amostra e poder estatístico

A normalidade da distribuição das variáveis contínuas em cada grupo foi verificada com o teste de Shapiro-Wilk. Os quatro grupos foram comparados utilizando análise de variância (ANOVA), se distribuição normal, ou teste de Kruskal-Wallis em caso contrário. Se encontrada diferença significativa, comparações de grupos pareados foi realizada com teste $\mathrm{T}$, ou Wilcoxon se não normal. O teste exato de Fisher foi usado para comparar as proporções das variáveis discretas.

Os valores são apresentados como Média \pm Desvio Padrão (DP) ou mediana e Intervalo de Confiança (IC). 


\subsection{Característica da amostra}

Foram recrutados 97 voluntários, sendo 47 consumidores de vinho tinto e 50 abstêmios. Após assinatura do termo de consentimento livre e esclarecido e realização dos exames iniciais, foram excluídos 6 voluntários, sendo 3 do grupo VT: 1 com diagnóstico de Doença de Parkinson, 1 por déficit cognitivo e 1 por tempo de ingestão de vinho tinto inferior a 5 anos; 2 do grupo ABS: 1 voluntário com passado importante de claustrofobia e 1 por implante dentário. Após finalizada a etapa de realização dos exames de RMf e feita a análise das imagens, foram excluídos mais 5 voluntários por achados incidentais, sendo 3 do grupo VT: 1 por meningioma, 1 com lesões sequelares e 1 com lesão do corpo caloso; e 2 do grupo ABS: 1 voluntário com meningioma e 1 com lesão sequelar.

Entre a randomização final para a definição dos 4 grupos até o término do protocolo foram excluídos mais 11 voluntários: 4 do grupo ABS com treinamento físico, sendo 2 por desistências, 1 por arritmia cardíaca e 1 com artropatia de joelho; 1 voluntário do grupo ABS sem treinamento físico por desistência; 4 do grupo VT com treinamento físico, sendo 2 por desistência, 1 devido a erros excessivos durante a execução dos paradigmas e 1 por erro de gravação da imagem de RMf; e 2 do grupo VT sem treinamento físico, sendo 1 por desistência e 1 por erros excessivos durante a execução dos paradigmas.

Com isso a amostra final foi composta de 73 voluntários, dos quais 17 eram abstêmios que realizaram treinamento físico, 20 abstêmios sem treinamento físico, 17 consumidores de vinho tinto que realizaram 0 treinamento físico e 19 consumidores de vinho tinto sem treinamento físico, 
conforme podemos verificar no fluxograma (Figura 7). A taxa de exclusão global desse estudo foi de $24 \%$.

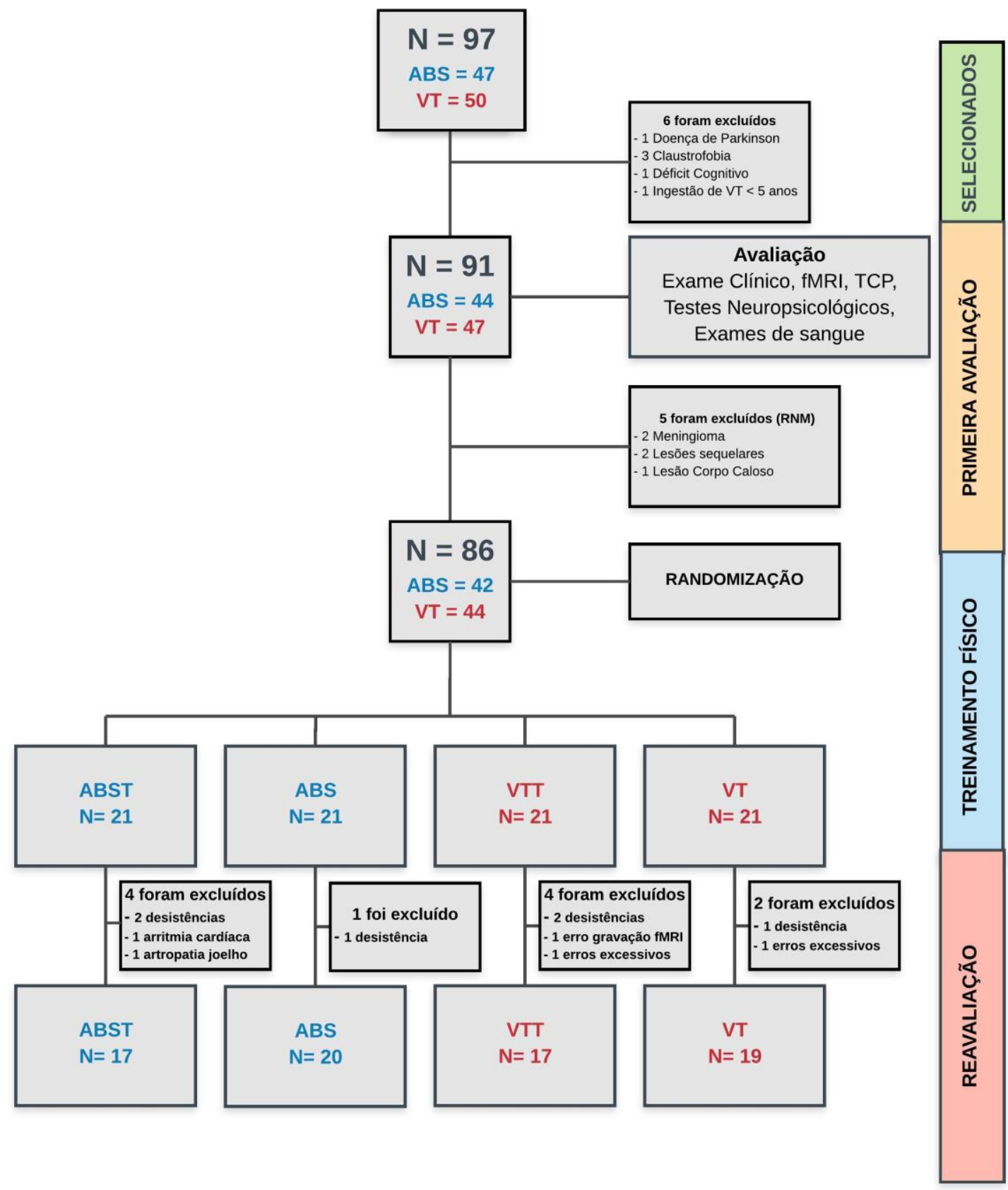

Figura 7- Fluxograma de recrutamento dos voluntários 
Abreviaturas:

- ABST: abstêmios com treinamento físico

- ABS: abstêmios sem treinamento físico

- VTT: consumidores regulares de vinho tinto com treinamento físico

- VT: consumidores regulares de vinho tinto sem treinamento físico

\subsection{Questionários e avaliação neuropsicológica}

\subsubsection{Dados pessoais}

O grupo ABS com treinamento físico (ABST) foi composto de 17 voluntários, com média de idade de 57,7 $\pm 5,2$ anos. Já o grupo $A B S$ sem treinamento físico (ABS) foi constituído de 20 voluntários, com média de idade de 59,1 \pm 5,1 anos. No grupo VT com treinamento físico (VTT) havia 17 voluntários, com média de idade de 61,1 \pm 7,3 anos. E o grupo VT sem treinamento físico (VT) tinha média de idade de 60,8 \pm 6 anos. Não houve diferença significativa entre as médias de idade dos grupos $(p=0,292)$.

\subsubsection{Escolaridade}

No grupo ABST a escolaridade em anos de estudo foi de 10,5 $\pm 4,2$ anos; já no grupo ABS a escolaridade foi de 13,8 \pm 3,6 anos, no grupo VTT foi de $13.9 \pm 3,5$ anos e no VT foi de 15,3 $\pm 1,9$ anos. 
Houve diferença estatisticamente significativa (testes Kruskal-Wallis) das medianas da duração da formação educacional dos grupos $(p=0,008)$ (Tabela 1), sendo que no grupo ABST os anos de estudo foram estatisticamente menores que nos demais grupos $(p<0,05)$.

Tabela 1- Descrição da Idade e escolaridade segundo grupos e resultados dos testes comparativos

\begin{tabular}{lccccc}
\hline Variável & $\begin{array}{c}\mathrm{ABST} \\
(\mathrm{N}=17)\end{array}$ & $\begin{array}{c}\mathrm{ABS} \\
(\mathrm{N}=20)\end{array}$ & $\begin{array}{c}\mathrm{VTT} \\
(\mathrm{N}=17)\end{array}$ & $\begin{array}{c}\mathrm{VT} \\
(\mathrm{N}=19)\end{array}$ & $\mathbf{p}$ \\
\hline \hline $\begin{array}{l}\text { Idade (anos) } \\
\text { média } \pm \mathrm{DP}\end{array}$ & $57,7 \pm 5,2$ & $59,1 \pm 5,1$ & $61,1 \pm 7,3$ & $60,8 \pm 6$ & 0,292 \\
$\begin{array}{l}\text { Escolaridade } \\
\text { (anos de estudo) } \\
\text { média } \pm \text { DP }\end{array}$ & & & & & \\
\hline
\end{tabular}

ANOVA; * Teste Kruskal-Wallis

\subsubsection{Fatores de risco}

Quanto aos fatores de risco clássicos, os quatro grupos foram homogêneos (tabela 2). 
Tabela 2- Fatores de risco

\begin{tabular}{l|l|l|l|l|l}
\hline & ABST $(n=17)$ & ABS(n=20) & VTT(n=17) & VT (n=19) & $p$ \\
\hline Tabagismo & $(0) 0 \%$ & $(2) 10 \%$ & $(1) 5,2 \%$ & $(1) 5 \%$ & 0,626 \\
\hline $\begin{array}{l}\text { Hipertensão } \\
\text { arterial }\end{array}$ & $(7) 38 \%$ & $(9) 45 \%$ & $(10) 58,8 \%$ & $(9) 47 \%$ & 0,352 \\
\hline Diabetes & $(3) 16,6 \%$ & $(2) 10 \%$ & $(1) 5,2 \%$ & $(3) 15 \%$ & 0,962 \\
\hline LDL >100 & $(9) 50 \%$ & $(14) 70 \%$ & $(14) 73,6 \%$ & $(13) 65 \%$ & 0,574 \\
\hline HDL baixo $(<40)$ & $(7) 38,8 \%$ & $(11) 55 \%$ & $(7) 36,8 \%$ & $(8) 40 \%$ & 0,576 \\
\hline Obesidade & $(4) 22,2 \%$ & $(8) 40 \%$ & $(8) 42,1 \%$ & $(5) 25 \%$ & 0,939 \\
\hline Triglicérides > 150 & $(3) 16,6 \%$ & $(7) 35 \%$ & $(9) 47,3 \%$ & $(10) 50 \%$ & 0,073 \\
\hline
\end{tabular}

ANOVA; * Teste Kruskal-Wallis; $L D L=$ low-density lipoproteins; $H D L=$ high density lipoproteins.

\subsubsection{Consumo de vinho tinto}

O tempo médio de consumo de vinho tinto foi de $26,1 \pm 15,7$ anos, sendo que todos os voluntários mostraram padrão regular de consumo dessa bebida nos 5 anos que antecederam a entrada dos mesmos no estudo.

A dose média diária foi de 1,8 $\pm 0,89$ taças, o que equivale a aproximadamente $21,7 \pm 10,6$ gramas por dia de etanol consumido na forma de vinho tinto. O tipo de vinho foi o consumido habitualmente pelo voluntário.

Nenhum dos voluntários do grupo VT apresentou comportamento e/ou sinais suspeitos para síndrome de abstinência alcoólica. 


\subsubsection{Teste de esforço cardiopulmonar}

Os dados (Tabela 3) da avaliação cardiopulmonar de esforço mostram que ambos os grupos submetidos ao treinamento físico aeróbio supervisionado por 3 meses, ABS e VT, aumentaram significativamente a potência máxima atingida e o consumo máximo de oxigênio, comprovando o efeito da intervenção por treinamento.

Tabela 3- Parâmetros do Teste cardiopulmonar segundo grupos e resultado dos testes comparativos

\begin{tabular}{|c|c|c|c|c|c|c|c|c|}
\hline \multirow{3}{*}{ Variável } & & \multicolumn{7}{|c|}{ Grupo } \\
\hline & \multicolumn{2}{|c|}{ ABST $\overline{(N=17)}$} & \multicolumn{2}{|c|}{ ABS $(\mathrm{N}=20)$} & \multicolumn{2}{|c|}{ VTT $(\mathrm{N}=17)$} & \multicolumn{2}{|c|}{ VT $(\mathrm{N}=19)$} \\
\hline & PRÉ & PÓS & PRÉ & PÓS & PRÉ & PÓS & PRÉ & PÓS \\
\hline $\begin{array}{l}\text { Potência Máxima } \\
\text { (Watts) }\end{array}$ & $171,2 \pm 39,1$ & $195,6 \pm 34,7^{\star}$ & $194,4 \pm 41$ & $193,9 \pm 41,3$ & $174,4 \pm 30$ & $200,9 \pm 30,8^{*}$ & $186,8 \pm 37,2$ & $177,8 \pm 33,8$ \\
\hline $\begin{array}{l}\text { VO2 Pico } \\
\text { (ml.kg-1. min-1) }\end{array}$ & $27,1 \pm 4,9$ & $29,7 \pm 4^{*}$ & $27,1 \pm 5,5$ & $27,6 \pm 6,1$ & $24,9 \pm 2,6$ & $27,1 \pm 3,5^{\star}$ & $25,7 \pm 5,1$ & $25,5 \pm 5,1$ \\
\hline FC $1 \min (\mathrm{bpm})$ & $142,8 \pm 17,1$ & $141 \pm 19,6$ & $142,2 \pm 15,8$ & $139,5 \pm 15,4$ & $140 \pm 9,9$ & $134,2 \pm 11,8^{\star}$ & $140,8 \pm 17,2$ & $134,5 \pm 14,2^{*}$ \\
\hline FC $2^{\circ} \min (b p m)$ & $127 \pm 15,9$ & $124,7 \pm 18,5$ & $128,3 \pm 14,6$ & $124,9 \pm 15,2$ & $123,4 \pm 11,8$ & $118,4 \pm 11$ & $125,1 \pm 18,3$ & $119,7 \pm 13,9$ \\
\hline
\end{tabular}

Comparações entre grupos para a potência máxima atingida

Gráficos 1 e 2- $\quad$ Potência máxima atingida nos ABS

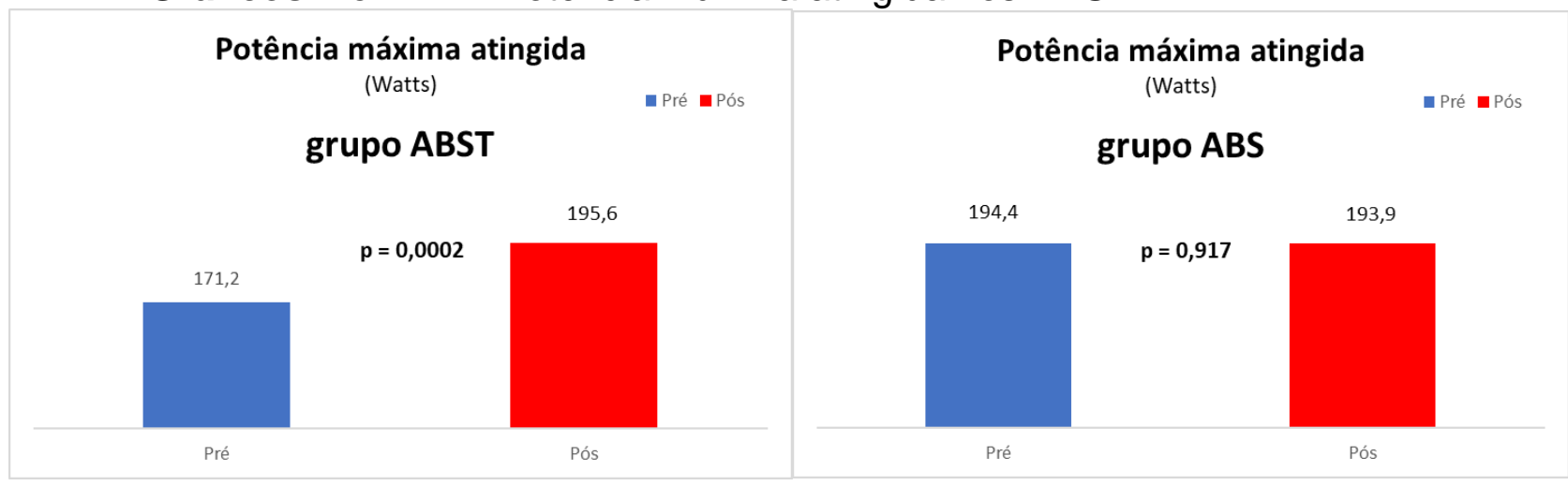


Gráficos 3 e 4- Potência máxima atingida nos bebedores de VT

Potência máxima atingida (Watts)

grupo VTT

$p=0,0006$

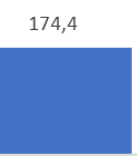

Pré
Potência máxima atingida

(Watts)

grupo VT

$p=0,026$

186,8

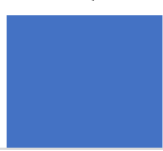

Pré
mPré m Pós

Pós

Comparações entre os grupos para o $\mathrm{VO}_{2} \mathrm{Pico}$

Gráficos 5 e 6- $\quad \mathrm{VO}_{2}$ pico nos $\mathrm{ABS}$

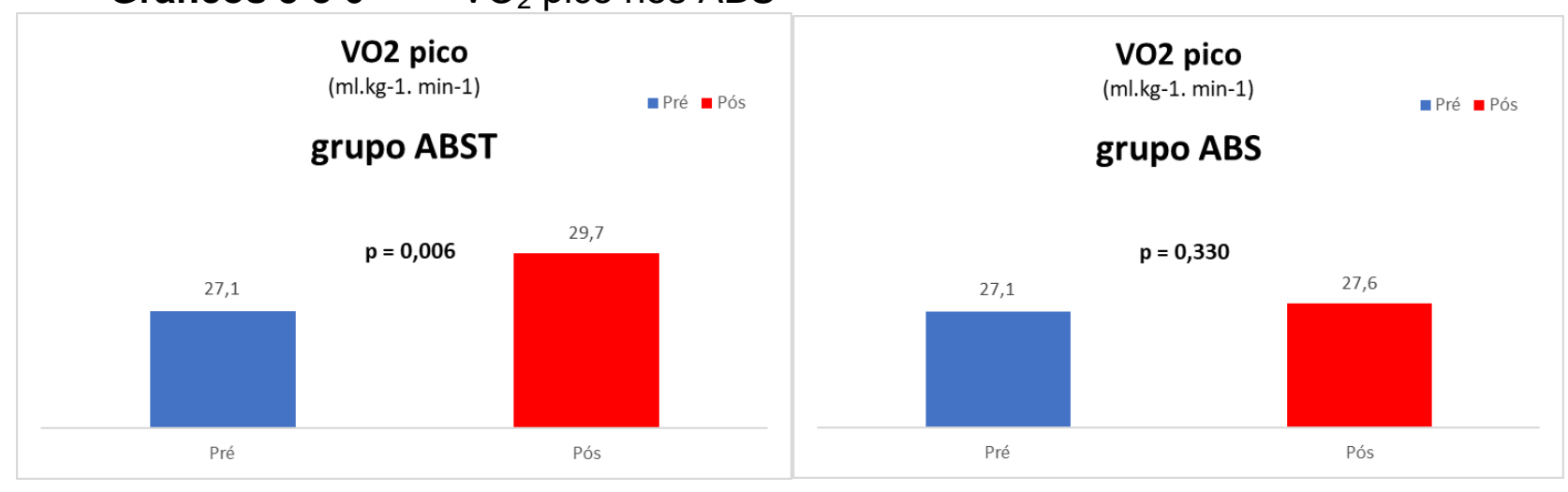

Gráficos 7 e 8- $\quad V_{2}$ pico nos bebedores de VT

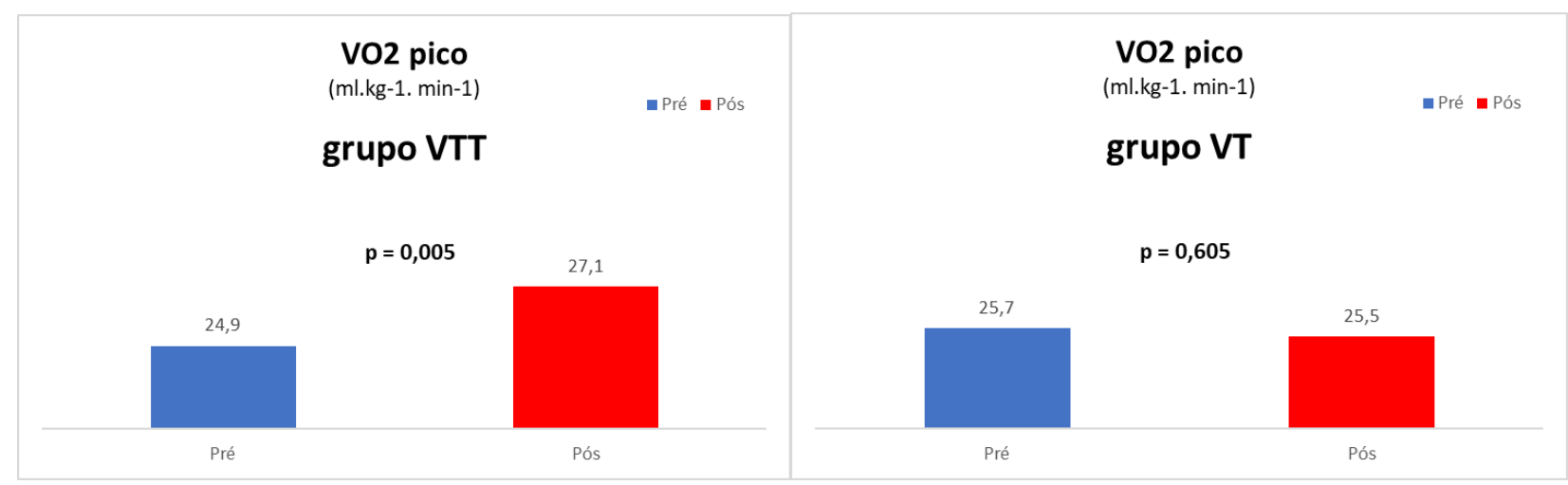


Podemos observar na Tabela 3, que a frequência cardíaca apenas apresentou diminuição significativa no $1^{\circ}$ minuto da fase de recuperação, no grupo vinho tinto. Portanto, na fase pós, este comportamento foi observado tanto nos indivíduos que realizaram treinamento físico $(p=0,02)$ assim como naqueles que não treinaram $(p=0,04)$.

\subsubsection{Análises Laboratoriais}

Os resultados iniciais dos exames de sangue, incluindo colesterol total, $H D L, L D L$, triglicerídeos e glicemia de jejum, não mostraram diferença significativa entre os grupos; tampouco houve modificações com treinamento físico, conforme mostra a tabela 4. Podemos observar que os consumidores de vinho tinto apresentam glicemia de jejum menor que os abstêmios, mas sem significância estatística.

Tabela 4- Exames laboratoriais

\begin{tabular}{|c|c|c|c|c|c|c|c|c|}
\hline \multirow{3}{*}{ Variável } & \multicolumn{8}{|c|}{ Grupo } \\
\hline & \multicolumn{2}{|c|}{ ABST $(\mathrm{N}=17)$} & \multicolumn{2}{|c|}{ ABS $(\mathrm{N}=20)$} & \multicolumn{2}{|c|}{ VTT $(\mathrm{N}=17)$} & \multicolumn{2}{|c|}{ VT $(\mathrm{N}=19)$} \\
\hline & PRÉ & PÓS & PRÉ & PÓs & PRÉ & PÓs & PRÉ & PÓS \\
\hline $\begin{array}{l}\text { Colesterol Total } \\
(\mathrm{mg} / \mathrm{dL})\end{array}$ & $183,9 \pm 42,8$ & $186,6 \pm 41,3$ & $192,2 \pm 41$ & $191,8 \pm 46,9$ & $202,7 \pm 50,4$ & $198,1 \pm 57,9$ & $190,6 \pm 34,6$ & $190,2 \pm 38,6$ \\
\hline $\begin{array}{l}\text { HDL } \\
\text { (mg/dL) }\end{array}$ & $43,2 \pm 9,8$ & $45,7 \pm 12,2$ & $42,2 \pm 11$ & $40,7 \pm 10$ & $40,6 \pm 9,5$ & $42,1 \pm 11,8$ & $46,4 \pm 14,2$ & $49,6 \pm 19,6$ \\
\hline $\begin{array}{l}\text { LDL } \\
(\mathrm{mg} / \mathrm{dL})\end{array}$ & $116,8 \pm 38,3$ & $116,6 \pm 34,8$ & $119,9 \pm 35,3$ & $120,1 \pm 35,9$ & $128,9 \pm 43,9$ & $122,5 \pm 47,3$ & $118,4 \pm 34,2$ & $111,3 \pm 35,4$ \\
\hline $\begin{array}{l}\mathrm{TG}^{*} \\
(\mathrm{mg} / \mathrm{dL})\end{array}$ & $118,9 \pm 57,1$ & $122,4 \pm 80,5$ & $157,1 \pm 125,7$ & $152,9 \pm 92,2$ & $172,2 \pm 117,2$ & $166,9 \pm 76,6$ & $144,8 \pm 67,1$ & $147,5 \pm 67,1$ \\
\hline $\begin{array}{l}\text { Glicose } \\
\text { (mg/dL) }\end{array}$ & $98,4 \pm 14,8$ & $96,4 \pm 11,2$ & $100,5 \pm 37,4$ & $96,1 \pm 41,2$ & $91,2 \pm 15,5$ & $93,7 \pm 16,4$ & $89,3 \pm 29,4$ & $92,2 \pm 12,9$ \\
\hline
\end{tabular}




\subsection{Avaliação Neuropsicológica}

\subsubsection{Rastreio do comprometimento cognitivo}

Foram analisados os testes de Miniexame do Estado Mental (MEM) de todos os voluntários selecionados, sendo 47 do grupo abstêmios e 50 do grupo consumidor de vinho tinto.

As pontuações médias do MEM dos pacientes que terminaram o protocolo estão na tabela 8 . Apenas 1 voluntário apresentou pontuação igual a 24 pontos, compatível com déficit cognitivo, sendo que o mesmo pertencia ao grupo VT. Este voluntário foi encaminhado para o serviço de Psicologia do Instituto de Psiquiatria (IPq) da FMUSP. Não houve diferença das médias (teste de Kruskal-Wallis) das pontuações entre os quatro grupos $(p=0.585)$.

Como meio de rastreio do comprometimento cognitivo também foi aplicado o Teste do Desenho do Relógio $(C D T)^{69}$. Para a interpretação dos dados, foram utilizados os critérios descritos por Sunderland (1989) que desenvolveu uma escala de dez pontos (dez para o melhor relógio e um para o pior). Assim cinco pontos são atribuídos para o desenho correto do círculo e dos números, e seis a dez pontos para a tarefa de indicar o horário "11:10". 0 valor de corte é de seis pontos do total. Não houve diferença entre as médias (teste de Kruskal-Wallis) das pontuações entre os quatro grupos $(p=0.709)$. 
Tabela 5- Descrição do minimental e CDT segundo grupos

\begin{tabular}{lccccc}
\hline Variável & $\begin{array}{c}\text { ABST } \\
(\mathrm{N}=17)\end{array}$ & $\begin{array}{c}\text { ABS } \\
(\mathrm{N}=20)\end{array}$ & $\begin{array}{c}\text { VTT } \\
(\mathrm{N}=17)\end{array}$ & $\begin{array}{c}\text { VT } \\
(\mathrm{N}=19)\end{array}$ & $\mathbf{p}$ \\
\hline \hline $\begin{array}{l}\text { Mini Mental } \\
\text { média } \pm \text { DP }\end{array}$ & $28,7 \pm 0,8$ & $29 \pm 0,8$ & $28,9 \pm 0,8$ & $29,1 \pm 0,8$ & $0,585^{*}$ \\
$\begin{array}{l}\text { CDT } \\
\text { média } \pm \text { DP }\end{array}$ & $9,4 \pm 0,7$ & $9,4 \pm 0,7$ & $9,5 \pm 0,7$ & $9,6 \pm 0,6$ & \\
\hline
\end{tabular}

ANOVA; * Teste Kruskal-Wallis

\subsection{AVALIAÇÃO PRÉ-EXERCÍCIO}

Comparação entre os grupos Abstêmios e Consumidores de vinho tinto

Inicialmente, foi realizada uma comparação entre os grupos abstêmios e consumidores de vinho tinto, antes da intervenção exercício físico, utilizando os testes neuropsicológicos e a ressonância magnética funcional.

\subsubsection{Testes Neuropsicológicos}

Nossos dados mostraram diferença entre os grupos nos testes que envolveram atenção e controle inibitório. Nos testes Trilhas A, Trilhas B e Stroop 1, os consumidores de vinho tinham desempenho melhor em comparação ao grupo Abstêmios, conforme exposto na tabela 6 . 
Tabela 6- Descrição dos tempos de execução dos testes neuropsicológicos segundo grupos

\begin{tabular}{|c|c|c|c|}
\hline \multirow[b]{2}{*}{ Teste } & \multicolumn{2}{|c|}{ Grupo } & \multirow[b]{2}{*}{$p$} \\
\hline & $\begin{array}{c}\text { ABS } \\
(N=37)\end{array}$ & $\begin{array}{c}V T \\
(N=36)\end{array}$ & \\
\hline $\begin{array}{l}\text { River } 1 \\
\text { média } \pm \mathrm{DP}\end{array}$ & $21,1 \pm 2,8$ & $21,8 \pm 2,2$ & 0,210 \\
\hline $\begin{array}{l}\text { River } 2 \\
\text { média } \pm \text { DP }\end{array}$ & $9,8 \pm 2,1$ & $10,4 \pm 1,6$ & 0,130 \\
\hline $\begin{array}{l}\text { Figura de } R \\
\text { média } \pm D P\end{array}$ & $32,9 \pm 3,6$ & $33,7 \pm 2,3$ & 0,250 \\
\hline $\begin{array}{l}\text { Trilhas } A \\
\text { média } \pm D P\end{array}$ & $52,5 \pm 20,4$ & $40,9 \pm 14,6$ & $0,007^{\star}$ \\
\hline $\begin{array}{l}\text { Trilhas } \mathrm{B} \\
\text { média } \pm \mathrm{DP}\end{array}$ & $126,6 \pm 50,3$ & $87,6 \pm 48,3$ & $0,001^{*}$ \\
\hline $\begin{array}{l}\text { Stroop } 1 \\
\text { média } \pm D P\end{array}$ & $18,9 \pm 6,5$ & $15,9 \pm 3,4$ & $0,015^{*}$ \\
\hline $\begin{array}{l}\text { Stroop } 2 \\
\text { média } \pm D P\end{array}$ & $23,9 \pm 8,3$ & $21 \pm 4,5$ & 0,070 \\
\hline $\begin{array}{l}\text { Stroop } 3 \\
\text { média } \pm \text { DP }\end{array}$ & $33,4 \pm 13,5$ & $30,1 \pm 8,2$ & 0.216 \\
\hline
\end{tabular}

\subsubsection{Ressonância Magnética Funcional}


Mapas de resposta cerebral mostrando regiões cerebrais com resposta maior na condição incongruente em relação à condição congruente
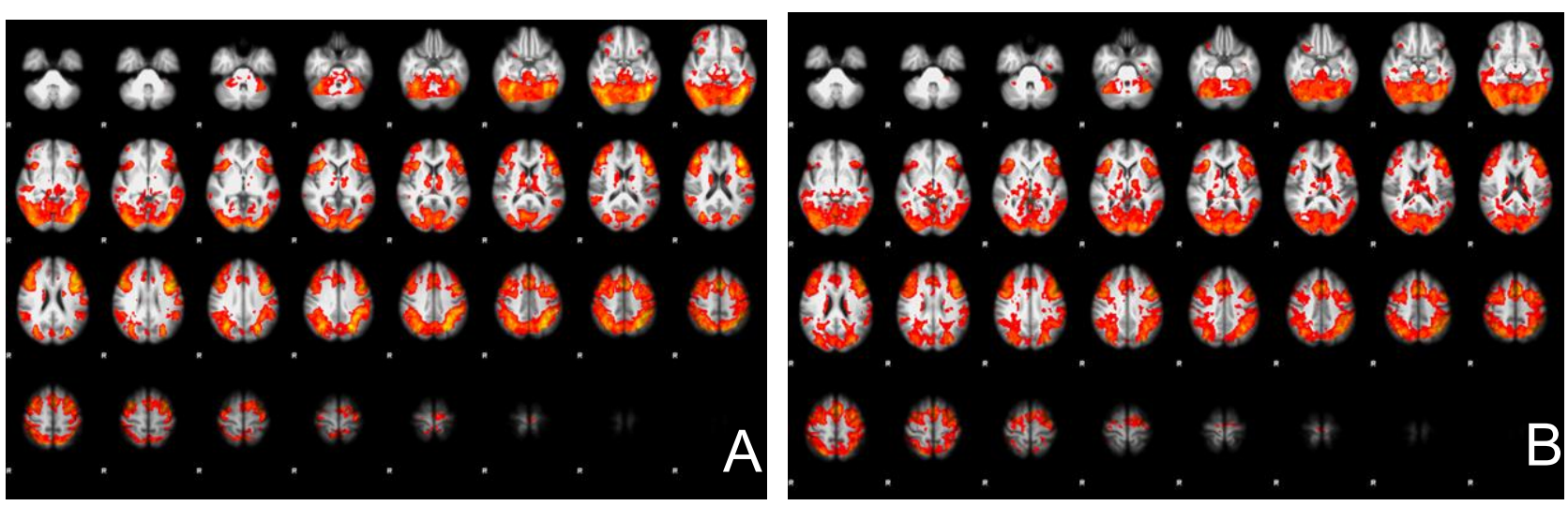

Figura 8A- Mapa de grupo Abstêmios $(n=37)$ do paradigma Stroop (condição incongruente > congruente): observam-se áreas com maior resposta neurovascular no aspecto anterior dos giros dos cíngulos, giros frontais médios e inferiores, giros pré-centrais, lóbulos parietais superiores, cúneos e giros occiptais superiores e médios, e hemisférios cerebelares $(Z>2,3 ; p<0,05)$.

Figura 8B- Mapa de grupo VT $(\mathrm{n}=36)$ do paradigma Stroop (condição incongruente > congruente): observam-se áreas com maior resposta cereral no aspecto anterior dos giros dos cíngulos, giros frontais médios e inferiores, giros pré-centrais, lóbulos parietais superiores, cúneos e giros occipitais superiores e médios, e hemisférios cerebelares $(Z>2,3 ; p<0,05)$.

Comentário: Segundo estudo de meta-análise realizado por Laird e colaboradores $^{70}$, no qual investigaram o teste Stroop Color em fMRI, paradigma utilizado para avaliar a resposta inibitória, as regiões cerebrais esperadas com maior resposta cerebral são o aspecto anterior do giro do cíngulo, giros frontais inferiores e médios e lóbulo parietal inferior esquerdo. Os nossos achados evidenciam que nos grupos ABS e VT, as áreas cerebrais com maior resposta no paradigma Stroop são semelhantes às demonstradas nesse estudo de referência. 
A figura 09 ilustra o mapa do teste ANOVA da comparação das médias das diferenças das áreas com maior resposta cerebral dos grupos Bebedor de vinho tinto e Abstêmios: paradigma Stroop com resposta maior na condição incongruente em relação à condição congruente

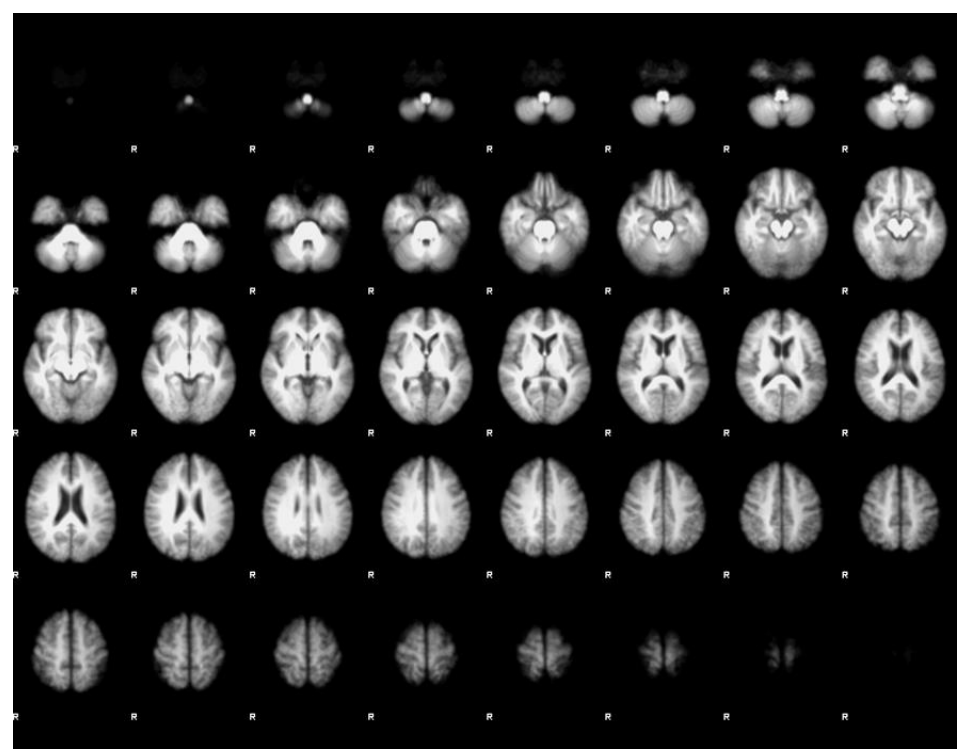

Figura 09- Mapa estatístico ABS (N=37) X VT (N=36) do paradigma Stroop (condição incongruente > congruente): não foram observadas áreas com maior resposta neurovascular $(Z>2,3$ e $p<0,05)$.

Para análise de diferenças entre os grupos ABS e VT, as comparações estudadas foram: VT > ABS e ABS > VT. Não foram observadas diferenças significativas no Mapa de resposta cerebral durante o paradigma Stroop.

Não foram observadas diferenças significativas das médias da acurácia e do tempo médio de respostas certas entre os grupos (Tabela 7).

Tabela 7- Dados comportamentais ABS X VT Stroop Pré

\begin{tabular}{l|c|c|c}
\hline & Abstêmios & Consumidor de VT & $p$ \\
\hline Acurácia (\%) & $90,2 \pm 16,8$ & $93,6 \pm 7,7$ & 0,272 \\
\hline Tempo de resposta (ms) & $878,3 \pm 147,3$ & $859,4 \pm 167,3$ & 0,610 \\
\hline
\end{tabular}




\section{2-BACK - Abstêmios e Consumidores de Vinho Tinto}

Mapas de resposta cerebral mostrando regiões cerebrais com maior resposta na condição ativa em relação à condição controle
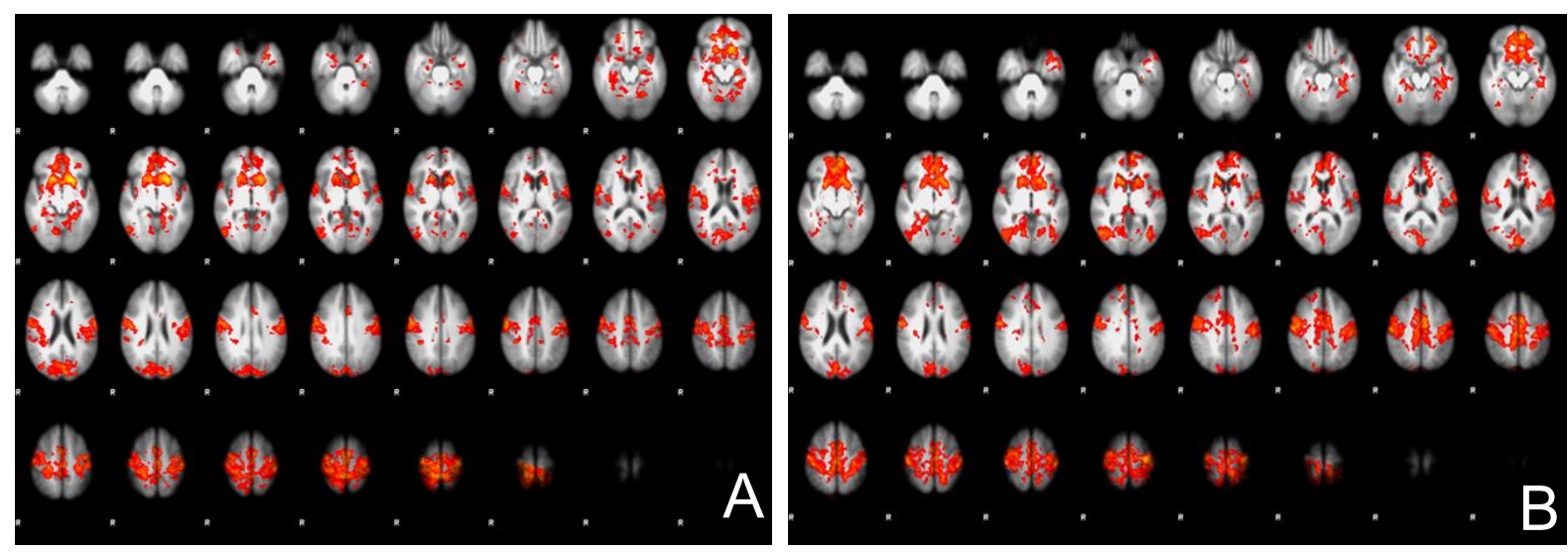

Figura 10A- Mapa de grupo Abstêmios ( $\mathbf{N}=37$ ) do teste 2-Back (condição ativa > neutra): observam-se áreas cerebrais com maior resposta neurovascular nos giros do cíngulo, porção mesial do aspecto posterior dos giros frontais superiores, giros pré e pós centrais bilaterais, lóbulo parietal superior direito, cúneos, giro occipital superior à direita, giro lingual direito e giros orbitários $(Z>2,3$; $p<0,05)$.

Figura 10B- Mapa de grupo VT (N=36) do paradigma 2-Back (condição ativa > neutra): observam-se áreas com maior resposta cerebral nos giros do cíngulo, giros pré e pós centrais bilaterais, pólo do lobo temporal esquerdo, cúneos (de forma mais extensa à direita), giros occipitais médios (de forma mais extensa à direita), giro lingual direito e giros orbitários $(Z>2,3 ; p<0,05)$.

Comentário: Segundo meta-análise realizada com fMRI em paradigmas 2-Back ${ }^{71}$, as áreas cerebrais esperadas com maior resposta; são o lóbulo parietal inferior bilateral, précúneo bilateral, áreas pré-motora e motora suplementar bilateral, giro do cíngulo e áreas préfrontais dorsolaterais e ventrolaterais bilaterais. Os nossos achados evidenciam que nos grupos ABS e VT, as áreas cerebrais com maior resposta são semelhantes às demonstradas nesse estudo de referência. 
Na figura 11 ilustra-se o mapa do teste ANOVA da comparação das médias das diferenças (subtração) das áreas com maior resposta cerebral dos grupos Bebedor de vinho tinto e Abstêmios: paradigma 2-Back com resposta maior na condição ativa em relação à condição neutra

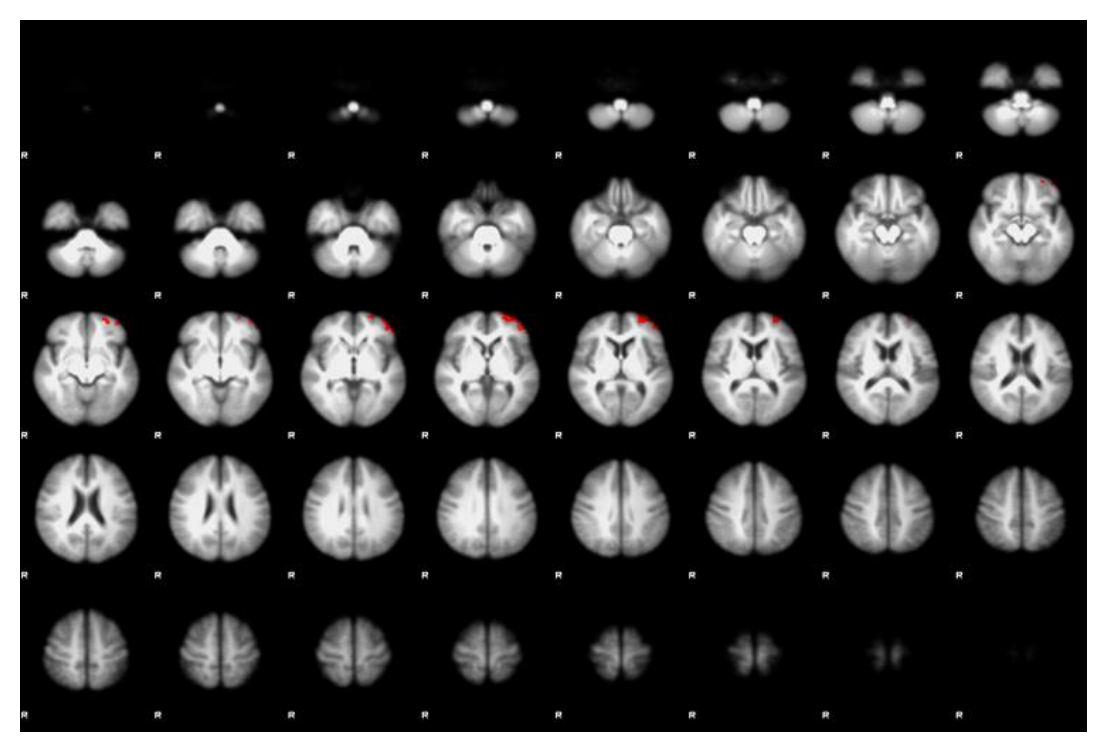

Figura 11- Mapa estatístico VT ( $n=36)$ X ABS ( $n=37)$, VT > ABS: paradigma 2-Back (condição ativa > neutra): observam-se áreas com maior resposta neurovascular no aspecto anterior do giro frontal médio esquerdo $(Z>2,3 ; p<0,05)$.

Para análise de diferenças entre os grupos VT e ABS, as comparações estudadas foram: consumidores de vinho tinto maior que abstêmios e abstêmios maior que consumidores de vinho tinto. Foram observadas áreas cerebrais com maior resposta neurovascular no aspecto anterior do giro frontal médio esquerdo (figura 11), entre os bebedores de vinho tinto maior que os abstêmios. 
Os bebedores de VT mostraram maior acurácia que os abstêmios no paradigma 2-Back. Não houve diferença significativa da média do tempo de resposta certa (Tabela 8).

Tabela 8- Dados comportamentais ABS X VT 2-Back PRÉ

\begin{tabular}{|c|c|c|c|}
\hline 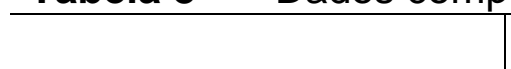 & Abstêmios & Consumidor VT & $p$ \\
\hline Acurácia (\%) & $91,7 \pm 10,4$ & $96,9 \pm 5,3$ & 0,009 \\
\hline Tempo de resposta (ms) & $713,6 \pm 120,3$ & $679,2 \pm 105,2$ & 0,198 \\
\hline
\end{tabular}

\subsection{EFEITOS DO TREINAMENTO FÍSICO}

\subsubsection{Testes Neuropsicológicos}

Analisando os resultados dos testes neuropsicológicos após a fase de treinamento físico, foi verificado que no grupo consumidor de vinho tinto ocorreu no teste Stroop 2, redução no tempo de resposta $(p=0,049)$, conforme exposto na tabela 10 e na figura 12. 
Tabela 9- Descrição dos tempos de execução dos testes neuropsicológicos 1

\begin{tabular}{|c|c|c|c|c|c|}
\hline \multirow[b]{2}{*}{ Variável } & \multicolumn{4}{|c|}{ Grupo } & \multirow[b]{2}{*}{$\mathbf{p}$} \\
\hline & $\begin{array}{c}\text { ABST } \\
(\mathrm{N}=17)\end{array}$ & $\begin{array}{c}A B S \\
(N=20)\end{array}$ & $\begin{array}{c}\text { VTT } \\
(\mathrm{N}=17)\end{array}$ & $\begin{array}{c}\mathrm{VT} \\
(\mathrm{N}=19)\end{array}$ & \\
\hline River 1 & & & & & 0,646 \\
\hline \multicolumn{6}{|l|}{ Pré } \\
\hline média $\pm \mathrm{DP}$ & $21,2 \pm 2,6$ & $21 \pm 3$ & $21,4 \pm 2,6$ & $22,2 \pm 1,8$ & \\
\hline \multicolumn{6}{|l|}{ Pós } \\
\hline média $\pm \mathrm{DP}$ & $21,7 \pm 1,6$ & $22,1 \pm 1,8$ * & $21,9 \pm 2,7$ & $22,7 \pm 1,4$ & \\
\hline River 2 & & & & & 0,192 \\
\hline \multicolumn{6}{|l|}{ Pré } \\
\hline média $\pm \mathrm{DP}$ & $10 \pm 1,8$ & $9,6 \pm 2,3$ & $10 \pm 1,8$ & $10,8 \pm 1,3$ & \\
\hline \multicolumn{6}{|l|}{ Pós } \\
\hline média $\pm \mathrm{DP}$ & $10,2 \pm 1$ & $10,8 \pm 1,4$ & $10,7 \pm 1,6$ & $10,9 \pm 1,1$ & \\
\hline Figura de Rey & & & & & 0,879 \\
\hline \multicolumn{6}{|l|}{ Pré } \\
\hline média $\pm \mathrm{DP}$ & $32,6 \pm 4,4$ & $33,1 \pm 2,9$ & $33,5 \pm 2,9$ & $33,8 \pm 1,7$ & \\
\hline \multicolumn{6}{|l|}{ Pós } \\
\hline média $\pm \mathrm{DP}$ & $32,7 \pm 4,2$ & $33,5 \pm 3,2$ & $34,2 \pm 2,7$ & $34,5 \pm 1,4$ & \\
\hline Trilhas A & & & & & 0,426 \\
\hline \multicolumn{6}{|l|}{ Pré } \\
\hline média $\pm \mathrm{DP}$ & $59,8 \pm 24,8$ & $61,7 \pm 66,6$ & $44,1 \pm 16,2$ & $38,2 \pm 12,7$ & \\
\hline \multicolumn{6}{|l|}{ Pós } \\
\hline média $\pm \mathrm{DP}$ & $52,2 \pm 22$ & $42,2 \pm 15,5$ & $39,9 \pm 12,6$ & $34,7 \pm 8$ & \\
\hline Trilhas B & & & & & 0,103 \\
\hline \multicolumn{6}{|l|}{ Pré } \\
\hline média $\pm \mathrm{DP}$ & $135,4 \pm 51,7$ & $119,5 \pm 49,3$ & $106,9 \pm 58,7^{\circ}$ & $70,3 \pm 28,3^{\circ}$ & \\
\hline \multicolumn{6}{|l|}{ Pós } \\
\hline média $\pm \mathrm{DP}$ & $136,7 \pm 64,5$ & $99,6 \pm 35,4$ & $103,6 \pm 42$ & $70,9 \pm 18,7$ & \\
\hline
\end{tabular}

EEG com distribuição normal e funçao de ligação identidade; As análises foram controladas pela idade e escolaridade ${ }^{*} p<0,05$ para comparação pareada entre os grupos no Pós treinamento; ${ }^{\circ} p<0,05$ comparação entre os grupos no Pré 


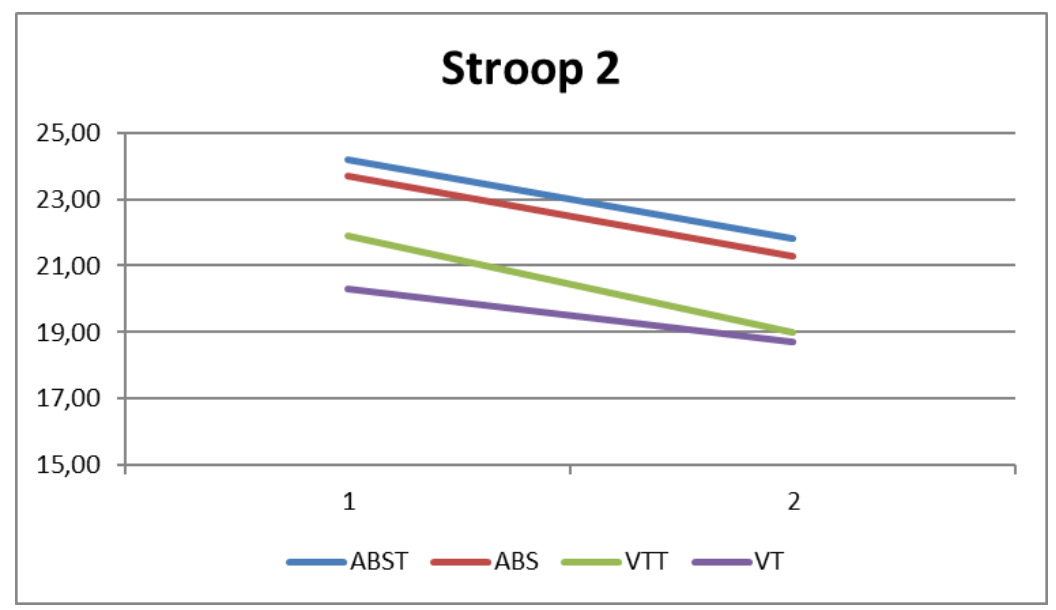

LEGENDA: Na abscissa, estão representadas a primeira avaliação (PRÉ) e a segunda

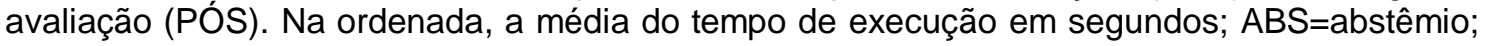
VT=bebedor vinho tinto; dados representam as médias dos grupos; para estatística ver tabela 10.

Figura 12- Gráfico do desempenho dos sujeitos no tempo de execução do subteste 2 do Stroop Color-Word Test

Tabela 10- Descrição dos tempos de execução dos testes neuropsicológicos 2

\begin{tabular}{|c|c|c|c|c|c|}
\hline \multirow[b]{2}{*}{ Variável } & \multicolumn{4}{|c|}{ Grupo } & \multirow[b]{2}{*}{$\mathbf{p}$} \\
\hline & $\begin{array}{c}\text { ABST } \\
(\mathrm{N}=17)\end{array}$ & $\begin{array}{c}\text { ABS } \\
(\mathrm{N}=20)\end{array}$ & $\begin{array}{c}\text { VTT } \\
(\mathrm{N}=17)\end{array}$ & $\begin{array}{c}\mathrm{VT} \\
(\mathrm{N}=19) \\
\end{array}$ & \\
\hline Stroop 1 & & & & & 0,701 \\
\hline \multicolumn{6}{|l|}{ Pré } \\
\hline média $\pm \mathrm{DP}$ & $19,9 \pm 7$ & $18 \pm 6$ & $16,4 \pm 3,2$ & $15,4 \pm 3,5$ & \\
\hline \multicolumn{6}{|l|}{ Pós } \\
\hline média \pm DP & $20,4 \pm 11,3$ & $17 \pm 5,9$ & $14,6 \pm 3,3$ & $16,2 \pm 4,9$ & \\
\hline Stroop 2 & & & & & 0,870 \\
\hline \multicolumn{6}{|l|}{ Pré } \\
\hline média \pm DP & $24,2 \pm 8,1$ & $23,7 \pm 8,7$ & $21,9 \pm 6$ & $20,3 \pm 2,7$ & \\
\hline \multicolumn{6}{|l|}{ Pós } \\
\hline média $\pm \mathrm{DP}$ & $21,8 \pm 6,7$ & $21,3 \pm 6,8$ & $19 \pm 3,4$ * & $18,7 \pm 3,3$ & \\
\hline Stroop 3 & & & & & 0,178 \\
\hline \multicolumn{6}{|l|}{ Pré } \\
\hline média $\pm \mathrm{DP}$ & $35,9 \pm 18,1$ & $31,2 \pm 7,6$ & $32,4 \pm 9,4$ & $28,2 \pm 6,8$ & \\
\hline \multicolumn{6}{|l|}{ Pós } \\
\hline média \pm DP & $31,2 \pm 14,8$ & $31,7 \pm 14,7$ & $27,3 \pm 5,1$ & $25,2 \pm 5,7$ & \\
\hline
\end{tabular}

EEG com distribuição normal e funçao de ligação identidade; As análises foram controladas pela idade e escolaridade

* $p<0,05$ para comparação pareada entre os grupos no Pós treinamento; ${ }^{\circ} p<0,05$ comparação entre os grupos no Pré 
No Teste River 1, que avaliou a memória, no grupo ABS sem treinamento físico, foi observado aumento no tempo de execução do teste $(p=0,038)$. Nota-se que todos os grupos apresentaram desempenho pior na fase de reavaliação para este teste.

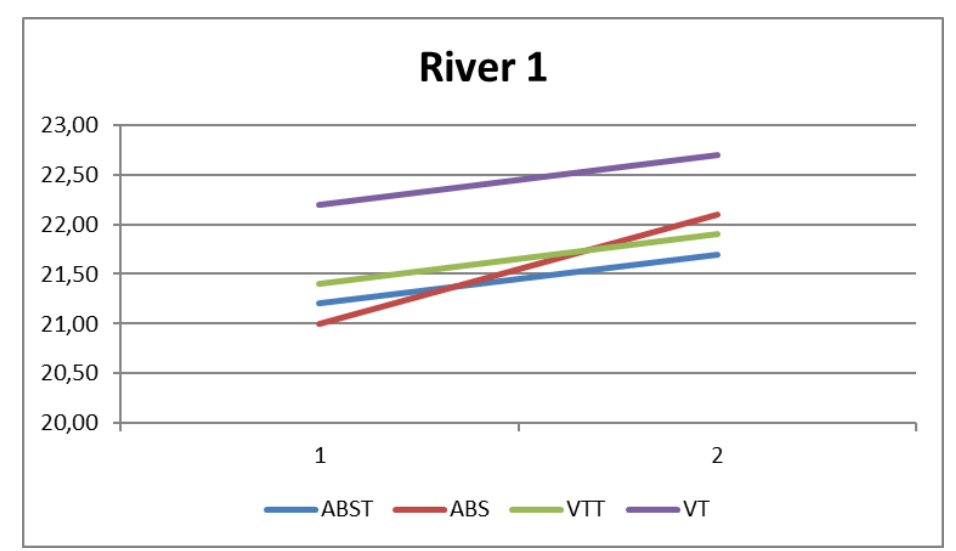

LEGENDA: Na abscissa, estão representadas a primeira avaliação (PRÉ) e a segunda

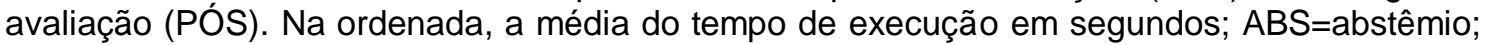
VT=bebedor vinho tinto; dados representam as médias dos grupos; para estatística ver tabela 9.

Figura 13- Gráfico do desempenho dos sujeitos no tempo de execução do Rivermead Behavioral Memory Test 1

Em síntese, analisando os resultados dos testes neuropsicológicos, o treinamento físico produziu melhora no tempo de execução apenas no grupo consumidor de vinho tinto no teste Stroop Color fase 2, Stroop 2, que avalia controle inibitório.

No teste River 1, que avaliou a memória, o grupo Abstêmio que não realizou treinamento físico apresentou piora significativa no tempo de realização deste teste. 


\subsubsection{Ressonância Magnética Funcional}

\section{STROOP - Abstêmios com treinamento físico}

As figuras 14A e 14B ilustram os mapas de resposta cerebral durante o paradigma Stroop mostrando regiões cerebrais com maior resposta na condição incongruente em relação à condição congruente PRÉ e Pós.
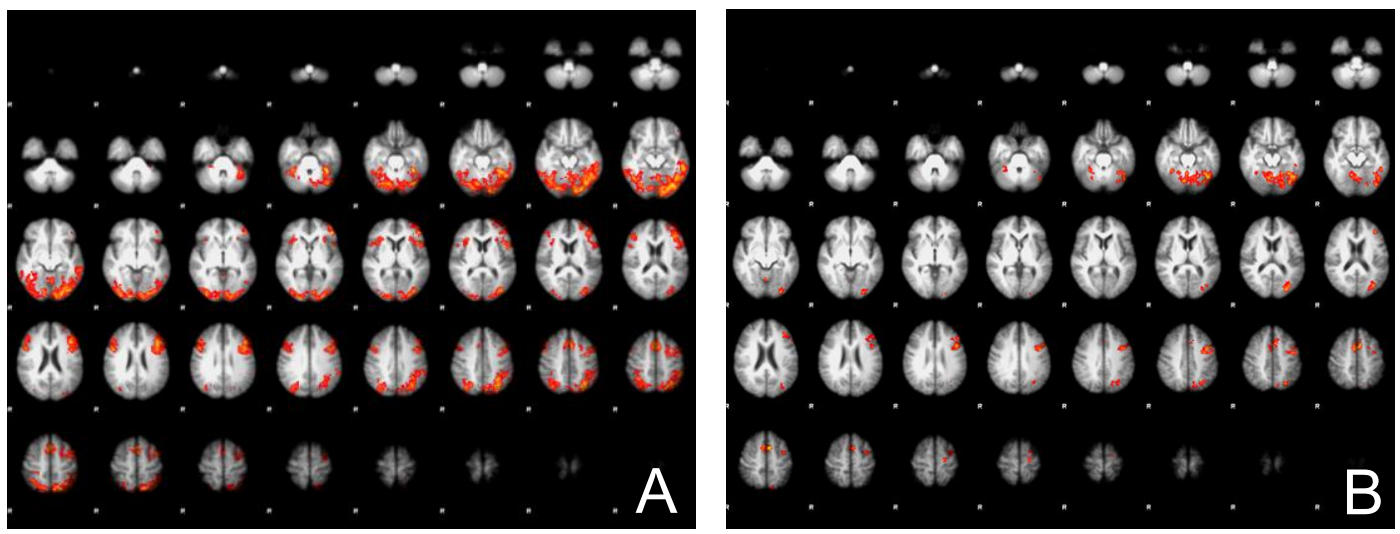

Figura 14A- ABS PRÉ com treinamento físico ( $\mathrm{N}=17)$ : Stroop (incongruente > congruente): observam-se áreas com maior resposta neurovascular nos hemisférios cerebelares, lobos occipitais (envolvendo áreas pericalcarinas), regiões temporoocciptais (de forma mais acentuada à esquerda), giros frontais inferiores e médios, aspecto anterior dos giros dos cíngulos e lóbulos parietais inferiores e superiores, de forma mais extensa à esquerda $(Z>2,3 ; p<0,05)$.

Figura 14B- ABS PÓS com treinamento físico ( $\mathrm{N}=17)$ : Stroop (incongruente > congruente): observam-se áreas com maior resposta neurovascular nos hemisférios cerebelares, região temporo-occipital esquerda, lóbulos parietais inferior e superior esquerdos, giro frontal médio esquerdo, aspecto anterior dos giros dos cíngulos $(Z>2,3 ; p<0,05)$. 
A figura 15 mostra a subtração das imagens 14A e 14B, pelo mapa do teste ANOVA mostrando as áreas com maior resposta cerebral no grupo Abstêmios com treinamento físico: PRÉ X PÓS durante o paradigma Stroop com resposta maior na condição incongruente em relação à condição congruente

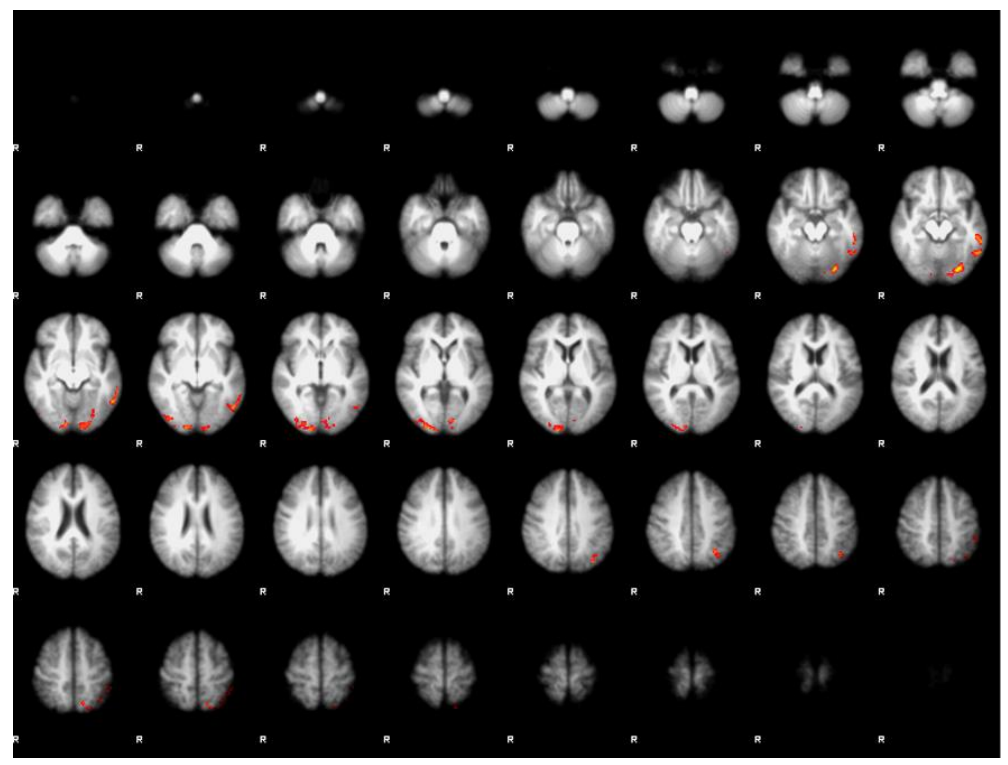

Figura 15- ABS PRÉ com treinamento físico $X$ ABS PÓS com treinamento físico: Stroop (incongruente > congruente): observam-se áreas com maior resposta cerebral lobos occipitais, transição temporo-occipital à esquerda e lóbulo parietal superior esquerdo $(Z>2,3$ e $p<0,05)$.

Já a tabela 11 mostra os dados comportamentais.

Tabela 11- Dados comportamentais ABST PRÉ X ABST PÓS Stroop

\begin{tabular}{l|c|c|c}
\hline & ABST PRÉ $(\mathrm{N}=17)$ & ABST PÓS $(\mathrm{N}=17)$ & \\
\hline Acurácia (\%) & $92,15 \pm 14,03$ & $96,44 \pm 3,06$ & $\mathrm{p}=0.2308$ \\
\hline $\begin{array}{l}\text { Tempo de reação } \\
\text { (ms) }\end{array}$ & $855,12 \pm 139,94$ & $817,33 \pm 134,59$ & $\mathrm{p}=0.1351$ \\
\hline
\end{tabular}

Comparação pareada dos dados comportamentais dos voluntários do grupo Abstêmios PRÉ X PÓS com treinamento físico para o paradigma Stroop 
Portanto os voluntários do grupo Abstêmios que realizaram treinamento físico (ABST) não apresentaram mudanças significativas na acurácia e no tempo de resposta durante a execução do paradigma Stroop, mas recrutaram menos áreas cerebrais que aquelas observadas na primeira avaliação (Fig. 14A e 14B).

\section{2-BACK - Abstêmios com treinamento físico}

As figuras $16 \mathrm{~A}$ e $16 \mathrm{~B}$ ilustram os mapas de resposta cerebral durante o paradigma 2-Back mostrando regiões cerebrais com maior resposta na condição ativa em relação à condição neutra - PRÉ e PÓS
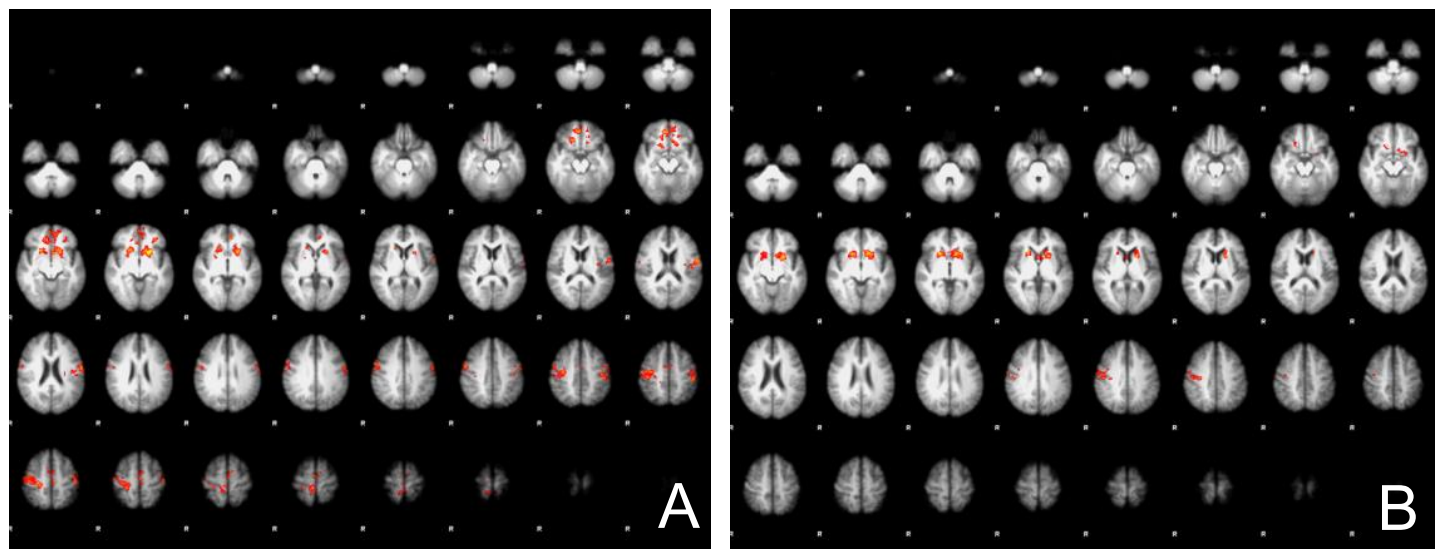

Figura 16A- ABS PRÉ com treinamento físico ( $N=17$ ): 2-Back (ativa > neutra): observam-se áreas com maior resposta cerebral nas regiões orbitofrontais, regiões nucleocapsulares, giros précentrais, mais notadamente à direita $(Z>2,3$ e $p<0,05)$.

Figura 16B- ABS PÓS com treinamento físico ( $N=17$ ): 2-Back (ativa > neutra): Observam-se áreas com maior resposta cerebral no aspecto posterior das regiões orbitofrontais, regiões núcleocapsulares e giro pré-central direito $(Z>2,3$ e $p<0,05)$. 
A figura 17 ilustra o resultado da subtração das figuras 16A e 16B, pelo mapa do teste ANOVA mostrando as áreas com maior resposta cerebral no grupo Abstêmios com treinamento físico: PRÉ X PÓS durante o paradigma 2-Back com maior resposta na condição ativa em relação à condição neutra

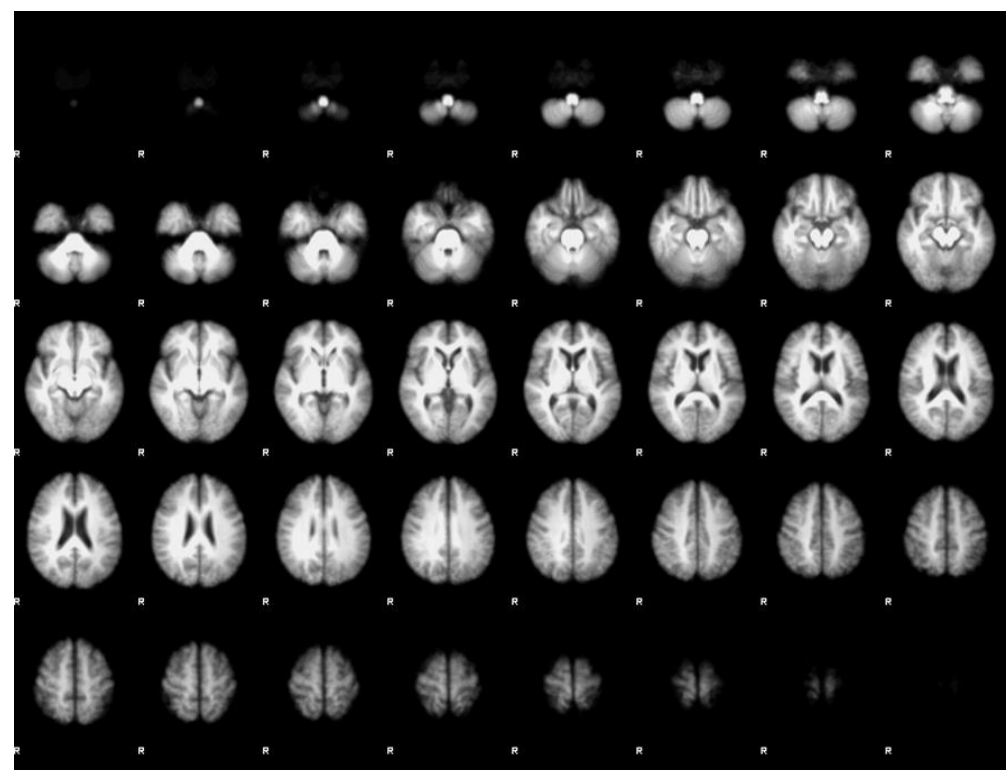

Figura 17- ABS PRÉ com treinamento físico $X$ ABS PÓS com treinamento físico: 2-Back (ativa > neutra): Não foram observam-se áreas com maior resposta cerebral $(Z>2,3$ e $p<0,05)$.

A tabela 12 ilustra os dados comportamentais.

Tabela 12- Dados comportamentais ABST PRÉ X ABST PÓS 2-Back

\begin{tabular}{l|c|c|c}
\hline & ABST PRÉ $(\mathrm{N}=17)$ & ABST PÓS $(\mathrm{N}=17)$ & \\
\hline Acurácia (\%) & $89,24 \pm 10,34$ & $93,00 \pm 8,86$ & $\mathrm{p}=0.0926$ \\
\hline Tempo de reação & $741,96 \pm 125,42$ & $722,59 \pm 111,75$ & $\mathrm{p}=0.4737$ \\
$(\mathrm{~ms})$ & & & \\
\hline
\end{tabular}

Comparação pareada dos dados comportamentais dos voluntários do grupo Abstêmios PRÉ X PÓS com treinamento físico para o paradigma 2-Back. 
Nossos dados mostram que os voluntários do grupo Abstêmios que realizaram treinamento físico, no paradigma 2-Back, não apresentaram mudanças significativas nas áreas de ativação cerebral, na acurácia e no tempo de resposta (Fig. 16A, 16B e Tabela 12).

STROOP - Abstêmios sem treinamento físico
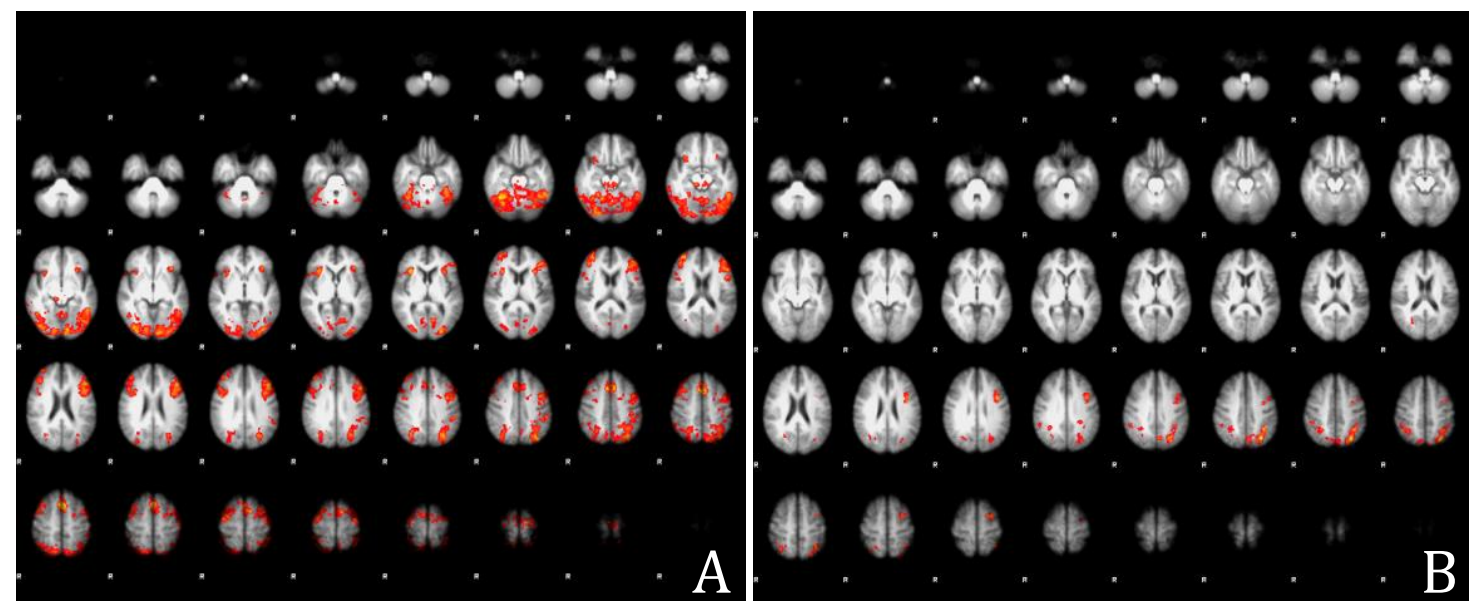

Figura 18A- ABS PRÉ sem treinamento físico $(\mathrm{N}=20)$ : Stroop (incongruente > congruente): observam-se áreas com maior resposta neurovascular nos hemisférios cerebelares, lobos occipitais (envolvendo áreas pericalcarinas), regiões temporooccipitais, giros frontais inferiores e médios (envolvendo as áreas pré-frontais), aspecto anterior dos giros dos cíngulos e lóbulos parietais inferiores e superiores, de forma mais extensa à esquerda $(Z>2,3$ e $p<0,05)$.

Figura 18B- ABS PÓS sem treinamento físico $(\mathrm{N}=20)$ : STROOP (incongruente > congruente): observam-se áreas com maior neurovascular no giro frontal médio esquerdo envolvendo área pré-frontal e nos lóbulos parietais superiores - de forma mais proeminente à esquerda $(Z>2,3$ e $p<0,05)$. 
As figuras $18 \mathrm{~A}$ e $18 \mathrm{~B}$ mostram os mapas de resposta cerebral durante o paradigma Stroop mostrando regiões cerebrais com maior resposta na condição incongruente em relação à condição congruente PRÉ e PÓS

A figura 19 ilustra a subtração das imagens das figuras $18 \mathrm{~A}$ e 18B, pelo mapa do teste ANOVA mostrando as áreas com maior resposta cerebral no grupo Abstêmios sem treinamento físico: PRÉ X PÓS durante o paradigma STROOP com maior resposta na condição incongruente em relação à condição congruente

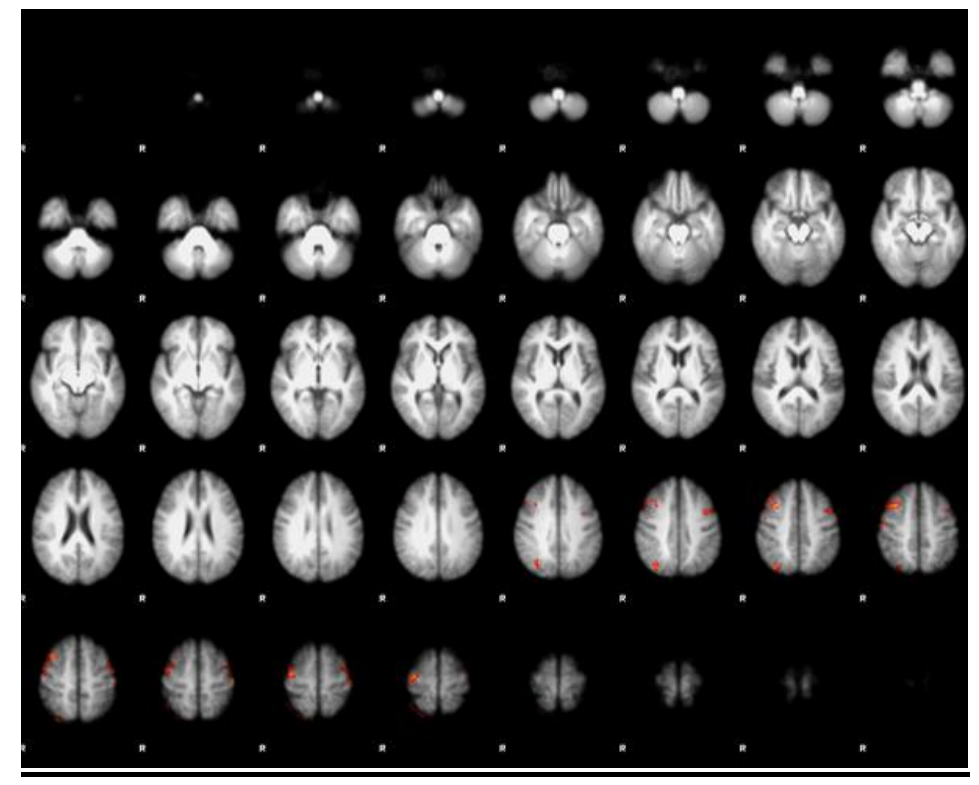

Figura 19- ABS PRÉ sem treinamento físico $X$ ABS PÓS sem treinamento físico: STROOP (incongruente > congruente): observam-se áreas com maior resposta cerebral nos giros frontais médios bilaterais, de forma mais extensa à direita, e lóbulo parietal superior direito $(Z>2,3$ e $p<0,05)$. 
Tabela 13- Dados comportamentais ABS PRÉ X ABS PÓS Stroop

\begin{tabular}{l|c|c|c}
\hline & ABS Pré $(\mathrm{N}=20)$ & ABS PÓS $(\mathrm{N}=20)$ & \\
\hline Acurácia (\%) & $88,53 \pm 19,02$ & $95,09 \pm 5,70$ & $\mathrm{p}=$ \\
& & & 0.0948 \\
\hline Tempo de reação & $898,07 \pm 153,97$ & $852,40 \pm 165,38$ & $\mathrm{p}=$ \\
$(\mathrm{ms})$ & & & 0.1253 \\
\hline
\end{tabular}

Comparação pareada dos dados comportamentais dos voluntários do grupo Abstêmios PRÉ X PÓS sem treinamento físico para o paradigma Stroop.

Nossos dados mostraram que os voluntários do grupo Abstêmios que não realizaram treinamento físico (ABS) apresentaram, na reavaliação, menor recrutamento de áreas cerebrais que aqueles observados na primeira avaliação (PRÉ), sem mudanças significativas na acurácia e tempo de resposta. 


\section{2-BACK - Abstêmios sem treinamento físico}

As figuras $20 \mathrm{~A}$ e $20 \mathrm{~B}$ ilustram os mapas de resposta cerebral durante o paradigma 2-Back mostrando regiões cerebrais com maior resposta na condição ativa em relação à condição neutra - PRÉ e PÓS
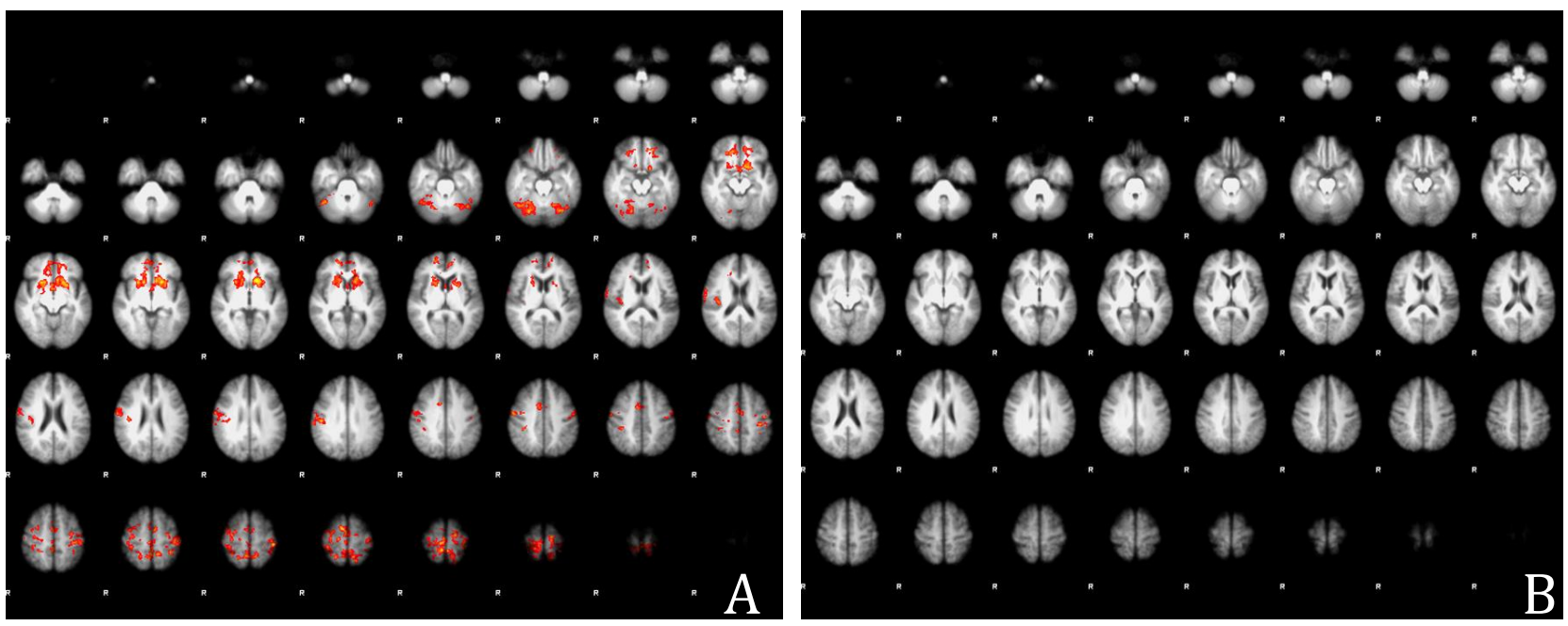

Figura 20A- ABS PRÉ sem treinamento físico ( $N=20$ ): 2-Back (ativa > neutra): observam-se áreas com maior resposta neurovascular nos hemisférios cerebelares, regiões orbitofrontais, regiões nucleocapsulares, giros pré-centrais (notadamente à direita), aspecto anterior do giro do cíngulo direito $(Z>2,3$ e $p<0,05)$.

Figura 20B- ABS PÓS sem treinamento físico ( $N=20$ ): 2-Back (ativa > neutra): Não foram observadas áreas com maior resposta cerebral $(Z>2,3$ e $p<0,05)$. 
A figura 21 representa a subtração das imagens das figuras $20 \mathrm{~A} e$ 20B, pelo mapa do teste ANOVA mostrando as áreas com maior resposta cerebral no grupo Abstêmios sem treinamento físico: PRÉ X PÓS durante o paradigma 2-Back com maior resposta na condição ativa em relação à condição neutra

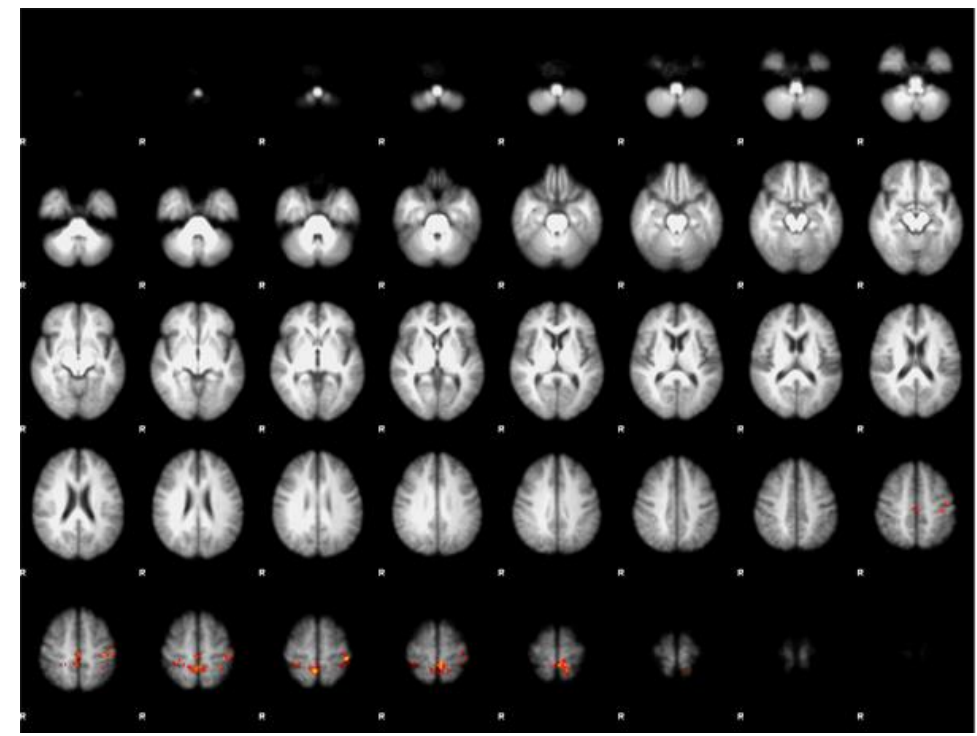

Figura 21- ABS PRÉ sem treinamento físico $X$ ABS PÓS sem treinamento físico: paradigma 2-Back (ativa > neutra): observam-se áreas com maior resposta cerebral no giro póscentral esquerdo, lóbulo parietal superior esquerdo e aspecto posterior do giro do cíngulo $(Z>2,3$ e $p<0,05)$.

Tabela 14- Dados comportamentais ABS PRÉ X ABS PÓS 2-Back

\begin{tabular}{l|c|c|c}
\hline & ABS PRÉ (N=20) & ABS PÓS (N=20) & \\
\hline Acurácia (\%) & $93,77 \pm 10,16$ & $93,44 \pm 8,70$ & $\mathrm{p}=0.8455$ \\
\hline Tempo de reação & $689,45 \pm 113,41$ & $670,74 \pm 127,91$ & $\mathrm{p}=0.4699$ \\
$(\mathrm{~ms})$ & & & \\
\hline
\end{tabular}

Comparação pareada dos dados comportamentais dos voluntários do grupo Abstêmios PRÉ X PÓS sem treinamento físico para o paradigma 2-Back. 
Nossos dados mostram que os voluntários do grupo Abstêmios que não realizaram treinamento físico (ABS), no paradigma 2-Back, recrutam menos áreas cerebrais que aquelas observadas na primeira avaliação (PRÉ), e sem mudanças significativas na acurácia e no tempo de resposta.

\section{STROOP - Vinho Tinto com treinamento físico}

As figuras $22 \mathrm{~A}$ e $22 \mathrm{~B}$ ilustram os mapas de resposta cerebral durante o paradigma Stroop mostrando regiões cerebrais com maior resposta na condição incongruente em relação à condição congruente PRÉ e PÓS
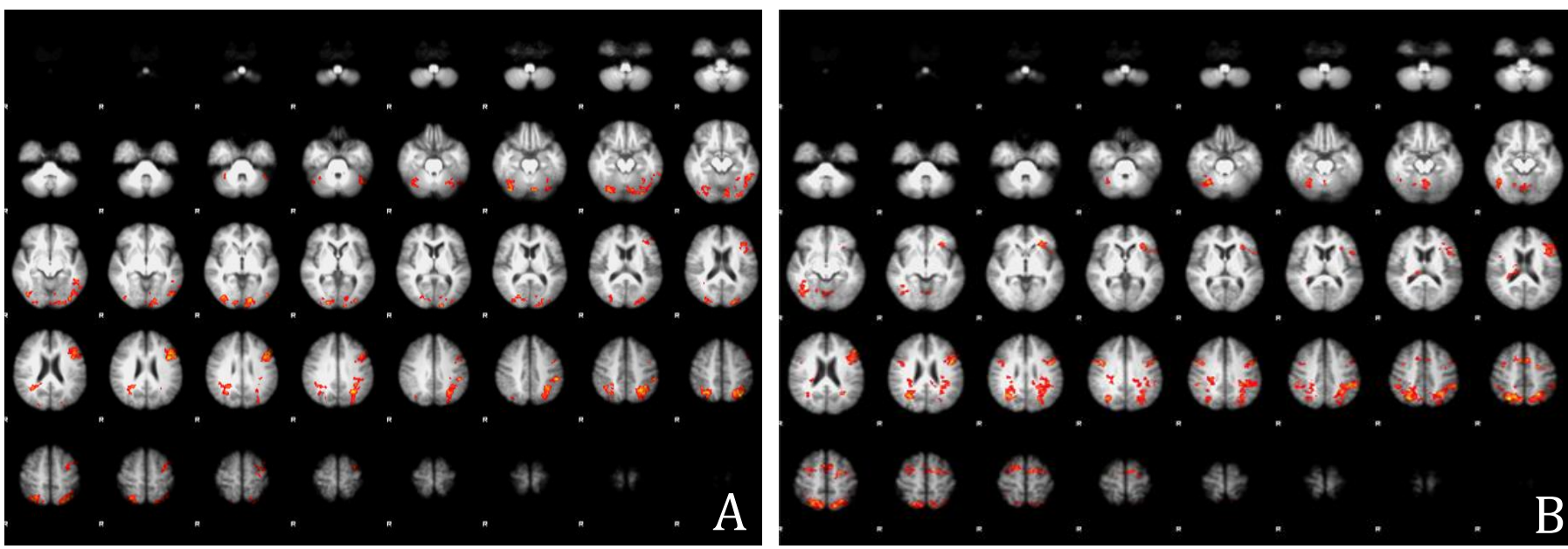

Figura 22A- VT PRÉ com treinamento físico $(\mathrm{N}=17)$ : Stroop (incongruente > congruente): observam-se áreas com maior resposta cerebral nos hemisférios cerebelares, lobos occipitais, giro frontal médio esquerdo (envolvendo área pré-motora), lóbulos parietais inferior esquerdo e superiores, de forma mais extensa à esquerda $(Z>2,3$ e $p<0,05)$.

Figura 22B- VT PÓS com treinamento físico $(\mathrm{N}=17)$ : Stroop (incongruente > congruente): observam-se áreas com maior resposta cerebral nos hemisfério cerebelar direito, lobo occipital direito, região temporo-occipital direita, giros frontais inferior esquerdo e médios, notadamente à esquerda, e envolvendo 
regiões pré-frontais, e lóbulos parietais superiores, de forma mais acentuada à esquerda $(Z>2,3$ e $p<0,05)$.

A figura 23 representa a subtração das figuras $22 \mathrm{~A}$ e $22 \mathrm{~B}$, pelo mapa do teste ANOVA mostrando as áreas com maior resposta cerebral no grupo Consumidor de vinho tinto com treinamento físico: PRÉ X PÓs durante o paradigma STROOP com maior resposta na condição incongruente em relação à condição congruente

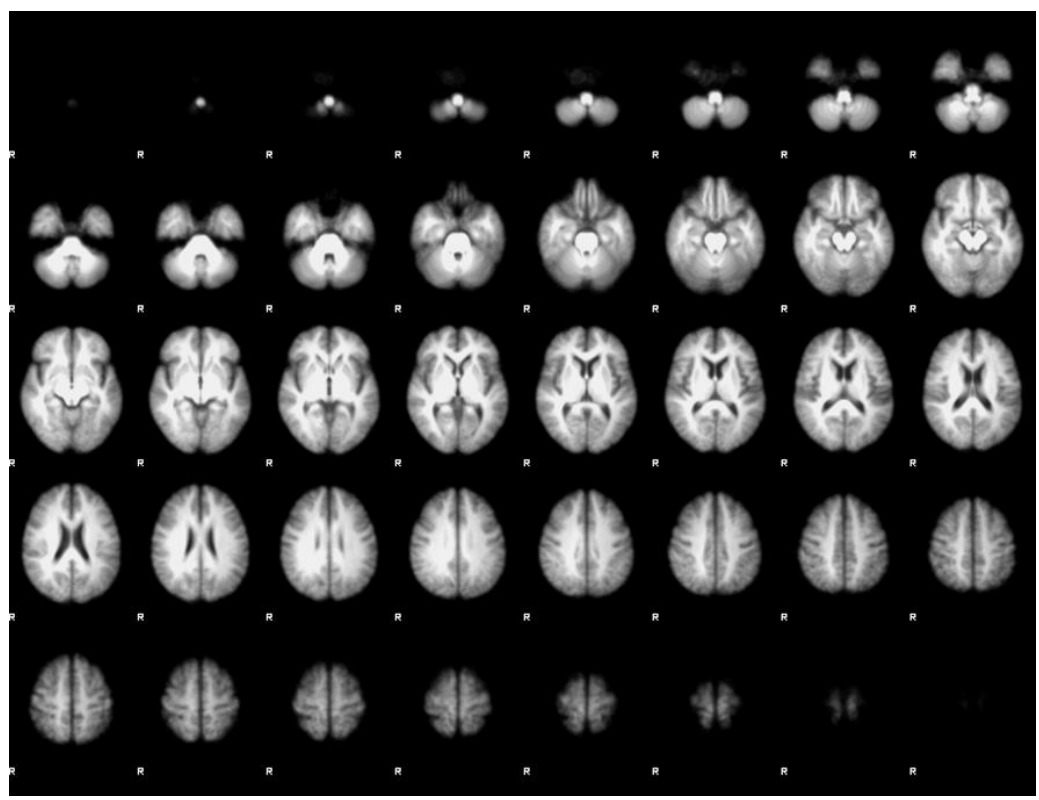

Figura 23- VT PRÉ com treinamento físico X VT PÓS com treinamento físico: paradigma Stroop (incongruente > congruente): Não foram observam-se áreas com maior resposta cerebral $(Z>2,3$ e $p<0,05)$.

Tabela 15- Dados comportamentais VTT PRÉ X VTT PÓS

\begin{tabular}{l|c|c|c}
\hline & VTT PRÉ (N=17) & VTT PÓS (N=17) & \\
\hline Acurácia (\%) & $92,54 \pm 9,20$ & $95,68 \pm 5,06$ & $\mathrm{p}=0.0505$ \\
\hline Tempo de reação (ms) & $898,67 \pm 187,48$ & $870,90 \pm 188,36$ & $\mathrm{p}=0.1105$ \\
\hline
\end{tabular}

Comparação pareada dos dados comportamentais dos voluntários do grupo VT PRÉ X PỎS com treinamento físico para o paradigma Stroop. 
Nota-se que os voluntários do grupo VT que realizaram treinamento físico supervisionado, não apresentam mudanças significativas nas áreas de ativação cerebral; porém houve tendência de aumento da acurácia $(p=0,05)$ sem alteração no tempo de resposta.

\section{2-BACK - Vinho Tinto com treinamento físico}

As figuras $24 \mathrm{~A}$ e $24 \mathrm{~B}$ ilustram os mapas de resposta cerebral durante o paradigma 2-Back mostrando regiões cerebrais com maior resposta na condição ativa em relação à condição neutra - PRÉ e PÓS
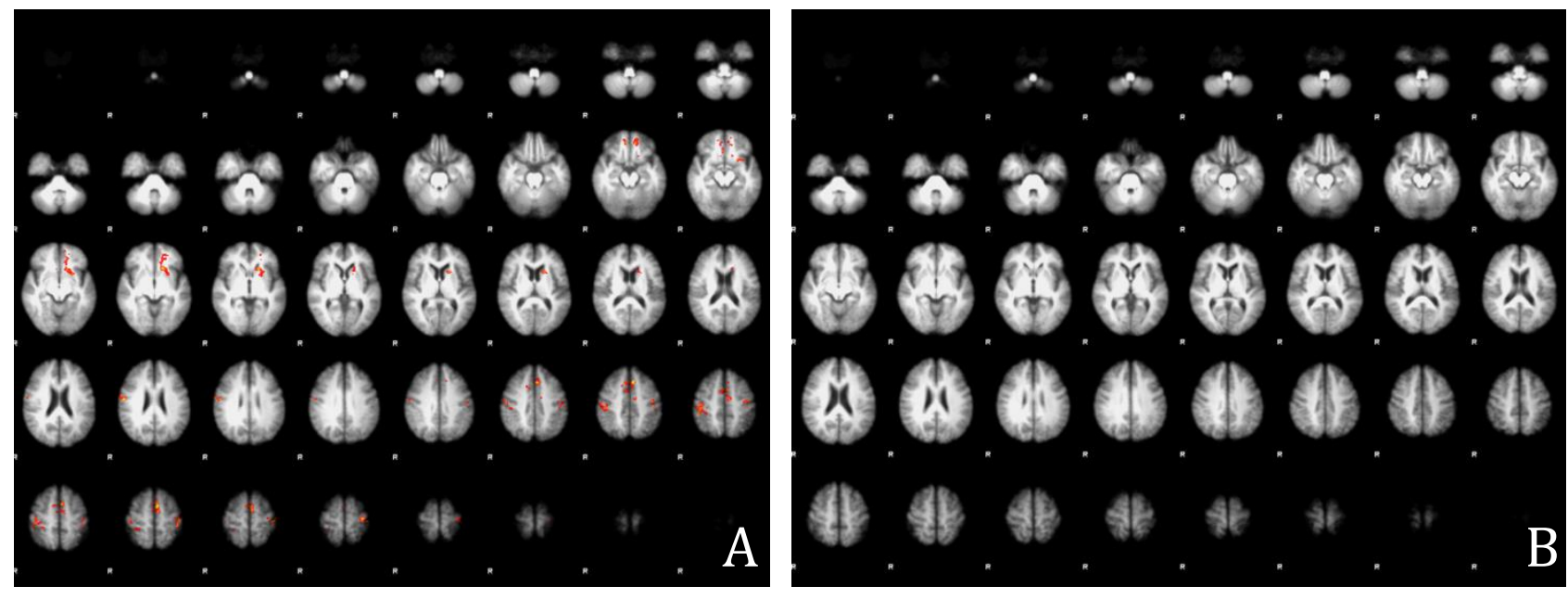

Figura 24A- VT PRÉ com treinamento físico ( $N=17$ ): 2-Back (ativa > neutra): observam-se áreas com maior resposta cerebral nas regiões orbitofrontais, região nucleocapsular esquerda, giros précentrais e aspecto anterior dos giros do cíngulo $(Z>2,3$ e $p<0,05)$.

Figura 24B- VT Pós com treinamento físico ( $N=17$ ): 2-Back (ativa > neutra): não foram observadas áreas com maior resposta cerebral $(Z>2,3$ e $p<0,05)$. 
A figura 25 representa a subtração das imagens das figuras $24 \mathrm{~A}$ e 24B, pelo mapa do teste ANOVA mostrando as áreas com maior resposta cerebral no grupo Consumidor de vinho tinto com treinamento físico: PRÉ X PÓS durante o paradigma 2-Back com resposta maior na condição ativa em relação à condição neutra

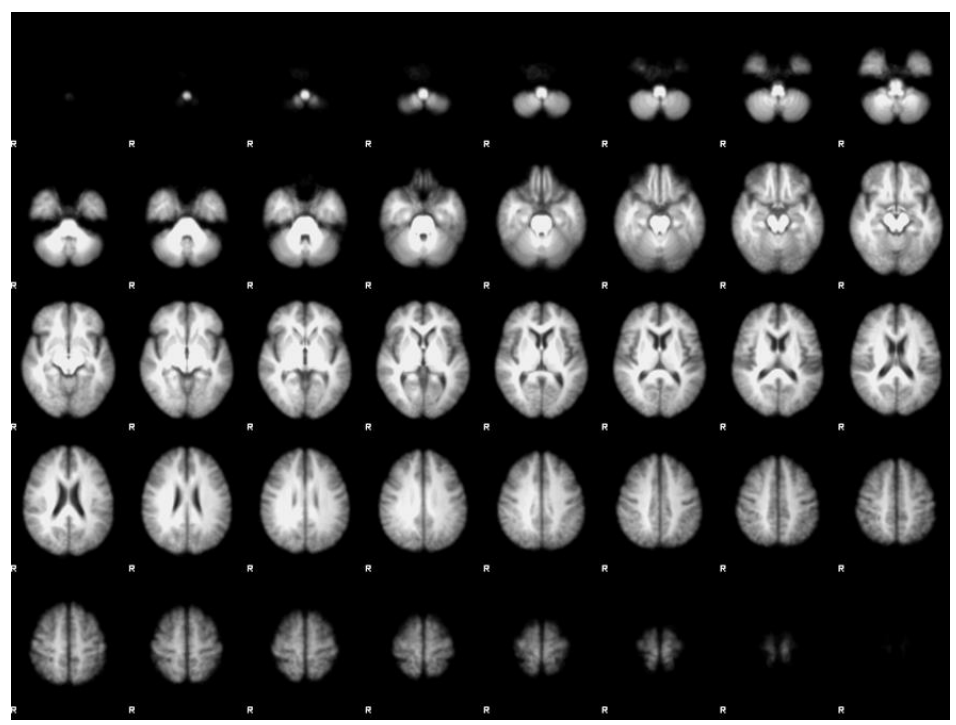

Figura 25- VT PRÉ com treinamento físico X VT PÓS com treinamento físico: paradigma 2-Back (ativa > neutra): não foram observamse áreas com maior resposta cerebral $(Z>2,3$ e $p<0,05)$.

Tabela 16- Dados comportamentais VTT PRÉ X VTT PÓS 2-Back

\begin{tabular}{l|c|c|c}
\hline & VTT PRÉ $(\mathrm{N}=17)$ & VTT PÓS $(\mathrm{N}=17)$ & \\
\hline Acurácia (\%) & $96,83 \pm 5,10$ & $95,50 \pm 8,20$ & $\mathrm{p}=0.5610$ \\
\hline Tempo de reação & $668,53 \pm 107,02$ & $673,71 \pm 87,77$ & $\mathrm{p}=0.8175$ \\
$(\mathrm{~ms})$ & & & \\
\hline
\end{tabular}

Comparação pareada dos dados comportamentais dos voluntários do grupo VT PRÉ X PÓS com treinamento físico para o paradigma 2-Back.

Observa-se que a comparação entre os voluntários do grupo VT que realizaram treinamento físico (VTT), no paradigma 2-Back, não apresentaram 
mudanças significativas nas áreas de ativação cerebral, na acurácia e no tempo de resposta.

\section{STROOP - Vinho Tinto sem treinamento físico}

As figuras $26 \mathrm{~A}$ e $26 \mathrm{~B}$ ilustram os mapas de resposta cerebral do grupo Vinho tinto sem treinamento físico durante o paradigma Stroop mostrando regiões cerebrais com maior resposta na condição incongruente em relação à condição congruente - PRÉ e PÓS
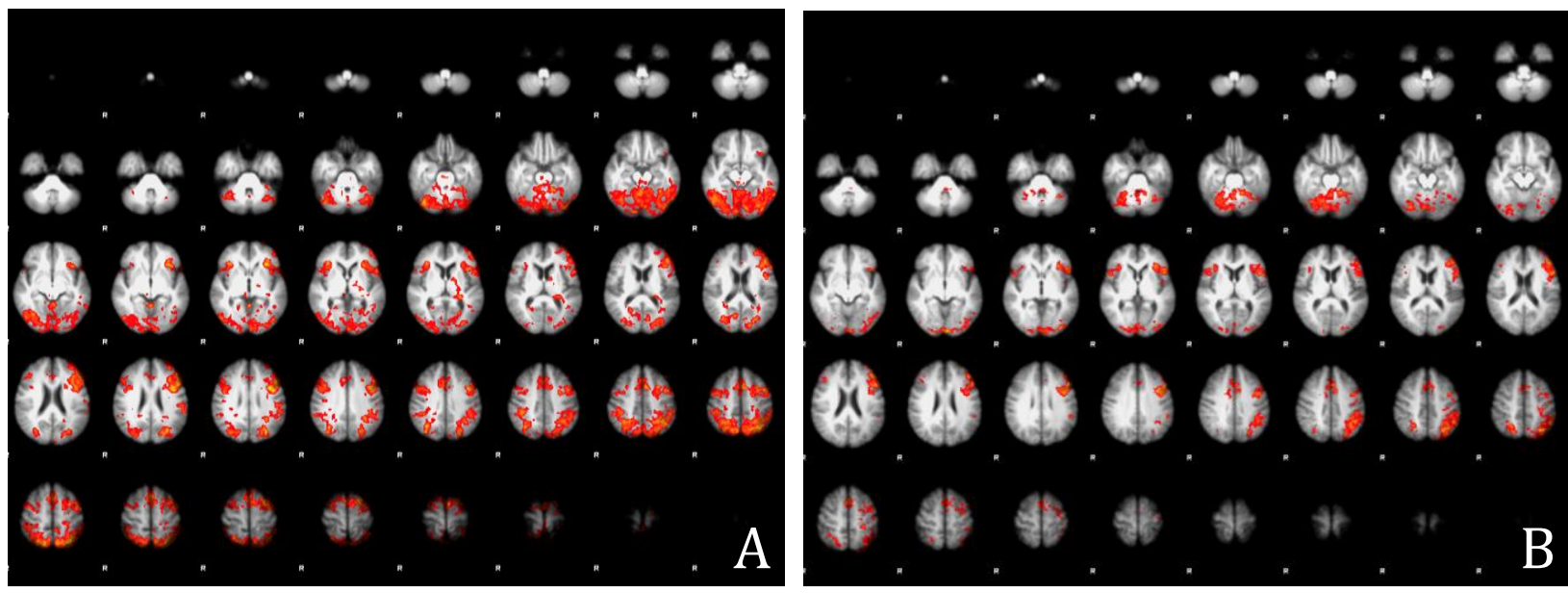

Figura 26A- VT PRÉ sem treinamento físico ( $N=19)$ : Stroop (incongruente $>$ congruente): observam-se áreas com maior resposta cerebral nos hemisférios cerebelares, lobos occipitais (envolvendo áreas pericalcarinas), regiões temporo-occipitais, giros frontais inferiores e médios, envolvendo as áreas pré-frontais, de forma mais extensa à esquerda, aspecto anterior dos giros dos cíngulos e lóbulos parietais inferiores e superiores, de forma mais extensa à esquerda( $Z>2,3$ e $p<0,05)$.

Figura 26B- VT PÓS sem treinamento físico $(\mathrm{N}=19)$ : Stroop (incongruente > congruente): observam-se áreas com maior resposta cerebral nos hemisférios cerebelares, de forma mais extensa à direita, lobos occipitais, região temporo-occipital esquerda, giros frontais inferiores e médios, envolvendo as áreas pré-frontais, de forma mais extensa à esquerda, aspecto anterior dos giros dos cíngulos e lóbulos parietais inferior esquerda e, notadamente, superiores, de forma mais extensa à esquerda( $Z>2,3$ e $p<0,05)$. 
A figura 27 representa a subtração das figuras $26 \mathrm{~A}$ e $26 \mathrm{~B}$, pelo mapa do teste ANOVA mostrando as áreas com maior resposta cerebral no grupo Consumidor de vinho tinto sem treinamento físico: PRÉ X PÓS durante o paradigma STROOP com maior resposta na condição incongruente em relação à condição congruente

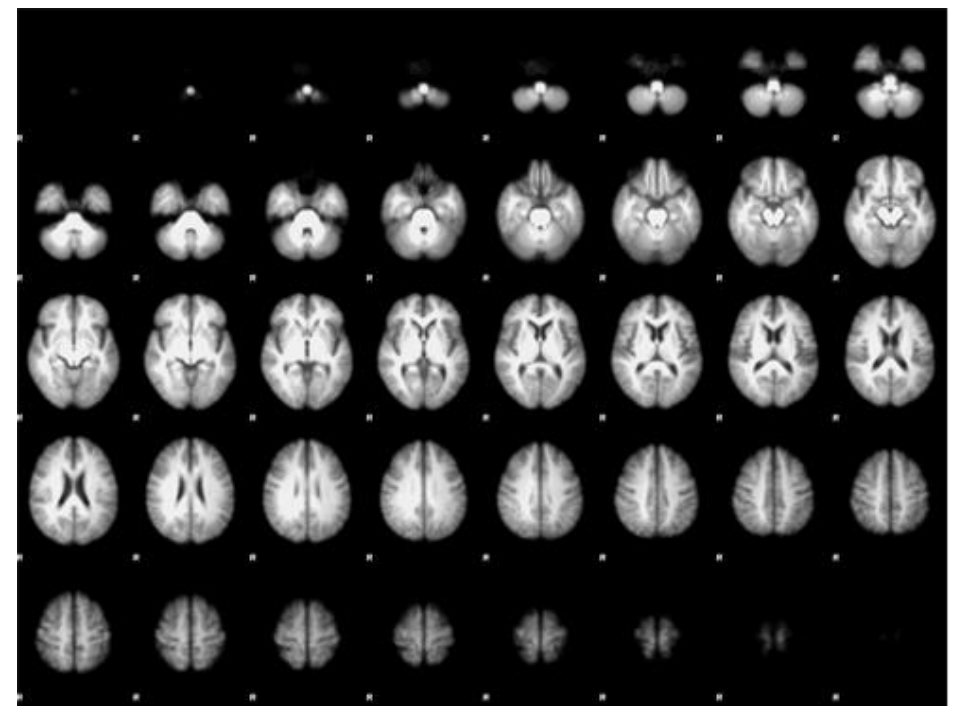

Figura 27- VT PRÉ sem treinamento físico X VT PÓs sem treinamento físico: STROOP (incongruente > congruente): não foram observam-se áreas com maior resposta cerebral $(Z>2,3$ e $p<0,05)$.

Tabela 17- Dados comportamentais VT PRÉ X VT PÓS

\begin{tabular}{l|c|c|c}
\hline & VT PRÉ $(\mathrm{N}=19)$ & VT PÓS $(\mathrm{N}=19)$ & \\
\hline Acurácia (\%) & $94,49 \pm 5,95$ & $96,31 \pm 3,85$ & $\mathrm{p}=0.1734$ \\
\hline Tempo de reação & $824,29 \pm 142,80$ & $834,10 \pm 146,81$ & $\mathrm{p}=0.7510$ \\
$(\mathrm{~ms})$ & & & \\
\hline
\end{tabular}

Comparação pareada dos dados comportamentais dos voluntários do grupo VT PRÉ X PÓS sem treinamento físico para o paradigma Stroop,

Observa-se que os voluntários do grupo VT que não foram submetidos ao treinamento físico supervisionado, não apresentaram 
mudanças significativas nas áreas de ativação cerebral, na acurácia e no tempo de resposta.

Nota-se que a simples inspeção das figuras 26A e 26B aparenta diferenças. No entanto, quando as imagens foram submetidas à técnica de subtração (figura 27) estas diferenças não aparecem segundo critérios estatísticos.

\section{2-BACK - Vinho Tinto sem treinamento físico}

As figuras $28 \mathrm{~A}$ e $28 \mathrm{~B}$ ilustram os mapas de resposta cerebral durante o paradigma 2-Back mostrando regiões cerebrais com maior resposta na condição ativa em relação à condição neutra - PRÉ e PÓS
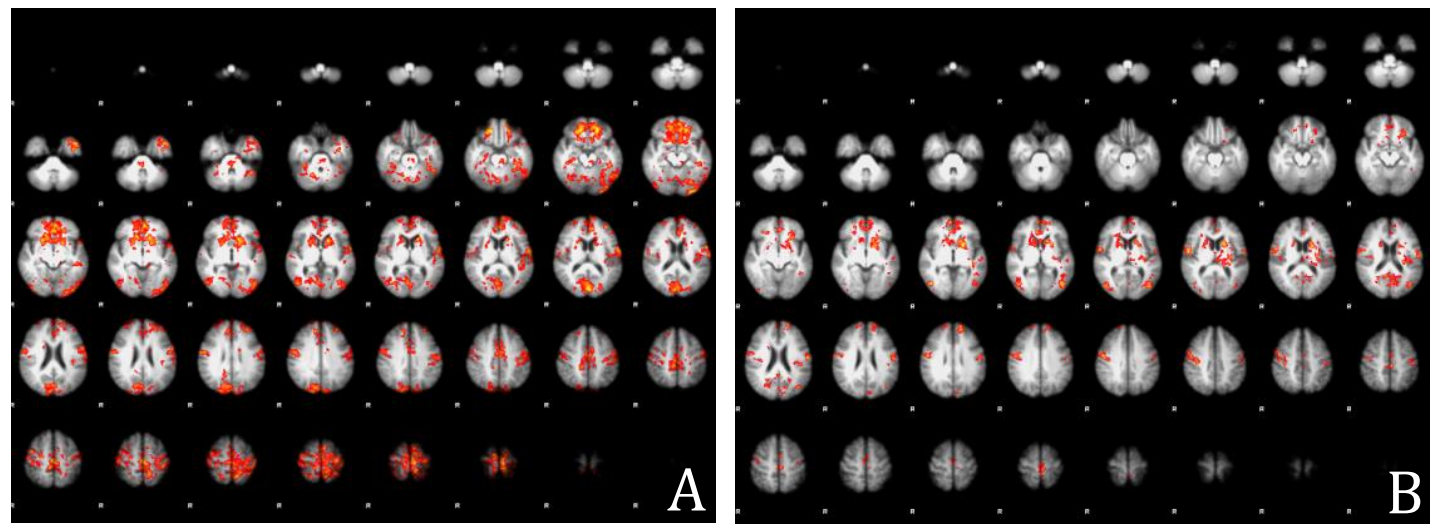

Figura 28A- VT PRÉ sem treinamento físico ( $\mathrm{N}=19$ ): 2-Back (ativa > neutra): foram observadas áreas com maior resposta cerebral nas regiões orbitofrontais, regiões nucleocapsulares, lobos occipitais, envolvendo as regiões pericalcarinas, região temporooccipital esquerda, giros pré-centrais, giros do cíngulo e lóbulo parietal superior esquerdo $(Z>2,3$ e $p<0,05)$.

Figura 28B- VT PóS sem treinamento físico $(\mathrm{N}=19$ ): 2-Back (ativa > neutra): foram observadas áreas com maior resposta cerebral nas regiões orbitofrontais, de forma mais extensa à esquerda, regiões nucleocapsulares, de forma mais extensa à esquerda, lobos occipitais envolvendo as regiões pericalcarinas, lóbulos parietais inferiores, giros pré-centrais e giros do cíngulo ( $Z>2,3$ e $p<0,05)$. 
A figura 29 representa a subtração das figuras $28 \mathrm{~A}$ e $28 \mathrm{~B}$, pelo Mapa do teste ANOVA mostrando as áreas com maior resposta cerebral no grupo Consumidor de vinho tinto sem treinamento físico: PRÉ X PÓS durante o paradigma 2-Back com maior resposta na condição ativa em relação à condição neutra.

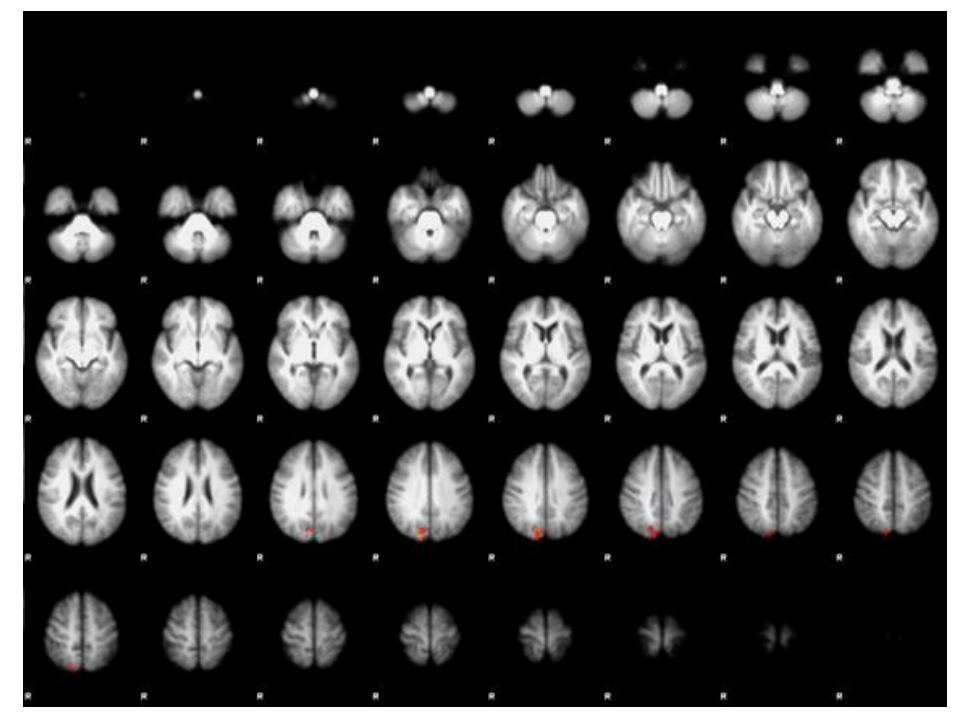

Figura 29- VT PRÉ sem treinamento físico X VT PÓS sem treinamento físico: paradigma 2-Back (ativa > neutra): observam-se áreas com maior resposta cerebral no lóbulo parietal superior direito $(Z>2,3$ e $p<0,05)$.

Tabela 18- Dados comportamentais VT PRÉ X VT PÓS

\begin{tabular}{l|c|c|c}
\hline & VT PRÉ $(\mathrm{N}=19)$ & VT PÓS $(\mathrm{N}=19)$ & \\
\hline Acurácia (\%) & $96,90 \pm 5,63$ & $97,59 \pm 5,00$ & $\mathrm{p}=0.7077$ \\
\hline $\begin{array}{l}\text { Tempo de reação } \\
(\mathrm{ms})\end{array}$ & $688,75 \pm 105,55$ & $685,09 \pm 104,55$ & $\mathrm{p}=0.8877$ \\
\hline
\end{tabular}

Comparação pareada dos dados comportamentais dos voluntários do grupo VT PRÉ X PÓS sem treinamento físico para o paradigma 2-Back.

Nota-se que os voluntários do grupo VT que não realizaram treinamento físico, no paradigma 2-Back, recrutam menos áreas cerebrais 
que aquelas observadas na primeira avaliação (PRÉ), e sem mudanças significativas na acurácia e no tempo de resposta.

\section{Análises não-pareadas entre bebedores e abstêmios}

Para analisar se houve diferenças nas avaliações finais, entre os 4 grupos estudados, procederam-se análises não pareadas, considerando áreas de ativação cerebral, acurácia e tempo de resposta nos paradigmas Stroop e 2Back.

\section{STROOP}

A figura 30 ilustra o mapa do teste ANOVA da comparação das médias das diferenças das áreas com maior resposta cerebral dos grupos Bebedores de vinho tinto e Abstêmios que fizeram treinamento físico: paradigma STROOP com resposta maior na condição incongruente em relação à condição congruente

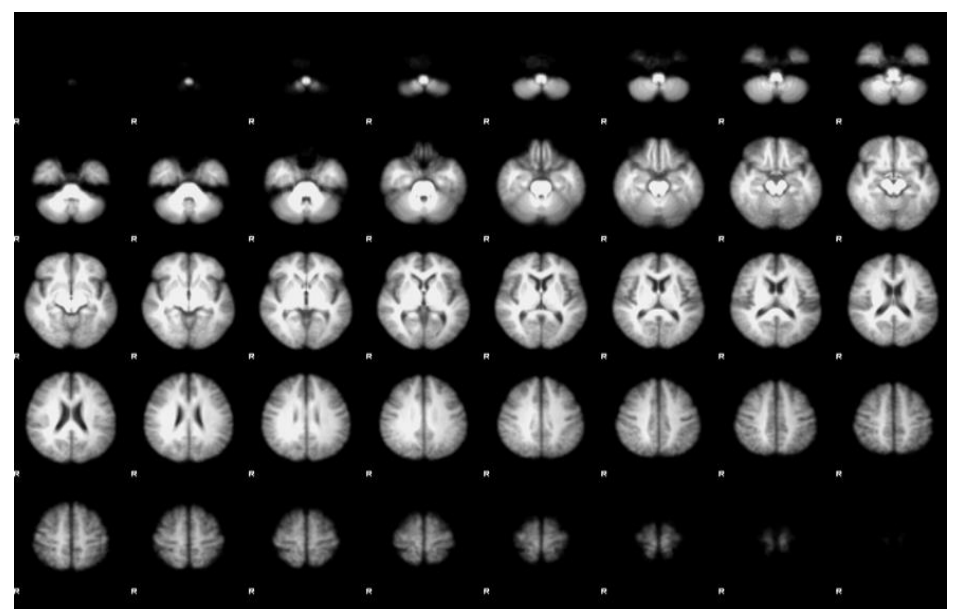

Figura 30- VT PÓS com treinamento físico X ABS PÓS com treinamento físico: paradigma Stroop (incongruente > congruente): não foram observam-se áreas com maior resposta cerebral $(Z>2,3$ e $\mathrm{p}<0,05)$. 
Tabela 19- Dados comportamentais VTT PÓS X ABS PÓS

\begin{tabular}{l|c|c|c}
\hline & VTT PÓS $(\mathrm{N}=17)$ & ABST PÓS $(\mathrm{N}=17)$ & \\
\hline Acurácia (\%) & $95,68 \pm 5,06$ & $96,44 \pm 3,06$ & $\mathrm{p}=0.060$ \\
\hline Tempo de reação (ms) & $832,98 \pm 188,36$ & $779,40 \pm 134,59$ & $\mathrm{p}=0.480$ \\
\hline
\end{tabular}

Comparação não pareada dos dados comportamentais dos voluntários do grupo VT PÓS X ABS PÓS com treinamento físico para o paradigma Stroop.

Os dados mostraram que não houve diferença significativa na comparação entre os voluntários do grupo VT e ABS que realizaram treinamento físico nas áreas de ativação cerebral, na acurácia e no tempo de resposta para o paradigma Stroop.

\section{2-BACK}

A figura 31 ilustra o mapa do teste ANOVA da comparação das médias das diferenças das áreas com maior resposta cerebral dos grupos Bebedores de vinho tinto e Abstêmios que fizeram treinamento físico: paradigma 2-Back com resposta maior na condição ativa em relação à condição neutral.

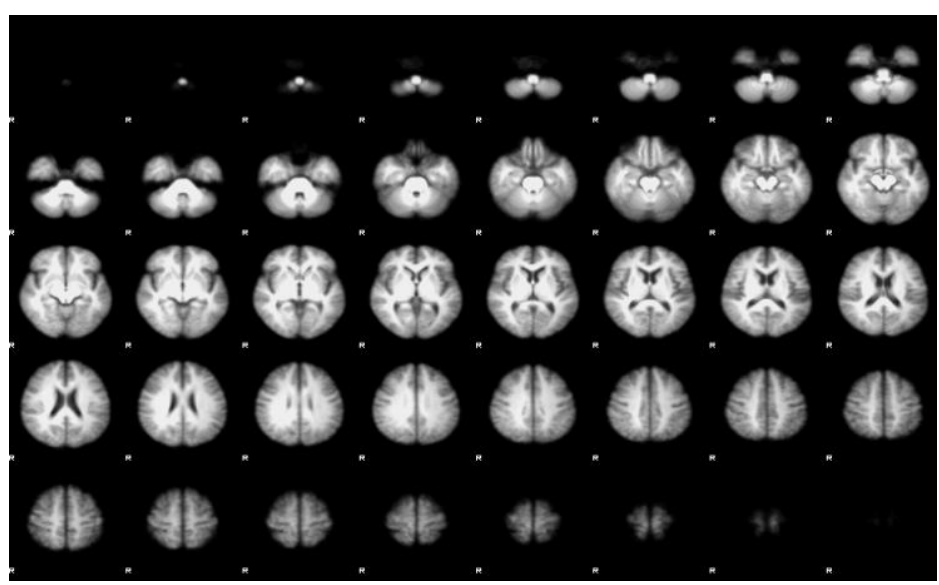

Figura 31- VT PÓS com treinamento físico $X$ ABS PÓS com treinamento físico: paradigma 2-Back (condição ativa > neutra): não foram observam-se áreas com maior resposta cerebral $(Z>2,3$ e $p<0,05)$. 
Tabela 20- Dados comportamentais VTT PÓS X ABST PÓS

\begin{tabular}{l|c|c|c}
\hline & VTT PÓS $(\mathrm{N}=17)$ & ABST PÓS $(\mathrm{N}=17)$ & \\
\hline Acurácia (\%) & $95,51 \pm 8,2$ & $93,00 \pm 8,86$ & $\mathrm{p}=0.40$ \\
\hline $\begin{array}{l}\text { Tempo de reação } \\
(\mathrm{ms})\end{array}$ & $673,71 \pm 87,77$ & $722,59 \pm 111,75$ & $\mathrm{p}=0.17$ \\
\hline
\end{tabular}

Comparação não pareada dos dados comportamentais dos voluntários do grupo VT PÓS X ABS PÓS com treinamento físico para o paradigma 2Back. Não foram observadas diferenças significativas de acurácia e tempo de reação entre as avaliações.

Os dados mostraram que não houve diferença significativa na comparação entre os voluntários do grupo VT e ABS que realizaram treinamento físico nas áreas de ativação cerebral, na acurácia e no tempo de resposta para o paradigma 2-Back. 


\section{STROOP}

A figura 32 ilustra o mapa do teste ANOVA da comparação das médias das diferenças das áreas com maior resposta cerebral dos grupos Bebedores de vinho tinto e Abstêmios que não fizeram treinamento físico: paradigma STROOP com resposta maior na condição incongruente em relação à condição congruente

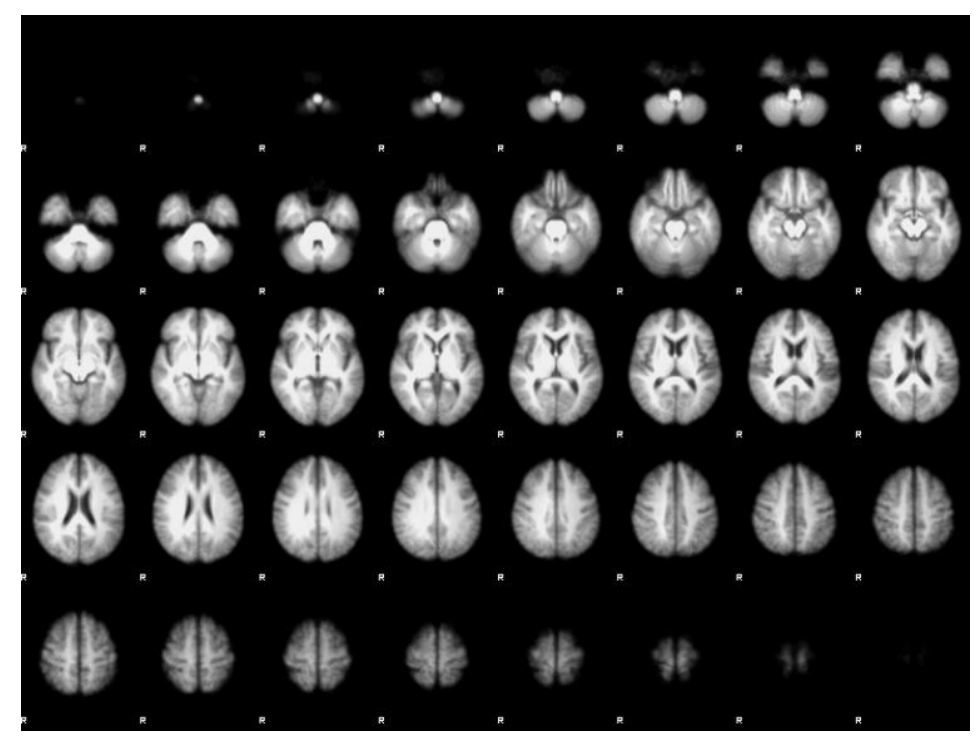

Figura 32- VT PÓS sem treinamento físico $X$ ABS PÓS sem treinamento físico: paradigma Stroop (contraste incongruente > congruente): não foram observam-se áreas com maior resposta cerebral $(Z>2,3$ e $p<0,05)$.

Tabela 21- Dados comportamentais VT PÓS X ABS PÓS

\begin{tabular}{l|c|c|c}
\hline & VT PÓS $(\mathrm{N}=19)$ & ABS PÓS $(\mathrm{N}=20)$ & \\
\hline Acurácia (\%) & $96,32 \pm 3,85$ & $95,09 \pm 5,7$ & $\mathrm{p}=0.44$ \\
\hline $\begin{array}{l}\text { Tempo de reação } \\
(\mathrm{ms})\end{array}$ & $834,10 \pm 146,81$ & $852,40 \pm 165,38$ & $\mathrm{p}=0.72$ \\
\hline
\end{tabular}

Comparação não pareada dos dados comportamentais dos voluntários do grupo VT PÓS X ABS PÓS sem treinamento físico para o paradigma Stroop. 
Observa-se que não houve diferença significativa entre os voluntários do grupo VT e ABS que não realizaram treinamento físico nas áreas de ativação cerebral, na acurácia e no tempo de resposta para o paradigma Stroop.

\section{2-BACK}

A figura 33 ilustra o mapa do teste ANOVA da comparação das médias das diferenças das áreas com maior resposta cerebral dos grupos Bebedor de vinho tinto e Abstêmios que não fizeram treinamento físico: paradigma 2-Back com resposta maior na condição ativa em relação à condição neutral.

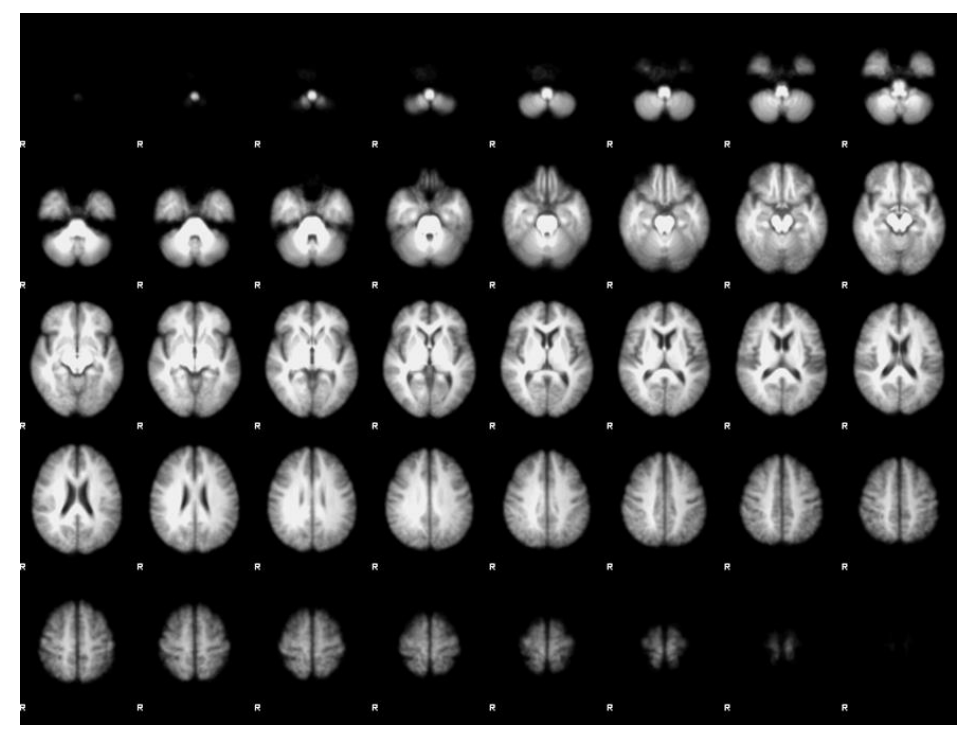

Figura 33- VT PÓS sem treinamento físico X ABS PÓS sem treinamento físico: paradigma 2-Back (ativa > neutra): não foram observam-se áreas com maior resposta cerebral $(Z>2,3$ e $p<0,05)$. 
Tabela 22- Dados comportamentais VT PÓS X ABS PÓS

\begin{tabular}{l|c|c|c}
\hline & VT PÓS $(\mathrm{N}=19)$ & ABS PÓS $(\mathrm{N}=20)$ & \\
\hline Acurácia (\%) & $97,59 \pm 5,0$ & $93,44 \pm 8,7$ & $\mathrm{p}=0.08$ \\
\hline $\begin{array}{l}\text { Tempo de reação } \\
(\mathrm{ms})\end{array}$ & $685,09 \pm 104,55$ & $670,74 \pm 127,91$ & $\mathrm{p}=0.70$ \\
\hline
\end{tabular}

Comparação não pareada dos dados comportamentais dos voluntários do grupo VT PÓS X ABS PÓS sem treinamento físico para o paradigma 2Back.

Nossos dados mostraram que não houve diferença significativa na comparação entre os voluntários do grupo VT e ABS que não realizaram treinamento físico nas áreas de ativação cerebral, na acurácia e no tempo de resposta para o paradigma 2-Back. 


\section{STROOP}

A figura 34 ilustra o mapa do teste ANOVA da comparação das médias das diferenças das áreas com maior resposta cerebral dos grupos Bebedor de vinho tinto com treinamento físico e Abstêmios sem treinamento físico: paradigma Stroop com resposta maior na condição incongruente em relação à condição congruente.

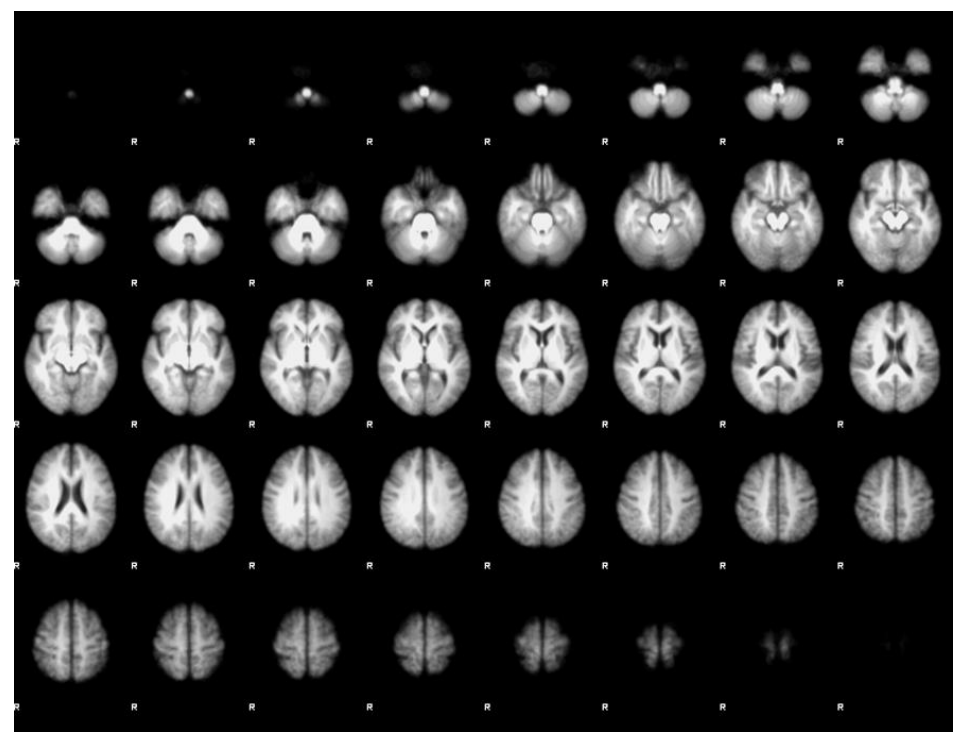

Figura 34- VT PÓS com treinamento físico X ABS PÓS sem treinamento físico: paradigma Stroop (incongruente > congruente): não foram observam-se áreas com maior resposta cerebral $(Z>2,3$ e $\mathrm{p}<0,05)$.

Tabela 23- Dados comportamentais VTT PÓS X ABS PÓS

\begin{tabular}{l|c|c|c}
\hline & VTT PÓS $(\mathrm{N}=17)$ & ABS PÓS $(\mathrm{N}=20)$ & \\
\hline Acurácia (\%) & $95,68 \pm 5,06$ & $95,09 \pm 5,7$ & $\mathrm{p}=0.60$ \\
\hline Tempo de reação (ms) & $870,90 \pm 188,36$ & $852,40 \pm 165,38$ & $\mathrm{p}=0.48$ \\
\hline
\end{tabular}

Comparação não pareada dos dados comportamentais dos voluntários do grupo VT PÓS com treinamento físico X ABS PÓS sem treinamento físico para o paradigma Stroop. 
Nota-se que não houve diferença significativa na comparação entre os voluntários do grupo VT PÓS com treinamento físico e ABS PÓS sem treinamento físico nas áreas de ativação cerebral, na acurácia e no tempo de resposta para o paradigma Stroop.

\section{2-BACK}

A figura 35 ilustra o mapa do teste ANOVA da comparação das médias das diferenças das áreas com maior resposta cerebral dos grupos Bebedores de vinho tinto com treinamento físico e Abstêmios que não fizeram treinamento físico: paradigma 2-Back com resposta maior na condição ativa em relação à condição neutra

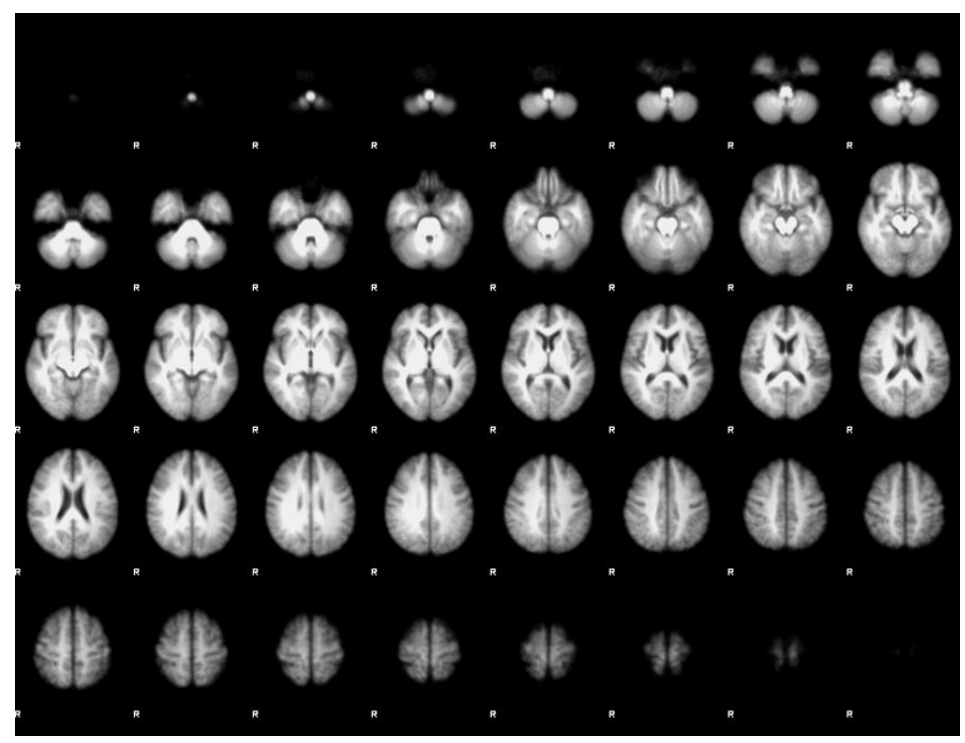

Figura 35- VT Pós sem treinamento físico X ABS Pós sem treinamento físico: paradigma 2-Back (ativa > neutra): não foram observadas áreas com maior resposta cerebral $(Z>2,3$ e $p<0,05)$. 
Tabela 24- Dados comportamentais VTT PÓS X ABS PÓS 2-Back

\begin{tabular}{l|c|c|c}
\hline & VTT PÓS $(\mathrm{N}=17)$ & ABS PÓS $(\mathrm{N}=20)$ & \\
\hline Acurácia (\%) & $95,51 \pm 8,2$ & $93,44 \pm 8,7$ & $\mathrm{p}=0.46$ \\
\hline Tempo de reação $(\mathrm{ms})$ & $673,71 \pm 87,77$ & $670,74 \pm 127,91$ & $\mathrm{p}=0.93$ \\
\hline
\end{tabular}

Comparação pareada dos dados comportamentais dos voluntários do grupo VT PÓS X ABS PÓS sem treinamento físico para o paradigma 2-Back.

Nossos dados mostraram que não houve diferença significativa na comparação entre os voluntários do grupo VT PÓS com treinamento físico e ABS PÓS sem treinamento físico nas áreas de ativação cerebral, na acurácia e no tempo de resposta para o paradigma 2-Back.

\subsection{RELAÇÃO $\mathrm{VO}_{2}$ E FUNÇÕES CEREBRAIS}

Para avaliar a relação entre $\mathrm{VO}_{2}$ pico e a resposta de áreas cerebrais, consideramos uma linha de corte na média do $\mathrm{VO}_{2}$ para todo o grupo.

Assim, verificamos que a média do $\mathrm{VO}_{2}$ pico nos bebedores de vinho tinto era de 25,3 ml.kg. $\mathrm{min}^{-1}$. Havia 18 indivíduos acima desta média e o $\mathrm{VO}_{2}$ pico era de 28,3 ml.kg.min ${ }^{1}$. Abaixo da média tinham 18 indivíduos com $\mathrm{VO}_{2}$ pico de 22,3 ml.kg. $\mathrm{min}^{-1}$.

No grupo abstêmios, a média do $\mathrm{VO}_{2}$ pico era de $27,3 \mathrm{ml} . \mathrm{Kg} \cdot \mathrm{ml} . \mathrm{kg} \cdot \mathrm{min}^{-}$

1. Havia 18 indivíduos acima desta média, com VO 2 pico de 31,6 ml.kg.min ${ }^{-1}$. E abaixo da média havia 19 indivíduos com $\mathrm{VO}_{2}$ pico de 22,8 $\mathrm{ml} \cdot \mathrm{kg} \cdot \mathrm{min}^{-1}$. 


\section{Consumidores de Vinho Tinto}

\section{STROOP}

A figura 36 ilustra o Mapa da correlação negativa do VO2 pico com a resposta BOLD na comparação das diferenças das sessões (PRÉ>PÓS) independente dos grupos para o contraste incongruente $>$ neutro do paradigma Stroop. Nas regiões do cúneo, pré-cúneo e giro pós-central direito (os dois primeiros fazem parte do substrato neuroanatômico do Stroop) existe uma correlação negativa entre VO2 pico e a resposta BOLD (menor VO2 pico, maior a resposta BOLD) observada na diferença de sessão (PÓS>PRÉ). Essa correlação negativa é maior na segunda avaliação (PÓS>PRÉ), independentemente do grupo (com ou sem exercício físico).

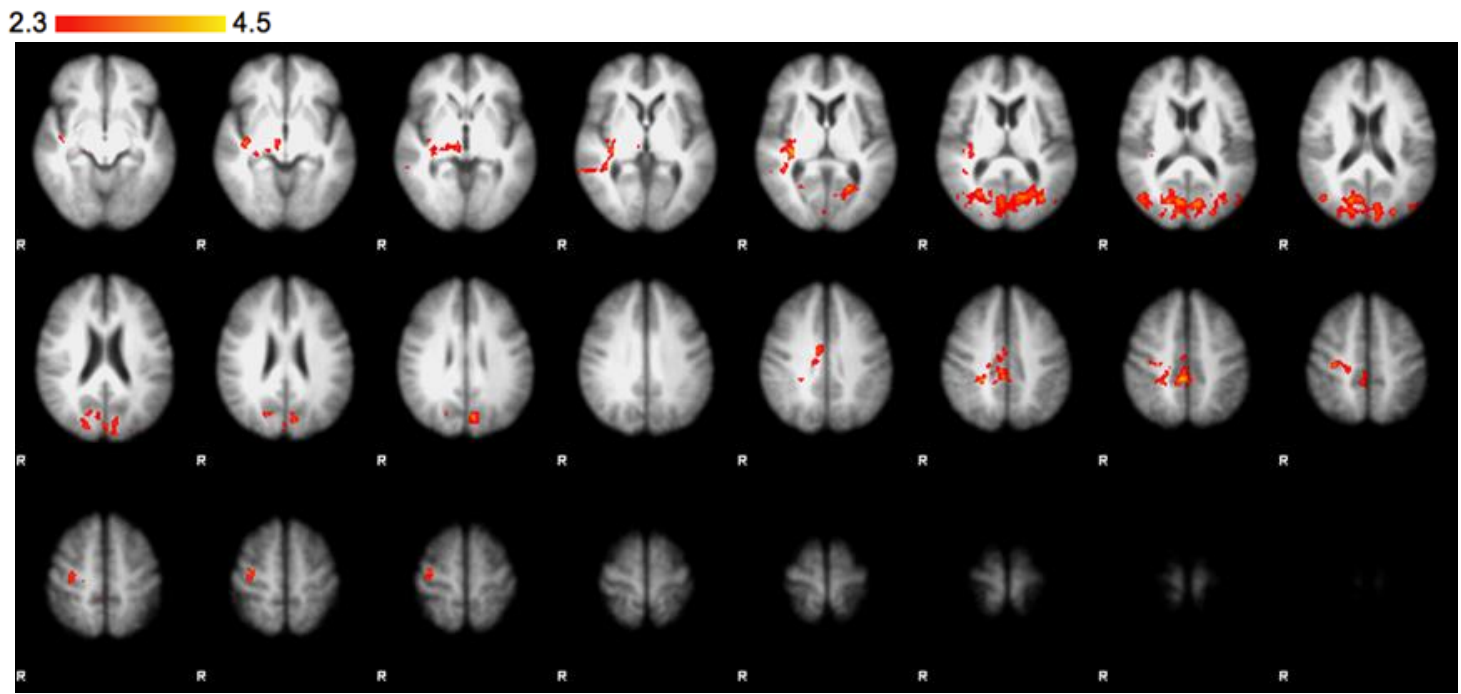

Figura 36- Mapa da correlação do $\mathrm{VO}_{2}$ pico e resposta $\mathrm{BOLD}$ 


\section{2- BACK}

A reposta BOLD nos giros frontais superior e médio esquerdos (que fazem parte do substrato neuroanatômico habitualmente recrutado durante a realização do 2-Back) tem correlação negativa com VO2 pico (quando menor VO2 pico, maior a resposta BOLD), em ambos os grupos (VT com treinamento e VT sem treinamento) no contraste PÓS > PRÉ. Assim, a influência da variável VO2 pico na resposta BOLD nas áreas descritas acima é semelhante na diferença entre sessões (PÓS > PRÉ) tanto no grupo com exercício como no sem exercício.

\section{Abstêmios}

\section{STROOP}

Nas regiões do polo do lobo temporal esquerdo, lobos occipitais envolvendo as áreas pericalcarinas, lóbulos parietais superiores (fazem parte do substrato neuroanatômico do Stroop) existe uma correlação negativa entre VO2 pico e a resposta BOLD (menor VO2 pico, maior a resposta BOLD) observada na diferença de sessão (PÓS > PRÉ). Essa corelação negativa é maior na segunda avaliação (PÓS > PRÉ), independentemente do grupo (com ou sem exercício físico).

\section{2-BACK}

Não foi observada correlação entre o VO2 pico e efeito BOLD. 
Em resumo, houve uma relação negativa entre $\mathrm{VO}_{2}$ pico e áreas ativadas, tanto em bebedores quanto em abstêmios, independente do treinamento físico. Essa relação só não foi observada no 2-Back entre os abstêmios. Portanto, a intensidade do exercício é que modula a ativação das áreas cerebrais.

\section{Resumo dos resultados}

Comparando os dois grupos, abstêmios e consumidores de vinho tinto, nas avaliações iniciais (PRÉ), foram encontrados os seguintes dados:

1- Testes neuropsicológicos: Os consumidores de vinho tinto têm melhor desempenho nos testes Trilhas A, Trilhas B e Stroop 1, que avaliaram a memória e a sustentação da atenção e atenção alternada.

2- Imagens: no paradigma 2-Back, observou-se que os consumidores de vinho apresentaram áreas com maior ativação cerebral na região anterior do giro frontal médio esquerdo e maior acurácia $(\mathrm{P}<0.009)$. Portanto, os bebedores parecem ter melhores funções cognitivas que os ABS, tanto nos testes neuropsicológicos quanto na fMRI (2-Back).

3. A escolaridade era menor entre os ABST do que nos demais grupos.

4. São apenas homens; mulheres foram excluídas porque tem sensibilidade diferente ao VT.

Após a intervenção, ou seja, o treinamento físico, observamos os seguintes dados: 
1- Testes neuropsicológicos:

a) foi encontrada diferença no teste Stroop 2, que avalia controle inibitório. Os consumidores de vinho tinto apresentaram redução no tempo do teste. Assim, com base nos testes neuropsicológicos, os bebedores não só têm melhor desempenho antes do exercício, como também respondem melhor ao exercício.

b) No teste River 1 os ABS (sem treinamento) mostraram aumento do tempo de realização do teste $(p<0,038)$.

2- Imagens:

a) Os VTT apresentaram maior acurácia no PÓS, sem mudanças nas áreas ativadas e nos tempos (Stroop). Pelo 2-Back não houve modificação em nenhum parâmetro. Assim, o VT produz maior acurácia.

b) No grupo VT não houve nenhuma alteração pelo Stroop. Pelo 2Back houve menos áreas ativadas.

c) Já os ABST recrutaram menos áreas após Ex, sem mudanças na acurácia/tempo. Pelo 2-Back nada mudou.

d) Os ABS recrutaram menos áreas pelo Stroop e pelo 2-Back, mas sem qualquer alteração na acurácia/tempo. Em suma os $A B S$, fazendo ou não Ex, recrutam menos áreas cerebrais no PÓS, e não mudam nem acurácia nem tempo.

e) Houve relação inversa entre VO2 pico e áreas ativadas, nos consumidores de VT no Stroop e 2-Back; nos ABS apenas no Stroop. 
Realizando a comparação final entre os 4 grupos (Anova), englobando imagens, acurácia e tempo de resposta, não foi encontrada nenhuma diferença com significância estatística entre os quatros grupos ao final do trabalho. Isto indica que embora haja diferenças entre os grupos em certos testes, a comparação global não é significativamente diferente. 
Em conclusão, os resultados deste estudo, tomados em conjunto demonstraram que:

- Indivíduos consumidores regulares de VT têm melhor função cognitiva em testes de memória e atenção, mesmo na fase pré-treinamento e respondem melhor ao exercício físico em comparação aos abstêmios.

- Existe correlação negativa entre o $\mathrm{VO}_{2}$ pico e a ativação cerebral, o que pode indicar que melhor desempenho físico pode induzir maior eficiência mental.

- Estes dados sugerem que existe modesto efeito aditivo do exercício físico sobre funções cognitivas em bebedores crônicos, moderados, de vinho tinto sem déficit cognitivo. 
O objetivo maior desta investigação era verificar se o exercício físico supervisionado poderia influenciar funções cognitivas em indivíduos bebedores crônicos de VT sem déficit cognitivo prévio, todos homens. Os achados principais são:

a. Na fase pré-exercício pelos testes psicológicos, os bebedores têm melhor desempenho nos tetes trilhas $\mathrm{A}$ e $\mathrm{B}$, e no Stroop 1; no que respeita à aéreas cerebrais ativadas pela $\mathrm{fMRI}$, paradigma 2-Back, os bebedores apresentaram maior ativação na região anterior do giro frontal médio e maior acurácia. Assim os bebedores mostraram melhores funções cognitivas que os abstêmios, tanto nos testes neuropsicológicos quanto pela fMRI.

Note-se que os abstêmios com treinamento físico tinham menor escolaridade que os demais grupos. A influência dessa diferença nos estudos permanece especulativa. Quanto à demografia, fatores de risco e achados clínicos, os dois grupos são comparáveis.

b. $\mathrm{Na}$ fase pós-exercício, nos testes neuro-psicológicos, os bebedores apresentaram redução no tempo de realização do teste Stroop 2, o qual avalia controle inibitório; por outro lado, os $A B S$ sem treinamento mostraram aumento no tempo de realização do teste River $1(\mathrm{p}<0,038)$. Assim com base nos testes neuropsicológicos, os bebedores não só têm melhores funções cognitivas pré-exercício, como também respondem melhor ao exercício.

Em suma, os abstêmios fazendo ou não exercício, recrutaram menos áreas cerebrais nos períodos pós comparados ao pré-exercício, e não sofreram mudanças nem na acurácia nem nos tempos de resposta. 
c. Quanto às imagens da fMRI no PRÉ, o paradigma 2-Back, observou-se que os consumidores de vinho apresentaram áreas com maior ativação cerebral na região anterior do giro frontal médio esquerdo e maior acurácia $(p<0.009)$. Portanto, os bebedores parecem ter melhores funções cognitivas que os abstêmios no PRÉ, tanto nos testes neuropsicológicos quanto na (2-Back). Os bebedores de VT que fizeram treinamento físico, mostraram tendência à maior acurácia no teste Stroop. Por outro lado, entre bebedores que não fizeram treinamento, não houve qualquer alteração no Stroop, mas houve menos áreas ativadas pelo 2-Back.

Assim, o VT associado ao exercício causa uma tendência de maior acurácia.

Já os abstêmios, ie, com treinamento recrutaram menor área após exercício, sem mudanças na acurácia e nos tempos de execução. Por outro lado, os abstêmios, ie, sem treinamento, recrutaram menos áreas cerebrais pelo Stroop e pelo 2-Back, mas sem qualquer alteração na acurácia ou nos tempos. Em suma os abstêmios, fazendo ou não exercício, recrutam menos áreas cerebrais no PÓS, e não mudam nem acurácia nem tempos.

d. Houve relação negativa entre $\mathrm{VO}_{2}$ pico e áreas cerebrais ativadas, tanto em bebedores de VT quanto em abstêmios. Tal relação só não foi observada no teste 2-Back, entre abstêmios. Esta relação inversa sugere que a intensidade do exercício físico é que modula a ativação das áreas cerebrais.

Por fim, a comparação final no pós-exercício, entre os 4 grupos estudados, incluindo imagens, acurácia e tempos, não mostrou diferenças significativas por ANOVA não pareada. Isso indica que, embora haja diferenças 
intra-grupos em certos testes, tais diferenças não alcançaram significância estatística.

Algumas considerações devem ser feitas na interpretação desses achados. A técnica da fMRI é uma medida indireta da função cerebral, portanto com vários fatores que podem alterar seus resultados; podemos avaliar extensão das áreas ativadas, mas não ter certeza de que avaliamos absolutamente todas as áreas envolvidas: podem haver regiões participando da tarefa que não foram detectadas - e nem ter certeza do que significa. Assim, o significado da ativação das áreas é ainda especulativo. Neste sentido, poderíamos estar diante de um fenômeno de alteração de conformação tecidual. Os dados atuais, não permitem diferenciação dessas possibilidades. Talvez se deva apenas concluir que, no que respeita às imagens, o exercício simplesmente interferiu, ou modulou, a atividade cerebral.

O que consistentemente se observou foi uma relação inversa entre o pico de $\mathrm{VO}_{2}$ atingido durante o teste cardiopulmonar e a resposta BOLD em determinadas regiões cerebrais; ou seja, quanto maior o $\mathrm{VO}_{2}$ pico menor resposta BOLD nessas áreas; o inverso também pode ser considerado, ie, quanto menor $\mathrm{O}_{2}$ pico maior a resposta BOLD nessas áreas. Isto sugere que a resposta BOLD tem uma dinâmica que se correlaciona inversamente com a do desempenho físico. Seria o caso de se dizer que quanto melhor é o desempenho físico, e portanto, maior é a oxigenação cerebral, menos áreas precisam ser recrutadas para realizar a mesma tarefa? Se essa premissa mostrar-se verdadeira, poderíamos considerar que o melhor desempenho físico induziria maior eficiência mental. No entanto, é difícil afirmar definitivamente essa conclusão porque a fMRI não mede diretamente a função neuronal, mas 
simplesmente identifica variações de suscetibilidade magnética relacionadas à oxigenação e volume sanguíneo cerebral regional. Evidentemente tal hipótese não pode ser afastada, visto que o exercício físico melhora a circulação cerebral como demonstrado por Jordan Querido ${ }^{72}$.

Assim, em se tratando de indivíduos sem déficit cognitivo evidente, como é o caso aqui, é possível que o estímulo do exercício estimule funções neuronais.

Outro aspecto essencial, diz respeito às características do exercício executado. A duração do exercício programado, ie, 12 semanas, é semelhante à de outros estudos como relatado na revisão Cochrane ${ }^{34}$; porém, outros trabalhos clínicos foram de maiores durações, ie, 6 a 12 meses, como no trabalho de Colcombe(73). Por outro lado, a intensidade do exercício parece ter sido adequada, visto que houve aumento significativo tanto na potência quanto no $\mathrm{VO}_{2}$ pico. Portanto, a intensidade do estímulo circulatório induzido pelo exercício foi provavelmente satisfatória.

Outro fator que pode influenciar os resultados é o treinamento, ie, a repetição do teste em si. No entanto observamos apenas tendência à melhoria no Stroop mas não no 2-Back. Portanto, o efeito da repetição do exame em si não parece explicar os resultados.

Uma análise final foi feita englobando bebedores e abstêmios, com e sem treinamento, na segunda avaliação, incluindo imagens, acurácia e tempo, usando Anova não pareada. Os resultados mostraram que não houve diferenças significativas entre os 4 grupos. Assim, embora houvesse diferenças intra-grupos, quando comparados entre si, tais diferenças não 
alcançaram significância estatística. Isto pode ser atribuída ao pequeno número de casos do estudo.

Finalmente, existem razões clínicas e fisiopatológicas que justificam efeitos positivos do exercício sobre funções cerebrais, tanto por mecanismos hemodinâmicos como metabólicos ${ }^{74}$. Assim, na metanálise de Angevaren et al (Cochrane) os aa. destacam que em 8 de 11 estudos, o exercício aeróbico resultou em aumento na capacidade física (aproximadamente $14 \%$ no $\mathrm{VO}_{2}$ ) e tal melhoria coincidiu com incremento na capacidade cognitiva com efeitos na função motora, velocidade cognitiva, auditiva e atenção visual. Destaque-se aqui a preservação da microcirculação cerebral documentada por Colcombe et al, que também usaram fMRI, a preservação do volume cerebral especificadamente do hipocampo em indivíduos ativos fisicamente comparados com sedentários, e a maior densidade de capilares cerebrais em indivíduos $\operatorname{ativos}^{75}$.

Por outro lado, vários efeitos de polifenóis de VT, especialmente resveratrol, podem induzir proteção cerebral. Destacam-se ações antioxidantes, aumento da produção e biodisponibilidade do NO por estímulo da eNOS, ações anti-agregação plaquetária, ações anti-proliferativas em artérias, inibição de $P 53^{42,51}$, em interferência na formação fibrilar de substância amiloide $^{57}$, mecanismo este responsabilizado pela menor incidência da Doença de Alzheimer em consumidores de VT. De especial importância é o estímulo que o resveratrol tem sobre SIRT-1. Em animais de experimentação KO para SIRT-1 observa-se degeneração neuronal. Resveratrol reduz significativamente tal degeneração, melhorando capacidade locomotora e memória dos animais ${ }^{56}$. 
O aspecto inovador do presente trabalho é a tentativa de analisar se essas duas intervenções, simultaneamente, teriam efeitos aditivos. Em síntese, o exercício físico programado, em bebedores crônicos de VT, parece proteger funções cognitivas. Nossas conclusões não são definitivas pelos motivos assinalados acima. Mas são sugestivas de que tal efeito aditivo possa ocorrer. Talvez em estudos com maior número de pacientes, essas possibilidades possam ser melhor avaliadas.

Portanto, nosso estudo deve ser considerado como gerador de hipóteses que poderão ser melhor investigadas em pesquisas subsequentes. 


\section{Referências Bibliográficas}


1. Bezerra FC, Almeida MI De, Nóbrega-Therrien SM. Estudos sobre envelhecimento no Brasil: revisão bibliográfica. Rev Bras Geriatr e Gerontol. 2012;15:155-67.

2. Murman DL. The Impact of Age on Cognition. Semin Hear. Thieme Medical Publishers. 2015;36:111-21.

3. Prohaska TR, Peters KE. Physical activity and cognitive functioning: Translating research to practice with a public health approach. Alzheimer's Dement. Elsevier. 2007;3:S58-64.

4. Heloísa F, Santos D, Andrade VM, et al. Envelhecimento: um processo multifatorial. Psicologia em Estudo. 2009.

5. Hurd MD, Martorell P, Delavande A, et al. Monetary costs of dementia in the United States. N Engl J Med. 2013;368:1326-34.

6. World Health Organization. The top causes of death. http://who.int/mediacentre/factsheets/fs310/en/.

7. Nitrini R, Bottino CMC, Albala $\mathrm{C}$, et al. Prevalence of dementia in Latin America: a collaborative study of population-based cohorts. Int Psychogeriatrics. Cambridge University Press. 2009;21:622.

8. Glover $\mathrm{GH}$. Overview of Functional Magnetic Resonance Imaging. Neurosurg Clin N Am. NIH Public Access. 2011;22:133-9.

9. Langballe EM, Ask H, Holmen J, Stordal E, et al. Alcohol consumption and risk of dementia up to 27 years later in a large, population-based sample: the HUNT study, Norway. Eur J Epidemiol. 2015;30:1049-56.

10. Hofman A, Breteler MMB, van Duijn CM, et al. The Rotterdam Study: objectives and design update. Eur J Epidemiol. Springer. 2007;22:819_ 29. 
11. Aging TCS of $\mathrm{H}$ and. The Canadian Study of Health and Aging: risk factors for Alzheimer's disease in Canada. Neurology. Wolters Kluwer Health, Inc. on behalf of the American Academy of Neurology. 1994;44:2073-80.

12. Charchat-Fichman H, Caramelli P, Sameshima K, et al. Declínio da capacidade cognitiva durante o envelhecimento. Rev Bras Psiquiatr. Associação Brasileira de Psiquiatria (ABP). 2005;27:79-82.

13. Pereira Damasceno B. Envelhecimento cerebral o problema dos limites entre o normal e o patológico. Arq Neuropsiquiatr. 1999;57:78-83.

14. Craik FIM. Memory Changes in Nomal and Pathological Aging. Can J Psychiatry. 2008;53:343-6.

15. Kester ASBADCFIMCJD. The Handbook of Memory Disorders. In: Alan D. Baddeley; Michael D. Kopelman; Barbara A. Wilson, editor. The Handbook of Memory Disorders. 2002. p. 543-67.

16. Peters R. Ageing and the brain. Postgrad Med J. BMJ Publishing Group. 2006;82:84-8

17. Giannakopoulos P, Bourasil C, Hof PR. The neuropathological changes associated with normal brain aging. Histol Histopathol. 1996;1:1075-88.

18. Heilig CW, Knopman DS, Mastri AR, et al. Dementia without Alzheimer pathology. Neurology. Wolters Kluwer Health, Inc. on behalf of the American Academy of Neurology. 1985;35:762-5.

19. Moseley M. Diffusion tensor imaging and aging - a review. NMR Biomed. Wiley-Blackwell. 2002;15:553-60.

20. Warburton DER, Nicol CW, Bredin SSD. Health benefits of physical activity: the evidence. CMAJ. Canadian Medical Association. 
2006;174:801-9.

21. Gordon B, Wang Z, Luo X. Chronic disease and the link to physical activity. J Sport Heal Sci. Elsevier. 2013;2:3-11.

22. Morland C, Andersson KA, Haugen $\varnothing \mathrm{P}$, et al. Exercise induces cerebral VEGF and angiogenesis via the lactate receptor HCAR1. Nat Commun. Nature Publishing Group; 2017.8:15557.

23. Kujala UM. Benefits of exercise therapy for chronic diseases. Br J Sports Med. BMJ Publishing Group. 2006;40:3-4.

24. Soedamah-Muthu SS, De Neve M, Shelton NJ, et al. Joint Associations of Alcohol Consumption and Physical Activity With All-Cause and Cardiovascular Mortality. Am J Cardiol. 2013;112:380-6.

25. Barak Y, Aizenberg D. Is dementia preventable? Focus on Alzheimer's disease. Expert Rev Neurother. 2010;10:1689-98.

26. Booth FW, Roberts CK, Laye MJ. Lack of exercise is a major cause of chronic diseases. Compr Physiol. NIH Public Access. 2012;2:1143-211.

27. Kruk J. Physical activity in the prevention of the most frequent chronic diseases: an analysis of the recent evidence. Asian Pac J Cancer Prev. 2007; 8(3):325-38.

28. Lautenschlager NT, Cox K, Cyarto E V. The influence of exercise on brain aging and dementia. Biochim Biophys Acta - Mol Basis Dis. 2012;1822:474-81.

29. Rolland Y, Abellan van Kan G, Vellas B. Healthy Brain Aging: Role of Exercise and Physical Activity. Clin Geriatr Med. 2010;26:75-87.

30. Gammack JK. Physical Activity in Older Persons. Mo Med. $2017 ; 114(2): 105-9$. 
31. Ebrahimi K, Majdi A, Baghaiee B, et al. Physical activity and beta-amyloid pathology in Alzheimer's disease: A sound mind in a sound body. EXCLI J. Leibniz Research Centre for Working Environment and Human Factors. 2017;16:959-72.

32. Cotman CW, Berchtold NC, Christie L-A. Exercise builds brain health: key roles of growth factor cascades and inflammation. Trends Neurosci. Elsevier Current Trends. 2007;30:464-72.

33. Colcombe S, Kramer AF. Fitness effects on the cognitive function of older adults: A meta-analytic study. Psychol Sci. SAGE PublicationsSage CA: Los Angeles, CA. 2003;14(2):125-30.

34. Angevaren M, Aufdemkampe $\mathrm{G}$, Verhaar $\mathrm{H}$, et al. Physical activity and enhanced fitness to improve cognitive function in older people without known cognitive impairment. In: Angevaren M, editor. Cochrane Database of Systematic Reviews. Chichester, UK: John Wiley \& Sons, Ltd; 2008.

35. O'keefe JH, Bybee KA, Lavie CJ. Alcohol and Cardiovascular Helath: the razor-sharp double-edged sword. J Am Coll Cardiol. 2007;50(11): 100914.

36. Opie LH, Lecour S. The red wine hypothesis: from concepts to protective signalling molecules. Eur Heart J. 2007;28:1683-93.

37. Knott CS, Coombs N, Stamatakis E, et al. All cause mortality and the case for age specific alcohol consumption guidelines: pooled analyses of up to 10 population based cohorts. BMJ. British Medical Journal Publishing Group. 2015;350:h384.

38. Rostron B. Alcohol Consumption and Mortality Risks in the USA. Alcohol Alcohol. 2012;47:334-9. 
39. Ronksley PE, Brien SE, Turner BJ, et al. Association of alcohol consumption with selected cardiovascular disease outcomes: a systematic review and meta-analysis. BMJ. British Medical Journal Publishing Group. 2011;342:1-13.

40. da Luz PL, Serrano C V, Chacra AP, et al. The effect of red wine on experimental atherosclerosis:lipid-independent protection. Exp Mol Pathol. Academic Press. 1999;65:150-9.

41. Coimbra SR, Lage SH, Brandizzi L, et al. The action of red wine and purple grape juice on vascular reactivity is independent of plasma lipids in hypercholesterolemic patients. Braz J Med Biol Res Brazilian J Med Biol Res. 2005;38:1339-47.

42. da Luz PL, Tanaka L, Brum PC, et al. Red wine and equivalent oral pharmacological doses of resveratrol delay vascular aging but do not extend life span in rats. Atherosclerosis. Elsevier 2016;224:136-42.

43. da Luz PL, Coimbra S, Favarato D, et al. Coronary artery plaque burden and calcium scores in healthy men adhering to long-term wine drinking or alcohol abstinence. Brazilian J Med Biol Res. 2014;47:697-705.

44. da Luz PL, Favarato D, Moriguchi EH, et al. Red wine, coronary calcification and long term clinical evolution. Brazilian J Med Biol Res. 2018;

45. da Luz PL, Fialdini RC, Nishiyama M. Red Wine, Resveratrol, and Vascular Aging: Implications for Dementia and Cognitive Decline. In: Diet and Nutrition in Dementia and Cognitive Decline. Elsevier; 2014. p. 94353.

46. Matsumoto C, Miedema MD, Ofman P, et al. An Expanding Knowledge of 
the Mechanisms and Effects of Alcohol Consumption on Cardiovascular Disease. J Cardiopulm Rehabil Prev. 2014;34:159-71.

47. Andrade AC, Cesena FH, Consolim-Colombo FM, et al. Short-term red wine consumption promotes differential effects on plasma levels of highdensity lipoprotein cholesterol, sympathetic activity, and endothelial function in hypercholesterolemic, hypertensive, and healthy subjects. Clinics. 2009;64:435-77.

48. Chiva-Blanch G, Arranz S, Lamuela-Raventos RM, et al. Effects of Wine, Alcohol and Polyphenols on Cardiovascular Disease Risk Factors: Evidences from Human Studies. Alcohol Alcohol. 2013; 48(3):270-7.

49. Sarr M, Chataigneau M, Martins S, et al. Red wine polyphenols prevent angiotensin II-induced hypertension and endothelial dysfunction in rats: Role of NADPH oxidase. Cardiovasc Res. 2006;71:794-802.

50. PL da Luz; Favarato, Desidério; Berwanger O. Ação do vinho tinto e Polifenóis sobre a Função Endotelial e Eventos Clínicos In: Endotélio e doenças cardiovasculares: biologia vascular e síndromes clínicas. Atheneu. 2016.

51. Guarente L. Sirtuins, Aging, and Medicine. N Engl J Med. 2011;364:2235-44.

52. Corder R, Douthwaite JA, Lees DM, et al. Endothelin-1 synthesis reduced by red wine. Nature. Nature Publishing Group; 2001;414:863-4.

53. Wallerath $\mathrm{T}$, Poleo $\mathrm{D}$, $\mathrm{Li} \mathrm{H}$, et al. Red wine increases the expression of human endothelial nitric oxide synthase: a mechanism that may contribute to its beneficial cardiovascular effects. J Am Coll Cardiol. 2003;41:471-8. 
54. Wallerath $\mathrm{T}$, Deckert $\mathrm{G}$, Ternes $\mathrm{T}$, et al. Resveratrol, a polyphenolic phytoalexin present in red wine, enhances expression and activity of endothelial nitric oxide synthase. Circulation. 2002;106:1652-8.

55. Spanier $\mathrm{G}, \mathrm{Xu} \mathrm{H}, \mathrm{Xia} \mathrm{N}$, et al. Resveratrol reduces endothelial oxidative stress by modulating the gene expression of superoxide dismutase 1 (SOD1), glutathione peroxidase 1 (GPx1) and NADPH oxidase subunit (Nox4). J Physiol Pharmacol. 2009;60 Suppl 4:111-6.

56. Gao J, Wang W-Y, Mao Y-W, et al. A novel pathway regulates memory and plasticity via SIRT1 and miR-134. Nature. Nature Publishing Group; 2010;466:1105-9.

57. Ladiwala ARA, Lin JC, Bale SS, et al. Resveratrol Selectively Remodels Soluble Oligomers and Fibrils of Amyloid $A \beta$ into Off-pathway Conformers. J Biol Chem. 2010;285:24228-37.

58. Fahadan PT GR. Heart-Brain Axis: Effects of Neurologic Injury on Cardiovascular Function. Circ Res. 2017; 120(3):559-572.

59. Wheeler MJ, Dempsey PC, Grace MS, et al. Sedentary behavior as a risk factor for cognitive decline? A focus on the influence of glycemic control in brain health. Alzheimer's Dement (New York, N Y). Elsevier 2017;3:291300.

60. Hajduk AM, Chaudhry SI. Sedentary Behavior and Cardiovascular Risk in Older Adults: a Scoping Review. Curr Cardiovasc Risk Rep.2016;10(1).

61. Samuels MA. The brain-heart connection. Circulation 2007; 116:77-84.

62. Meneghelo RS. III Diretrizes da Sociedade Brasileira de Cardiologia sobre Teste Ergométrico. Arq Bras Cardiol. 2010.

63. Wilson BA, Cockburn J, Baddeley AD. The Rivermead Behavioural 
Memory Test. Bury St. Edmunds, UK.: Thames Valley Test Corporation; 1985.

64. Rabin L, Barr W, Burton L. Assessment practices of clinical neuropsychologists in the United States and Canada: A survey of INS, NAN, and APA Division 40 members. Arch Clin Neuropsychol. 2005;20:33-65.

65. Rey A. Teste de cópia e de reprodução de memória de figuras geométricas complexas: Manual. São Paulo: Casa do Psicólogo; 1999.

66. Stroop JR. Studies of interference in serial verbal reactions. J Exp Psychol. 1935;18:643-62.

67. Carter CS, Mintun M, Cohen JD. Interference and Facilitation Effects during Selective Attention: An H215O PET Study of Stroop Task Performance. Neuroimage. Academic Press; 1995;2:264-72.

68. Mumford JA, Nichols TE. Power calculation for group fMRI studies accounting for arbitrary design and temporal autocorrelation. Neuroimage. 2008;39:261-8

69. Sunderland T, Hill JL, Mellow AM, et al. Clock drawing in Alzheimer's disease. A novel measure of dementia severity. J Am Geriatr Soc. $1989 ; 37: 725-9$.

70. Laird AR, McMillan KM, Lancaster JL, et al. A comparison of label-based review and ALE meta-analysis in the Stroop task. Hum Brain Mapp. 2005;25:6-21.

71. Owen AM, McMillan KM, Laird AR, et al. N-back working memory paradigm: A meta-analysis of normative functional neuroimaging studies. Hum Brain Mapp. 2005;25:46-59. 
72. Querido JS, Sheel AW. Regulation of Cerebral Blood Flow During Exercise. Sport Med. 2007;37:765-82.

73. Colcombe SJ, Erickson KI, Scalf PE, et al. Aerobic exercise training increases brain volume in aging humans. J Gerontol A Biol Sci Med Sci. 2006;61:1166-70.

74. Vogel T, Brechat P-H, Leprêtre P-M, et al. Health benefits of physical activity in older patients: a review. Int J Clin Pract. 2009;63:303-20.

75. Colcombe SJ, Erickson KI, Raz N, et al. Aerobic fitness reduces brain tissue loss in aging humans. J Gerontol A Biol Sci Med Sci. 2003;58:17680. 


\section{Apêndices}


Apêndice A- TERMO DE CONSENTIMENTO LIVRE E ESCLARECIDO

\section{Hospital das Clínicas da Faculdade de Medicina da Universidade de São Paulo- HCFMUSP \\ TERMO DE CONSENTIMENTO LIVRE E ESCLARECIDO}

\section{DADOS DE IDENTIFICAÇÃO DO SUJEITO DA PESQUISA OU RESPONSÁVEL LEGAL}

1. NOME:

DOCUMENTO DE IDENTIDADE № :

SEXO :.$M \square \quad F$

DATA NASCIMENTO: ........................

ENDEREÇO №

APTO:

BAIRRO:

CIDADE

CEP:.

TELEFONE: DDD

..)

2.RESPONSÁVEL LEGAL

NATUREZA (grau de parentesco, tutor, curador etc.)

DOCUMENTO DE IDENTIDADE :

SEXO: $M \square \quad F \square$

DATA NASCIMENTO.: .....................

ENDEREÇO:

BAIRRO:

№

CIDADE:

APTO:

CEP:

TELEFONE: DDD

..).

\section{DADOS SOBRE A PESQUISA}

\section{TÍTULO DO PROTOCOLO DE PESQUISA}

Estudo de Índices de Envelhecimento e Prevalência de Aterosclerose em Bebedores de Vinho Habituais vs. Abstêmios; subestudo efeitos do treinamento físico e ingestão de vinho tinto na função cognitiva de indivíduos sadios.

PESQUISADOR: Prof. Dr. Protásio Lemos da Luz

CARGO/FUNÇÃO: Pesquisador Senior do InCor

INSCRIÇÃO CONSELHO REGIONAL № 12811

UNIDADE DO HCFMUSP: Unidade Clínica de Aterosclerose InCor

3. AVALIAÇÃO DO RISCO DA PESQUISA:

$\begin{array}{lll}\text { RISCO MÍNIMO } & X & \text { RISCO MÉDIO } \\ \text { RISCO BAIXO } & \square & \text { RISCO MAIOR }\end{array}$

4. DURAÇÃO DA PESQUISA: 2 anos 


\section{1 - Desenho do estudo e objetivo(s) "essas informações estão sendo fornecidas para sua participação voluntária neste estudo, que visa..."; ou "o objetivo deste estudo é...";}

A idade avançada é um dos mais importantes fatores de risco para o coração. Por outro lado, a nossa população está envelhecendo; a adoção de estilo de vida sadio é uma alternativa muito atraente: é barato e portanto pode ser adotado por pobres e ricos, sem contraindicações. A alimentação representa um aspecto essencial no estilo de vida. O consumo de vinho tinto é um hábito em algumas comunidades, especialmente entre espanhóis, italianos, franceses e portugueses. Membros de confrarias em nosso meio representam um grupo especial, pelo uso sistemático e moderado do vinho; para a maioria destas pessoas consumir vinho é um hábito agradável, não necessariamente um tratamento. Supostamente, porém, o vinho tinto confere proteção contra enfermidades cardiovasculares e mesmo não cardíacas; se o consumo de vinho é de fato protetor é ainda uma questão em aberto, pois as pessoas que tomam vinho regularmente fazem mais exercício físico, se preocupam mais com a dieta, e também os componentes genéticos poderiam explicar os efeitos benéficos do vinho.

\section{2 - Descrição dos procedimentos que serão realizados, com seus propósitos e identificação dos que} forem experimentais e não rotineiros;

Serão realizados exames laboratoriais e de índices de envelhecimento (no sangue), teste cardiopulmonar, treinamento físico supervisionado, ressonância magnética funcional cerebral e avaliação neuropsicológica.

\section{3 - Relação dos procedimentos rotineiros e como são realizados - coleta de sangue por punção periférica da veia do antebraço; exames radiológicos;}

No exame de sangue somente será sentida a picada para coleta. O teste cardiopulmonar será realizado em um cicloergômetro, onde as pessoas irão realizar esforço progressivo até a exaustão, seguindo protocolo de rampa. A ressonância magnética funcional cerebral será feita com técnicas de alta resolução e protocolo de alto contraste anatômico em um sistema de ressonância magnética 3.0 T(Achieva- Philip), bobina de 8 canais.

\section{4 - Descrição dos desconfortos e riscos esperados nos procedimentos dos itens 2 e 3;}

No exame de sangue somente será sentida a picada para coleta. O teste cardiopulmonar é um exame que leva a pessoa até próximo à exaustão, esta permanecendo monitorizada durante todo o exame, apresentando baixo risco de eventos graves (arritmias cardíacas, infarto, angina). A ressonância magnética funcional cerebral não utilizará contraste e terá duração de 38 minutos.

5 - Benefícios para o participante (Por exemplo: Não há benefício direto para o participante... Tratase de estudo experimental testando a hipótese de que... Somente no final do estudo poderemos concluir a presença de algum benefício...; 
O presente estudo oferece a oportunidade ímpar de elucidar se essa proteção tem bases sólidas ou não, com base na análise de dados objetivos, como os índices de envelhecimento celular, consumo de oxigênio (teste cardiopulmonar) e avaliação cognitiva (avaliação neuropsicológica e ressonância magnética cerebral funcional). Poderemos com este projeto compreendermos o verdadeiro papel do vinho tinto na saúde humana. Acrescente-se a isso, que se o estudo comprovar os benefícios do vinho, isso terá considerável implicação econômica.

6 - Relação de procedimentos alternativos que possam ser vantajosos, pelos quais o paciente pode optar;

Poderemos não proibir em doses moderadas o consumo de vinho tinto.

7 - Garantia de acesso: em qualquer etapa do estudo, você terá acesso aos profissionais responsáveis pela pesquisa para esclarecimento de eventuais dúvidas. O principal investigador é o Dr. Protásio Lemos da Luz, que pode ser encontrado no endereço Av. Dr. Eneas de Carvalho Aguiar, 44 bloco 2 - 5 andar sala 8 Telefone(s) (11) 2661-5952. Se você tiver alguma consideração ou dúvida sobre a ética da pesquisa, entre em contato com o Comitê de Ética em Pesquisa (CEP) - Rua Ovídio Pires de Campos, 225 - 5o andar - tel: 2661-6442 ramais 16, 17, 18 ou 20, FAX: 2661-6442 ramal 26 - E-mail: cappesq@hcnet.usp.br 8 - É garantida a liberdade da retirada de consentimento a qualquer momento e deixar de participar do estudo, sem qualquer prejuízo à continuidade de seu tratamento na Instituição;

09 - Direito de confidencialidade - As informações obtidas serão analisadas em conjunto com outros pacientes, não sendo divulgado a identificação de nenhum paciente;

10 - Direito de ser mantido atualizado sobre os resultados parciais das pesquisas, quando em estudos abertos, ou de resultados que sejam do conhecimento dos pesquisadores; 11 - Despesas e compensações: não há despesas pessoais para o participante em qualquer fase do estudo, incluindo exames e consultas. Também não há compensação financeira relacionada à sua participação. Se existir qualquer despesa adicional, ela será absorvida pelo orçamento da pesquisa. 12 - Compromisso do pesquisador de utilizar os dados e o material coletado somente para esta pesquisa."Acredito ter sido suficientemente informado a respeito das informações que li ou que foram idas para mim, descrevendo o estudo "Efeitos do treinamento físico e ingestão de vinho tinto na função cognitiva de indivíduos sadios”.

Eu discuti com o Dr. Protásio Lemos da Luz sobre a minha decisão em participar nesse estudo. Ficaram claros para mim quais são os propósitos do estudo, os procedimentos a serem realizados, seus desconfortos e riscos, as garantias de confidencialidade e de esclarecimentos permanentes. Ficou claro também que minha participação é isenta de despesas e que tenho garantia do acesso a 
tratamento hospitalar quando necessário. Concordo voluntariamente em participar deste estudo e poderei retirar o meu consentimento a qualquer momento, antes ou durante o mesmo, sem penalidades ou prejuízo ou perda de qualquer benefício que eu possa ter adquirido, ou no meu atendimento neste Serviço.

Assinatura do paciente/representante legal Data

Assinatura da testemunha

Data

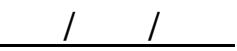

Para casos de pacientes menores de 18 anos, analfabetos, semi-analfabetos ou portadores de deficiência auditiva ou visual.

\section{(Somente para o responsável do projeto)}

Declaro que obtive de forma apropriada e voluntária o Consentimento Livre e Esclarecido deste paciente ou representante legal para a participação neste estudo.

Data 1 


\title{
Apêndice B- PERGUNTAS SOBRE INGESTÃO DE BEBIDA ALCOÓLICA
}

\author{
CÓDIGO DO PRIMEIRO EXAME:
}

DATA DO PRIMEIRO EXAME:

TREINAMENTO FÍSICO: ( )SIM ( )NÃO

CÓDIGO DO SEGUNDO EXAME:

DATA DO SEGUNDO EXAME:

Dose padrão pela OMS: 10 a 12 gramas de etanol/dia

1 taça é aproximadamente $100 \mathrm{ml}$ e equivale a $12 \mathrm{~g}$ de etanol na forma de vinho tinto ou espumante;

1 lata é aproximadamente $330 \mathrm{ml}$ e equivale a $12 \mathrm{~g}$ de etanol na forma de cerveja; 1 dose de destilado é aproximadamente $30 \mathrm{ml}$ e equivale a $12 \mathrm{~g}$ de etanol na forma dessa bebida

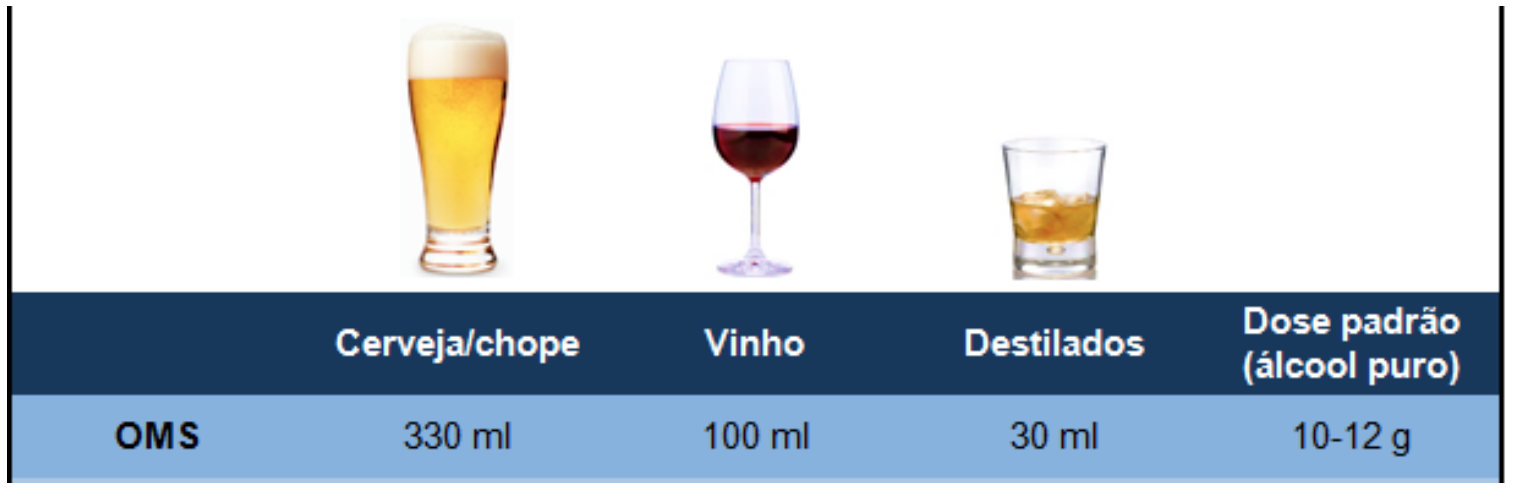

1)Há quanto tempo o senhor ingere vinho tinto? anos

2)Qual(is) o(s) tipo(s) de vinho tinto (espécie de uva) o senhor tomou nos ÚLTIMOS 5 ANOS DA DATA DA PRIMEIRA AVALIAÇÃO?

-Primeiro ano* (20_):

-Segundo ano (20_):

-Terceiro ano (20__):

-Quarto ano (20_):

-Quinto ano (20_):

*Primeiro ano = ano da realização da primeira avaliação; Segundo ano = ano anterior ao ano da primeira avaliação e assim sucessivamente. 
3)Qual a estimativa da dose diária média de consumo de vinho tintocontando

TODOS OS ANOS DESDE QUE O SENHOR COMEÇOU A CONSUMIR ESSA BEBIDA? (taças/dia)

\begin{tabular}{ll}
\hline TAÇAS/DIA & $\begin{array}{c}\text { CONSUMO } \\
\text { MÉDIO* }\end{array}$ \\
\hline Até 2 taças de & \\
vinho tinto/dia & \\
Mais de 2 taças \\
de vinho \\
tinto/dia \\
Qual a dose \\
aproximada \\
(taças/dia) \\
\hline
\end{tabular}

* preencher com " $X$ " na linha condizente, bem como informar a dose diária aproximada na última linha.

4)Consumindo essa dose referida na questão anterior, o senhor deixa de realizar adequadamente algumas das seguintes atividades:

( ) atividades realizadas nasua profissão

( ) atividades intelectuais

( ) atividades domésticas normalmente realizadas

( ) interação com amigos e familiares (por ficar mais agressivo ou emotivo)

5)Qual a dose diária que o senhor consumiu de vinho tinto nos ÚLTIMOS 5 ANOS DA DATA DA PRIMEIRA AVALIAÇÃO?

\begin{tabular}{|c|c|c|c|c|c|}
\hline TAÇAS/DIA & $1^{\circ}$ ano $(20)$ & $2^{\circ}$ ano $(20)$ & $3^{\circ}$ ano $(20)$ & $4^{\circ}$ ano $(20)$ & $5^{\circ}$ ano $(20)$ \\
\hline Segunda-feira & taças & taças & taças & taças & taças \\
\hline Terça-feira & taças & taças & taças & taças & taças \\
\hline Quarta-feira & taças & taças & taças & taças & taças \\
\hline Quinta-feira & taças & taças & taças & taças & taças \\
\hline Sexta-feira & taças & taças & taças & taças & taças \\
\hline Sábado & taças & taças & taças & taças & taças \\
\hline Domingo & taças & taças & taças & taças & taças \\
\hline $\begin{array}{l}\text { Dose diária } \\
\text { média }\end{array}$ & taças & taças & taças & taças & taças \\
\hline
\end{tabular}

5.A)Qual dose máxima diária o senhor chegou a consumir de vinho tinto? (taças/dia). Por quanto tempo?

5.B)Qual a dose mínima diária o senhor chegou a consumir de vinho tinto?(taças/dia). Por quanto tempo?

5.C)Está progressivamente aumentando a dose de consumo diário de vinho tinto nos ÚLTIMOS 5 ANOS DA DATA DA PRIMEIRA AVALIAÇÃO?

Se sim, qual o motivo? 
5.D)Está progressivamente reduzindo a dose de consumo diário de vinho tinto nosÚLTIMOS 5 ANOS DA DATA DA PRIMEIRA AVALIAÇÃO?

? Se sim, qual o motivo?

5.D)A dose de consumo diário de vinho tinto está estável nos ÚLTIMOS 5 ANOS DA DATA DA PRIMEIRA AVALIAÇÃO?

6)Nos ÚlTIMOS 5 ANOS DA DATA DA PRIMEIRA AVALIAÇÃO, o senhor consumiu outro tipo de bebida alcoólica além do vinho tinto? (SIM ou NÃO)

( ) CERVEJA - (dose em latas/SEMANA)

\begin{tabular}{lccccr}
\hline LATAS/SEMANA & $\mathbf{1 0}^{\circ}$ ano $(\mathbf{2 0})$ & $\mathbf{2}^{\circ}$ ano $\left.\mathbf{2 0}\right)$ & $\mathbf{3}^{\circ}$ ano $(\mathbf{2 0})$ & $\mathbf{4}^{\circ}$ ano $(\mathbf{2 0})$ & $\mathbf{5}^{\circ}$ ano $(\mathbf{2 0})$ \\
\hline $\begin{array}{l}\text { Até } \mathbf{1 4} \text { latas de } \\
\text { cerveja/semana }\end{array}$ & latas & latas & latas & latas & latas \\
$\begin{array}{l}\text { Até } \mathbf{1 4} \text { latas de } \\
\text { cerveja/semana }\end{array}$ & latas & latas & latas & latas & latas \\
$\begin{array}{l}\text { Qual a dose } \\
\begin{array}{l}\text { aproximada? } \\
\text { (latas/semana) }\end{array}\end{array}$ & latas & latas & latas & latas & latas \\
\hline
\end{tabular}

( )ESPUMANTE - (dose em taças/SEMANA)

\begin{tabular}{|c|c|c|c|c|c|}
\hline TAÇAS/SEMANA & 10 ano $(20)$ & $2^{\circ}$ ano $(20$ ) & $3^{\circ}$ ano $(20)$ & $4^{\circ}$ ano $(20)$ & $55^{\circ}$ ano (20) \\
\hline $\begin{array}{l}\text { Até 14 } \\
\text { taças/semana }\end{array}$ & taças & taças & taças & taças & $\overline{\text { taças }}$ \\
\hline $\begin{array}{l}\text { Até } 14 \\
\text { taças/semana }\end{array}$ & taças & taças & taças & taças & taças \\
\hline $\begin{array}{l}\text { Qual a dose } \\
\text { aproximada? } \\
\text { (ltacas/semana) }\end{array}$ & taças & taças & taças & taças & taças \\
\hline
\end{tabular}

VINHO BRANCO - (dose em taças/SEMANA)

\begin{tabular}{|c|c|c|c|c|c|}
\hline TAÇAS/SEMANA & $1^{\circ}$ ano (20) & $2^{\circ}$ ano $(20)$ & $3^{\circ}$ ano $(20)$ & $4^{\circ}$ ano $(20)$ & $5^{\circ}$ ano $(20)$ \\
\hline $\begin{array}{l}\text { Até } 14 \\
\text { taças/semana }\end{array}$ & taças & taças & taças & taças & taças \\
\hline $\begin{array}{l}\text { Até } 14 \\
\text { taças/semana }\end{array}$ & taças & taças & taças & taças & taças \\
\hline $\begin{array}{l}\text { Qual a dose } \\
\text { aproximada? } \\
\text { (Itaças/semana) }\end{array}$ & taças & taças & taças & taças & taças \\
\hline
\end{tabular}

( )WHISKY, PINGA, VODKA, LICOR -medida (dose de destilado/SEMANA) 


\begin{tabular}{lrrrrr}
\hline DOSES/SEMANA & $\mathbf{1}^{\circ}$ ano $(\mathbf{2 0})$ & $\mathbf{2}^{\circ}$ ano $(\mathbf{2 0})$ & $\mathbf{3}^{\circ}$ ano $(\mathbf{2 0})$ & $\mathbf{4}^{\circ}$ ano $(\mathbf{2 0})$ & $\mathbf{5}^{\circ}$ ano $(\mathbf{2 0})$ \\
\hline $\begin{array}{l}\text { Até } \mathbf{1 4} \\
\text { doses/semana }\end{array}$ & doses & doses & doses & doses & doses \\
$\begin{array}{l}\text { Até } \mathbf{1 4} \\
\text { doses/semana }\end{array}$ & doses & doses & doses & doses & doses \\
$\begin{array}{l}\text { Qual a dose } \\
\begin{array}{l}\text { aproximada? } \\
\text { (doses/semana) }\end{array}\end{array}$ & doses & doses & doses & doses & doses \\
\hline
\end{tabular}

7)NosÚlTIMOS 5 ANOS DA DATA DA PRIMEIRA AVALIAÇÃo, o senhor apresentouintoxicação alcoólica aguda ("ficou bêbado")? Quantas vezes isso aconteceu?

-Primeiro ano (20_):

-Segundo ano (20_):

-Terceiro ano (20__):

-Quarto ano (20_):

-Quinto ano (20_):

8)0 senhor tem o teve algum problema de saúde, familiar ou profissional relacionado ao seu hábito de consumir vinho tinto ou outra bebida alcoólica nos ÚLTIMOS 5 ANOS DA DATA DA PRIMEIRA AVALIAÇÃO? Qual(ais)?

-Primeiro ano (20_):

-Segundo ano (20_):

-Terceiro ano (20__):

-Quarto ano (20_):

-Quinto ano (20_):

9)0 senhor tem dificuldade em ficar sem consumir vinho tinto ou outra bebida alcoólica?

10)Caso fique sem consumir bebida alcoólica por mais de 2 dias, o senhor apresenta uma necessidade intensa para consumir esse tipo de bebida?

11) Caso fique sem consumir bebida alcoólica por mais de 2 dias, o senhor apresenta inquietação atípica com aumento dos batimentos do coração ou sudorese excessiva?

12)0 senhor se sente dependente da bebida alcoólica? 


\section{Apêndice C- FICHA CLÍNICA}

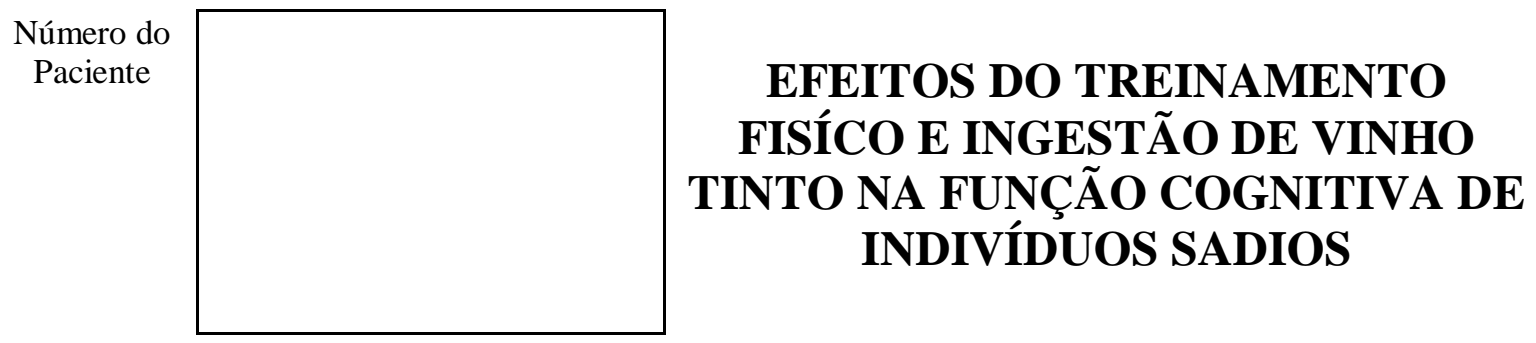

Nome do Investigador:

Data da Inclusão do paciente no estudo:

l 1

Horário:

\section{IDENTIFICAÇÃO DO PACIENTE:}

Sobrenome:

Nome:

Data Nasc. Idade: Sexo:

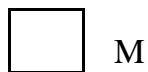
$\mathrm{F}$

Raça:

Religião:

Profissão:

Estado Civil:

Natural:

Procedência:

Endereço (Rua, $\mathrm{n}^{\mathrm{o}}$ ):

Cidade: Cep:

Telefone:

Escolaridade: anos completos) Renda Familiar:

Vinho Tinto:

Consumo médio/dia:

Tempo de Consumo:

Bebidas alcóolicas:

Quais:

Quantidade consumida/dia: 


\section{QUADRO CLÍNICO}

\section{FATORES DE RISCO:}

- Hipertensão
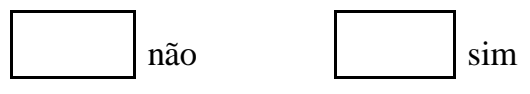

- Diabetes mellitus
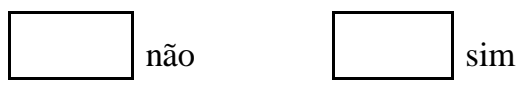

- Tabagismo
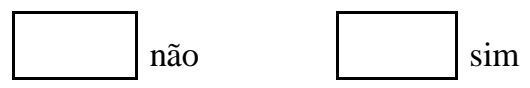

- Hipercolesterolemia
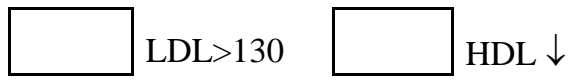

- Hipertrigliceridemia
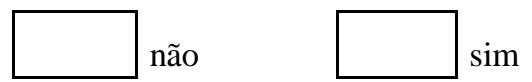

- História Familiar
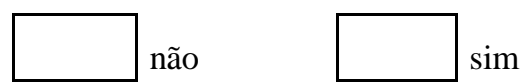

- Atividade física

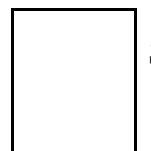

Sedent. Frequência: duração: tipo:

- Depressão
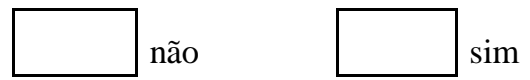

- Doença aterosclerótica conhecida:

- Historia de Fobia:

- Uso de lente corretiva:

- Outros:

\section{ANAMNESE:}

- Angina
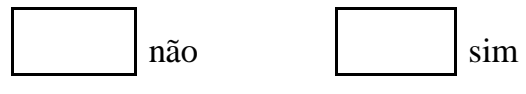

- Dispnéia
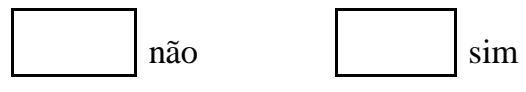

- Palpitações
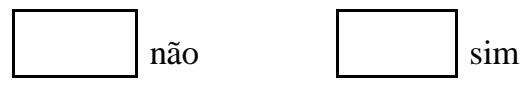

- Edema
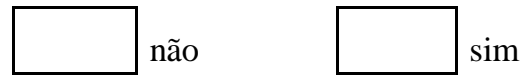

- Claudicações:

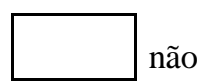
$\operatorname{sim}$

- Outros:

\section{MEDICAÇÃO EM USO:}


V. EXAME FÍSICO:

Peso:

Altura:

IMC:

Circunf. Abdominal

Circunf. Pélvica

Relação quadril/cintura:

Pulmões:

Coração:

Pulsos:

Carótidas:

Abdomen:

Edema:

$\mathrm{FC}$ :

PAS:

PAD:

Dados relevantes do exame clínico: 


\section{Apêndice D- AVALIAÇÃO DE ANOS DE ESCOLARIDADE}

Perguntas:

1. Quantos anos o senhor frequentou FORMALMENTE (matrícula formal) a escola?

- ensino fundamental: anos

- ensino médio: anos

- total: anos

2. O senhor frequentou a escola na rede pública ou privada (particular)? Quantos anos em cada?

- rede pública:___ anos

- rede privada (particular): anos

3. O senhor fez supletivo? Quanto tempo?

- para ensino fundamental (colocar o tempo):

- para ensino médio (colocar o tempo):

- para ensinos fundamental e médio (colocar o tempo):

4. O senhor fez faculdade?

- Curso (s):

- Universidade/Faculdade:

- Tempo de estudo:

5. O senhor fez pós-graduação:

- Mestrado (área/tempo):

- Doutorado (área/tempo):

- Pós-doutorado (área/tempo): 
Apêndice E- PROTOCOLO DA AVALIAÇÃO NEUROPSICOLÓGICA

\begin{tabular}{|c|c|c|c|c|}
\hline \multirow{6}{*}{ 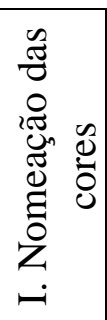 } & Verde & Rosa & Azul & Marrom \\
\hline & Rosa & Marrom & Verde & Azul \\
\hline & Azul & Verde & Rosa & Marrom \\
\hline & Marrom & Rosa & Azul & Verde \\
\hline & Rosa & Azul & Verde & Marrom \\
\hline & Marrom & Verde & Azul & Rosa \\
\hline
\end{tabular}

\begin{tabular}{|c|c|c|c|c|}
\hline \multirow{6}{*}{ 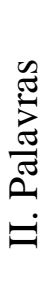 } & Verde & Rosa & Azul & Marrom \\
\hline & Rosa & Marrom & Verde & Azul \\
\hline & Azul & Verde & Rosa & Marrom \\
\hline & Marrom & Rosa & Azul & Verde \\
\hline & Rosa & Azul & Verde & Marrom \\
\hline & Marrom & Verde & Azul & Rosa \\
\hline
\end{tabular}

\begin{tabular}{|c|c|c|c|c|}
\hline \multirow{4}{*}{$\circlearrowright$} & Verde & Rosa & Azul & Marrom \\
\cline { 2 - 5 } & Rosa & Marrom & Verde & Azul \\
\cline { 2 - 5 } & Azul & Verde & Rosa & Marrom \\
\cline { 2 - 5 } & Marrom & Rosa & Azul & Verde \\
\cline { 2 - 5 } & Rosa & Azul & Verde & Marrom \\
\cline { 2 - 5 } & Marrom & Verde & Azul & Rosa \\
\hline
\end{tabular}

\section{STROOP}

Seg $=$

Erros =

Seg $=$

Erros =

Seg $=$

Erros = 
TESTE DE TRILHAS (TMT-A)

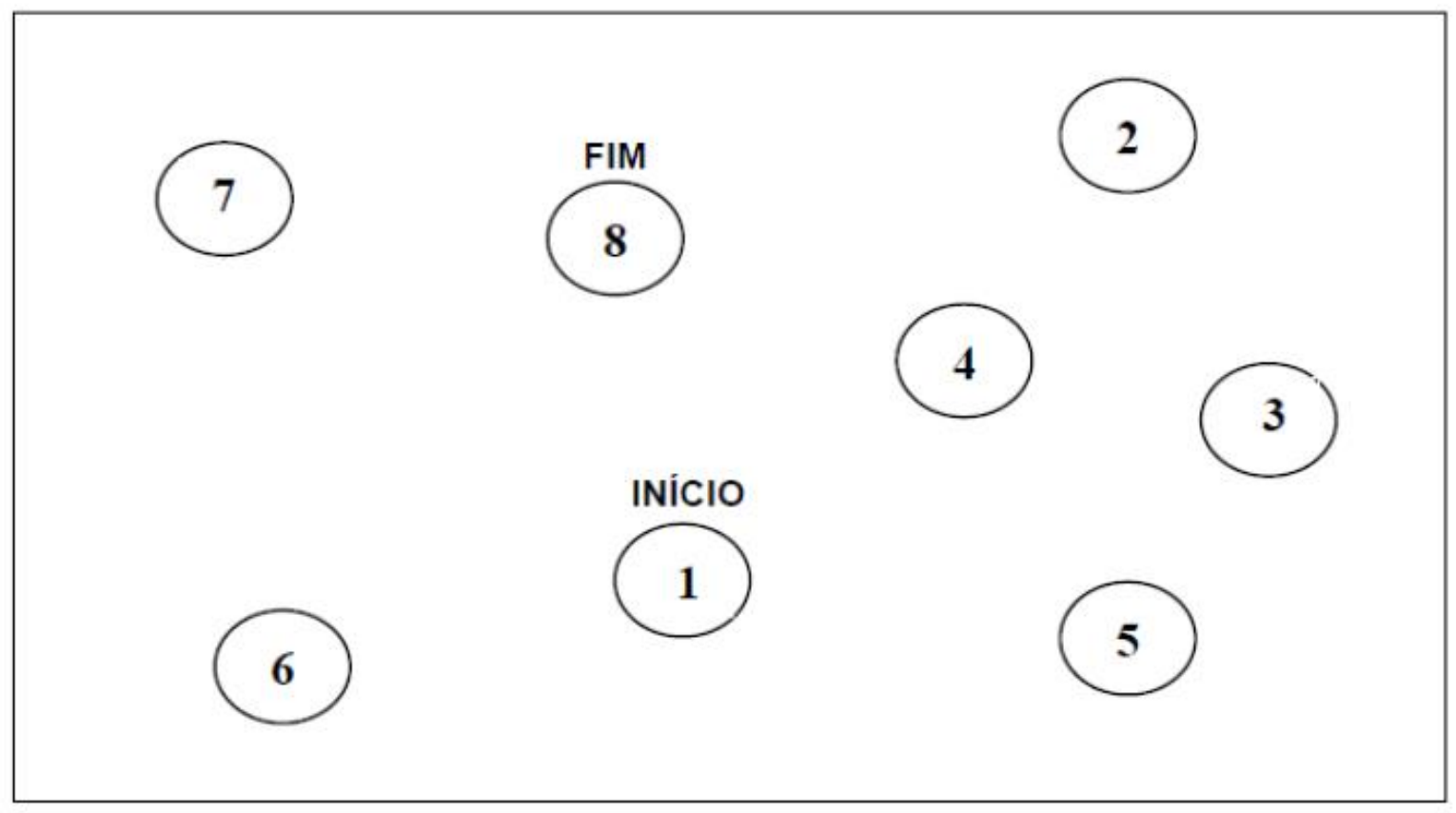

TESTE DE TRILHAS (TMT-B)

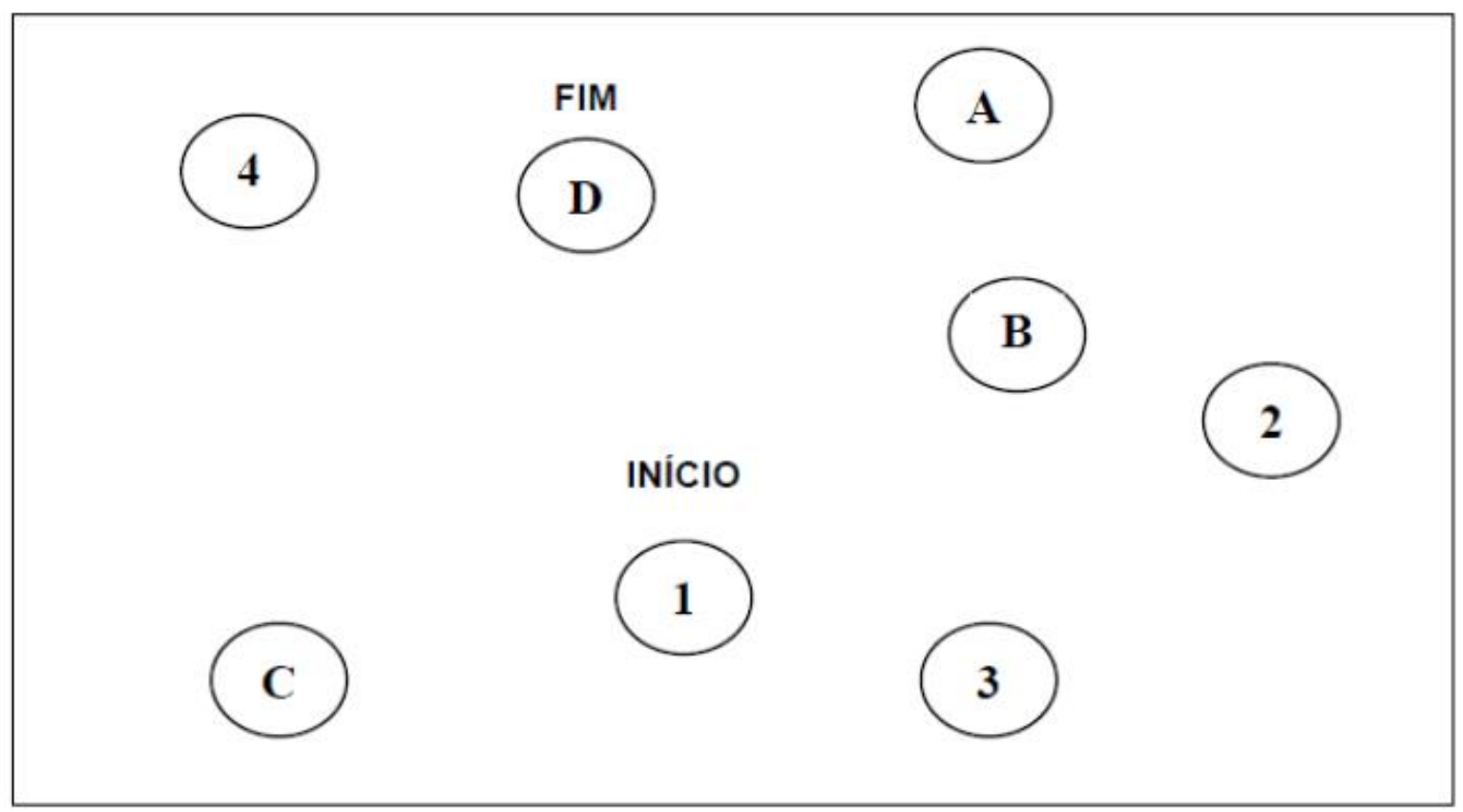




\section{5}

\section{7}

21

20

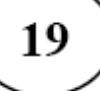

16

18

(4)

22

\section{5}

13

(6)

7

INícIO

(1)

3

\section{2}

8

10

FIM

25

11 
FIM

13
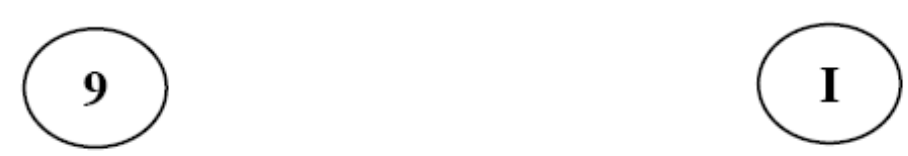

10
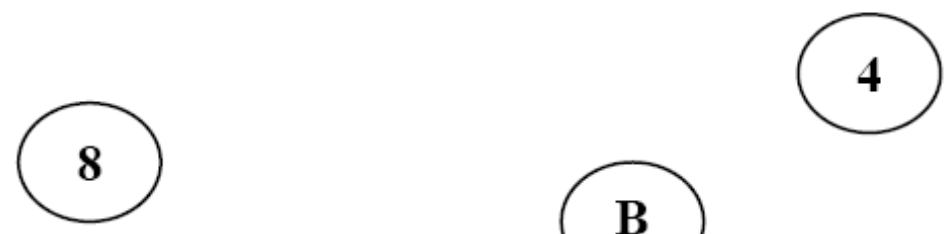

(B)
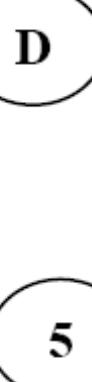

7

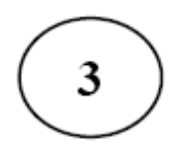

(H)

INICIO

(1)

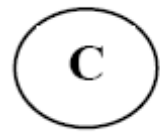

12

G

(M)

(A)

2

6

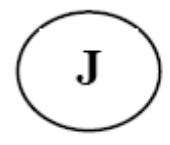

(F)

E

L 


\section{RBMT}

\section{Teste comportamental de memória de Rivermead}

Guia de procedimento e folha de registro Versão A

- Esta folha de registro fornece um sumário do procedimento para assegurar que o teste seja feito consistentemente na orden correla

- Por favor. siga as instruções no manual para a orientação detalhada do procedimento e pontuação.
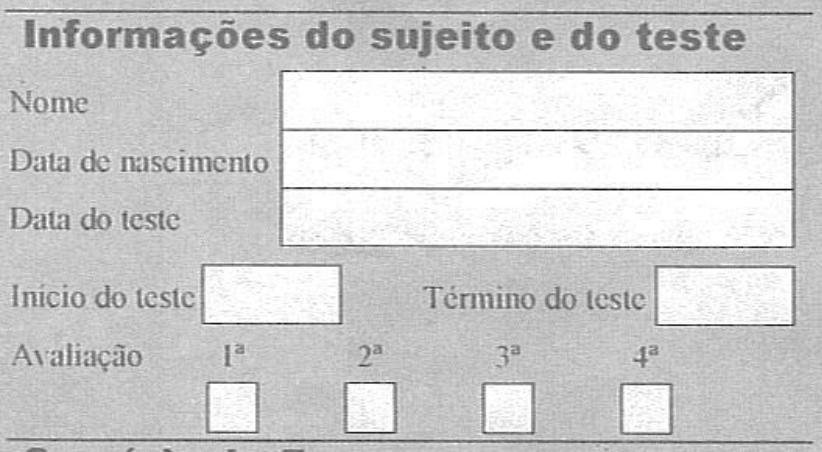

\section{Sumário de Escores}

Escore de Perfil Escore de Padronizado Triagem $(2,1$ ou 0$) \quad(1$ ou 0$)$

1 Nome

2 Sobrenome
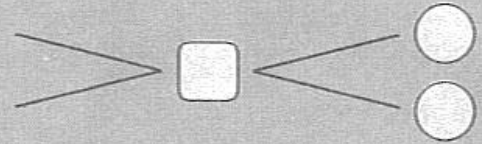

3 Pertence

+ Consulta

5 Figuras

6a Estória (imediato)

6b Estoria (após intervalo)

Rosios

8a Caminho (imediato)

$8 \mathrm{~b}$ Caminho (após intervalo)
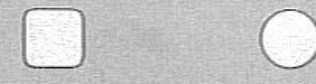

2

(1)
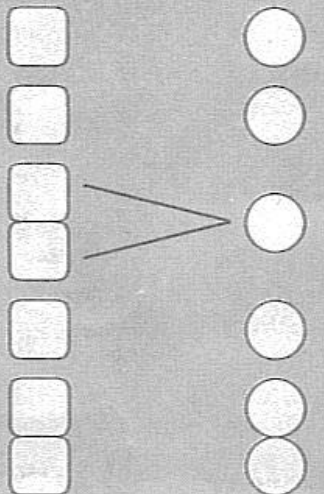

9 Recado (imediato e após intervalo)
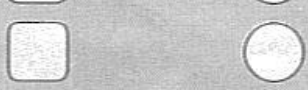

0 Orientação (não incluindo data)

11 Data

Total
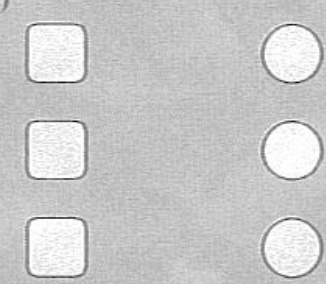

máximo $=24$ máximo $=12$

Versão Original Thames Valley Test Company 7-9. The green. Flempton Bury St Edmunds Suffolk IP28 6EI. Reino t'nido
Versâo Traduzida para o Portugué: Editora Cognição LTDA Rua México 11/1401. Centro Rio de Janeiro, RJ CEP: 2(0031-141. Brasil

\section{- 1 e 2 Nome e Sobrenome}

Apresente a Folografia e diga: 'Quero que você guarde na memória o nome desta pessoa. O nome dela é Carolina Santos. Você pode repetir o nome? Mais tarde vou perguntar o nome dela.'

\section{- 3 Pertence}

Diga: 'Você pode me emprestar alguma coisa? (objeto não valioso) Agora vou guardar o seu____ aqui. Guarde o objeto $\mathrm{cm}$ uma gaveta e assegure-se de que o sujeito veja onde o objeto ć escondido. Quando eu disser "nós terminamos o teste" quero que você peça seu e diga onde eu o coloquei."

\section{- 4 Consulta}

Diga: 'Vou programar este despertador para tocar em 15 minutos (demonstre o despertador e programe) Quando tocar, quero que você pergunte sobre a nossa próxima entrevista. Diga algo como: "Quando tenho que vê-lo novamente?" ou palavras que transmitam esta idéia.'

\section{- 5 Figuras}

Diga: 'Vou mostrar algumas figuras para você lembrar. Olhe cada uma cuidadosamente, e diga o nome do que está desenhado. Vou mostrar cada uma por cinco segundos para the dar uma chance de memorizar. Mais tarde vou mostrar mais figuras e quero que você escolha as que vai ver agora.' Apresente os desenhos numerados de I a 10 , no verso. Se o sujeito nomear incorretamente. dê o nome correto e anote que o sujeito pode ter dificuldades de percepção.

\section{- 6a Estória (imediato)}

Diga: 'Você vai ouvir uma estória curta. Ouça com atençâo, e quando tiver teminado diga tudo o que puder lembrar.' Toque a fita 'estorias - versão A'. Após o término da estoria. diga: 'Agora diga tudo o que puder lembrar.' Grave a resposta do sujeito. para pontuar após o teste.

\section{- 5 Figuras}

Diga: Vamos voltar às figuras que the mostrei mais cedo. Para cada figura quero que você diga "sim" se já viu antes, ou "não" em caso contrário.'

Apresente as 20 figuras. numeradas de 11 a 30 no verso. na ordem indicada (As figuras previamente apresentadas são indicadas por numeros em sobreserito). Não deve haver intervalos na apresentação. O sujeito deve ser encorajado a adivinhar. se estiver em dúvida. O sujeito não deve ver os números atrús dos cartões.

Registre as respostas: $\mathrm{S}$ para $\operatorname{sim} . \mathrm{N}$ para não

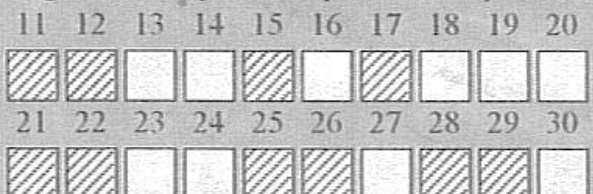

\section{- 7 Rostos}

Diga: Vou lhe mostrar alguns rostos. Olhe cada um com atençāo e diga se a pessoa é homem ou mulher. Diga também se a pessoa tem mais ou menos de 40 anos. Isto é só para ajuda-lo a se concentrar já que você terá que lembrar deles mais tarde.'

Apresente as 5 fotografias. numeradas de 1 a 5 no verso, na ordem indicada. Barbara Wilson Janet Cockbum Ilan Baddaley
Copyright (c) 1991
Traduçâo:

Rosinda M. Oliveira Sergio L. Sclmidt
Ecte teste não pode set reproduzido completo nem em partes em nenhuma

forma sem permissão por escrito dos editores. 


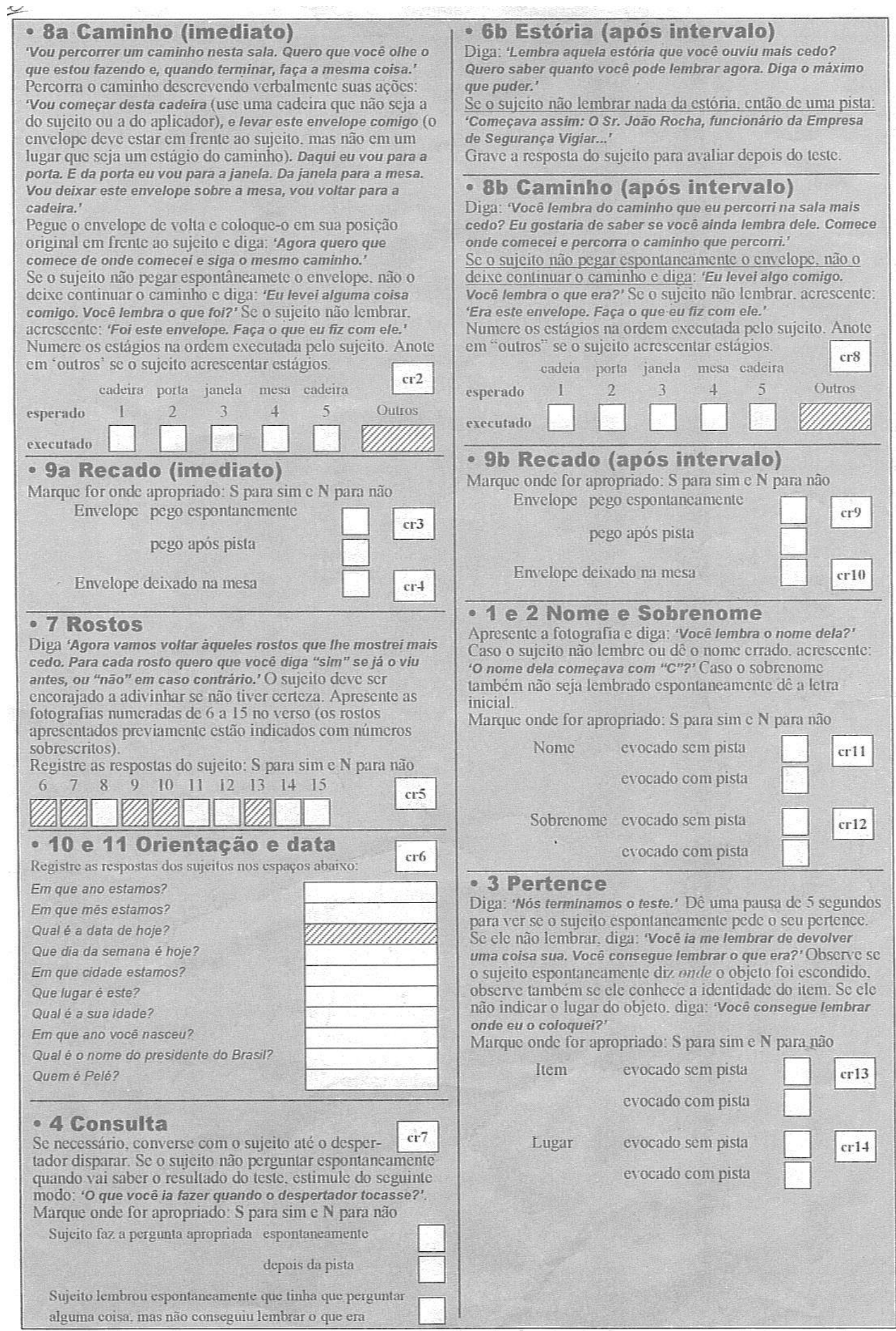


Pontuação

Para atribuir pontuação a cada um dos itens remeta-se ao campo de resposta (cr) indicado.

\section{Nome}

Veja $\operatorname{cr} 11$

\section{Escore}

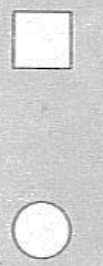

\section{Escore Bruto}

Nome evocado sem pista $=2$ evocado com pista $=1$

Escore de Perfil Padronizado Atribua o escore depois

Escore de Triagem

Se o sujeito evocou o nome sem pista $=1$ (De outro modo $=0$ )

\section{- 2 Sobrenome}

\section{Veja cr12}

\section{Escore}

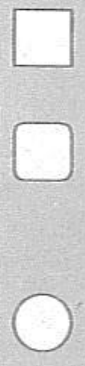

\section{Escore Bruto}

Nome evocado sem pista $=2$ evocado com pista $=1$

\section{Escore de Perfil Padronizado}

Some os Escores Brutos obtidos no item anterior (1 Nome) e neste item.

Escore Bruto

Escore de Perfil Padronizado

$\leq 2$

Escore de Triagem

Se o sujeito evocou o sobrenome sem pista $=1$ (De outro modo $=0$ )

\section{- 3 Pertence}

Para item' veja cr13, para 'lugar' veja er14

\section{Escore}

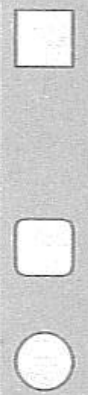

\section{Escore Bruto}

Some os escores para 'item'e 'lugar'

item lembrado sem pista $=2$ lembrado com pista $=1$

lugar lembrado sem pista $=2$ lembrado com pista $=1$

\section{Escore de Perfil Padronizado}

Escore Bruto

Escore de Perfil Padronizado $\quad 0 \quad 1 \quad 2$

\section{Escore de Triagem}

Se o sujeito evocou espontancamentc o itcm e o lugar onde estava escondido $=1$

(De outro modo $=0$ )

\section{- 4 Consulta}

\section{Veja cr 7}

Escore

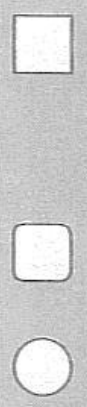

\section{Escore Bruto}

Pergunta apropriada feita espontaneamente $=2$ após a pista $=1$

Sujeito lembrou espontaneamente que devia perguntar alguma coisa mas não conseguiu lembrar o que era $=1$

Escore de Perfil Padronizado

$\begin{array}{llll}\text { Escore Bruto } & 0 & 1 & 2\end{array}$ Escore de Perfil Padronizado 0 l 2

Escore de Triugem

Pergunta apropriada feita sem pista, quando despertador disparou $=1$

(De outro modo $=0$ )

\section{- 5 Figuras}

O total de acertos corresponde ao número de quadriculos hachurados marcados com S. em cr1.

\section{Total de acertos}

O número de falso positivos corresponde ao número de quadrículos brancos marcados com S, em cr1

Número de falso positivos

Escore

\section{Escore Bruto}

Subtraia o número de falso positivos do número total de acertos.

\section{Escore de Perfil Padronizado}

Escore

Escore de Perfil Padronizado

$\leq 8 \quad 9$

Escore de Triagem

Todos os cinco rostos identificados corretamente sem nenhum falso positivo $=1$

(De outro modo $=0$ )

\section{- 6a Estória (imediato)}

Registre na Folha de Estória cada uma das 21 'idéias evocadas corretamente ou parcialmente.

\section{Escore}

O escore é baseado nos pontos dados pelas 'idéias'

evocadas corretamente. Logo. os pontos devem ser contados e calculados após o término do teste (Consulte o manual para avaliar as repostas).

\section{$\square$ Escore Bruto}

Cada 'idéia' evocada literalmene ou usando um sinônimo muito próximo $=1$

Cada 'idéia' evocada parcialmente. ou evocado com sinônimo aproximando $=0.5$

\section{Escore de Perfil Padronizado}

Escore Bri

Escore de Triagem

Atribua escore depois

\section{- 6b Estória (após intervalo)}

Registre na Folha de Estória cada uma das 21 'idéias evocadas corretamente ou parcialmente.

Escore

Atribua o escore do mesmo modo que para Estória (imediato) mas deduza um ponto do total se o sujeito precisou de pisla para começar

\section{Escore Bruto}

Cada 'idéia' evocada literalmene ou usando um sinônimo muito próximo $=1$

Cada 'idéia' evocada parcialmente, ou evocado com sinônimo aproximando $=0.5$

\section{Escore de Perfil Padronizado}

Escore Bruto $\leq 1,5 \quad 2-3,5 \geq 4$ Escore de Perfil Padronizado $0 \quad 1 \quad 2$

\section{Escore de Triagen}

Se o sujeito evocou pelo menos seis 'idéias' em Estória (imediato) e pelo menos quatro 'idéias' em Estória (após intervalo) $=1$ (De outro modo =0) 


\section{- 7 Rostos}

O total de acertos corresponde ao número de quadrículos hachurados marcados com S, em cr5.

Total de acertos

O número de falso positivos corresponde ao número de quadrículos brancos marcados com $\mathrm{S}$, em cr5. Número de falso positivos

Escore

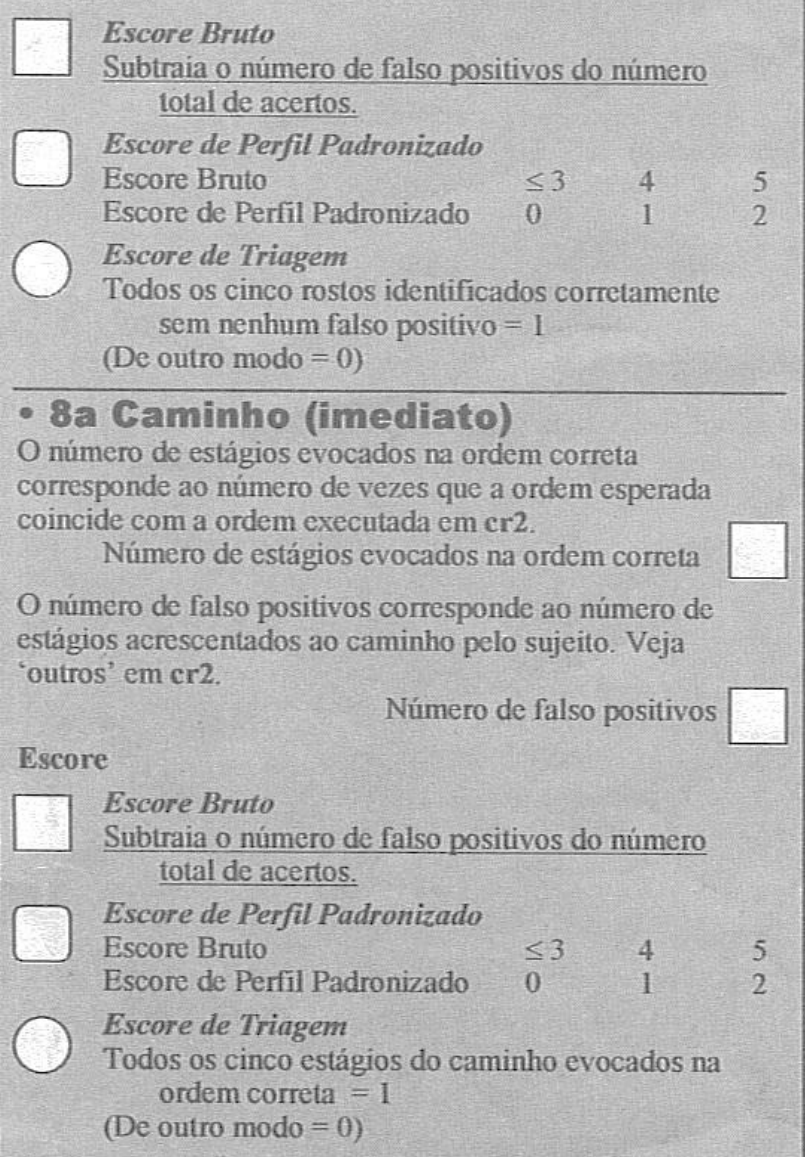

\section{- 8b Caminho (após intervalo)}

O número de estágios evocados na ordem correta corresponde ao número de vezes que a ordem esperada coincide com a ordem execulada em cr8.

Número de estágios evocados na ordem correta

O número de falso positivos corresponde ao número de estágios acrescentados ao caminho pelo sujeito. Veja 'outros' em cr8.

Número de falso positivos

\section{Escore}

Escore Bruto

Subtraia o número de falso positivos do número total de acertos.

Escore de Perfil Padronizado

Escore Bruto

Escore de Perfil Padronizado

Escore de Triagem

Todos os cinco estágios do caminho evocados na ordem $\operatorname{correta}=1$

(De outro modo =0)

\section{- 9a Recado (imediato)}

Veja cr3 e cr4

\section{Escore}

\section{Escore Bruto}

Some os escores para 'pegar' e 'deixar'. Escore para 'pegar'

Envelope pego espontaneamente $=2$

Escore para 'deixar'

$$
\text { pego após pista }=1
$$

Envelope deixado no lugar correto $=1$

Escore de Perfil Padronizado

Atribua o escore depois

Escore de Triagem

Atribua o escore depois

\section{- 9b Recado (após intervalo)}

Veja cr9 e cr10.

Escore

\section{$\square$ Escore Bruto}

Some os escores para 'pegar' e 'deixar' Escore para 'pegar'

Envelope pego espontaneamente $=2$ pego após pista $=1$

Escore para 'deixar':

Envelope deixado no lugar correto $=1$

\section{Escore de Perfil Padronizado}

Some os Escores Brutos obtidos no item anterior [ $9 a$ Recado (imediato)] e neste item.

Escore Bruto $\leq 4 \quad 5 \quad 6$

Escore de Perfil Padronizado 0012

Bscore de Triagem

Envelope pego e deixado no lugar certo nas evocações imediata e após intervalo $=1$

(de outro modo $=0$ )

\section{- 10 Orientação \\ Veja cr6.}

Escore

\section{Escore Bruto}

Número total de respostas corretas para as perguntas de Orientação, isto é,excluíndo Data

(Máximo $=9$ )

\section{Escore de Perfil Padronizado}

$\begin{array}{llll}\text { Escore Bruto } & 57 \quad 8 & 9\end{array}$

Escore de Perfil Padronizado 0 1 2

\section{Escore de Triagem}

Todas as nove respostas de Orientação corretas $=1$ (De outro modo =0)

\section{- 11 Data}

Veja cr6 (quadriculo hachurado)

Escore

Escore Bruto
Data correta $=1$

Escore de Perfil Padronizado

Escore Bruto $\geq$ Dois dias Um dia Data

Escore de

Perfil Nadronizado de diferença de diferença correta

Escore de Triagem

Data correta $=1$

(De outro modo $=0$ ) 
Apêndice F- PROTOCOLO DA REAVALIAÇÃO NEUROPSICOLÓGICA

\begin{tabular}{|c|c|c|c|c|}
\hline \multirow{6}{*}{ 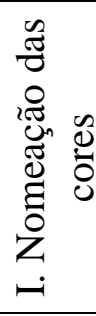 } & Verde & Rosa & Azul & Marrom \\
\hline & Rosa & Marrom & Verde & Azul \\
\hline & Azul & Verde & Rosa & Marrom \\
\hline & Marrom & Rosa & Azul & Verde \\
\hline & Rosa & Azul & Verde & Marrom \\
\hline & Marrom & Verde & Azul & Rosa \\
\hline \multirow{6}{*}{ 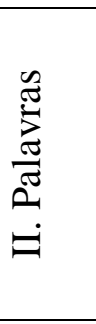 } & Verde & Rosa & Azul & Marrom \\
\hline & Rosa & Marrom & Verde & Azul \\
\hline & Azul & Verde & Rosa & Marrom \\
\hline & Marrom & Rosa & Azul & Verde \\
\hline & Rosa & Azul & Verde & Marrom \\
\hline & Marrom & Verde & Azul & Rosa \\
\hline \multirow{6}{*}{$\begin{array}{l}\stackrel{\tilde{U}}{0} \\
\text { Uे } \\
\Xi\end{array}$} & Verde & Rosa & Azul & Marrom \\
\hline & Rosa & Marrom & Verde & Azul \\
\hline & Azul & Verde & Rosa & Marrom \\
\hline & Marrom & Rosa & Azul & Verde \\
\hline & Rosa & Azul & Verde & Marrom \\
\hline & Marrom & Verde & Azul & Rosa \\
\hline
\end{tabular}

Seg $=$

Erros =

Seg $=$

Erros =

Seg $=$

Erros $=$ 
TESTE DE TRILHAS (TMT-A)

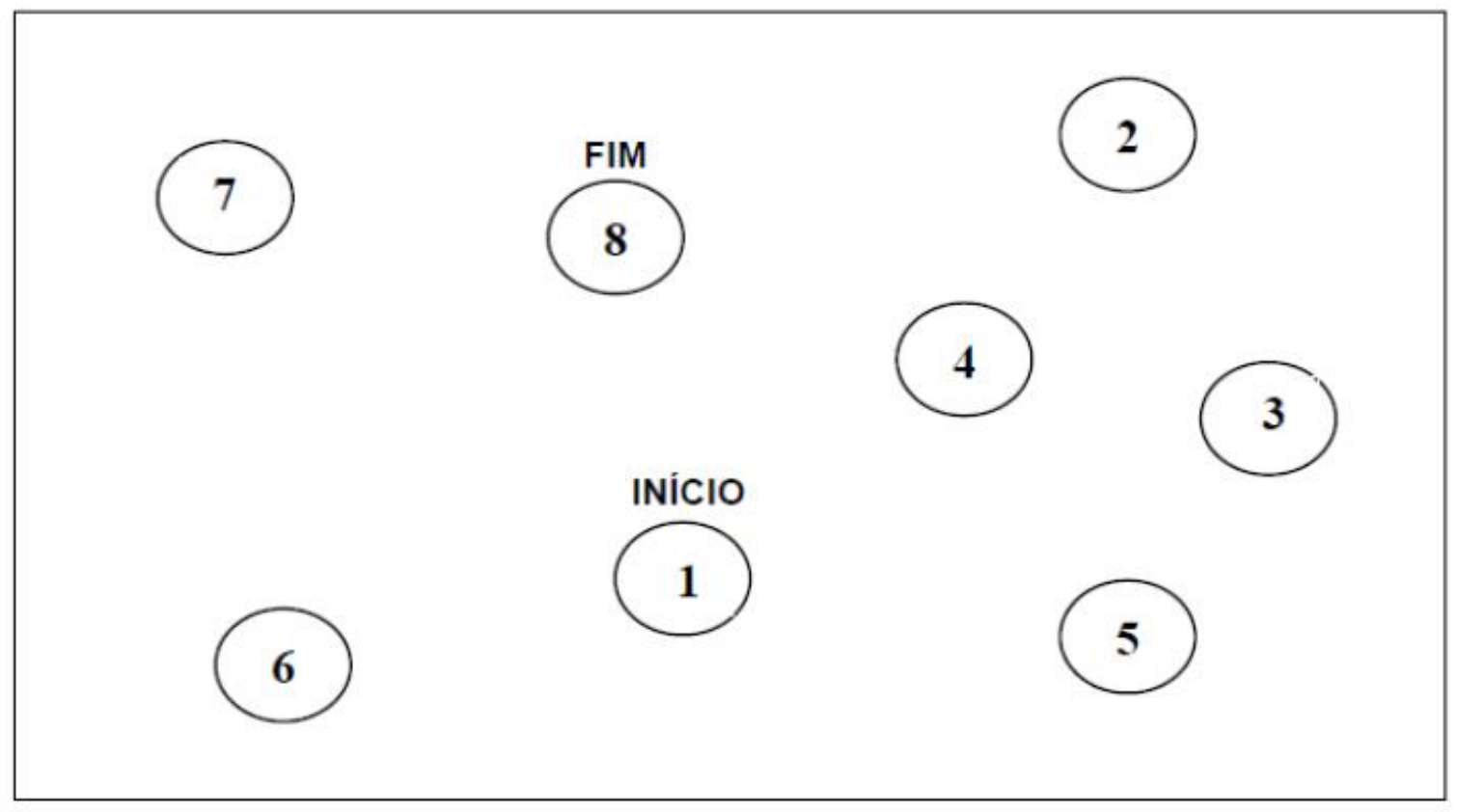

TESTE DE TRILHAS (TMT-B)

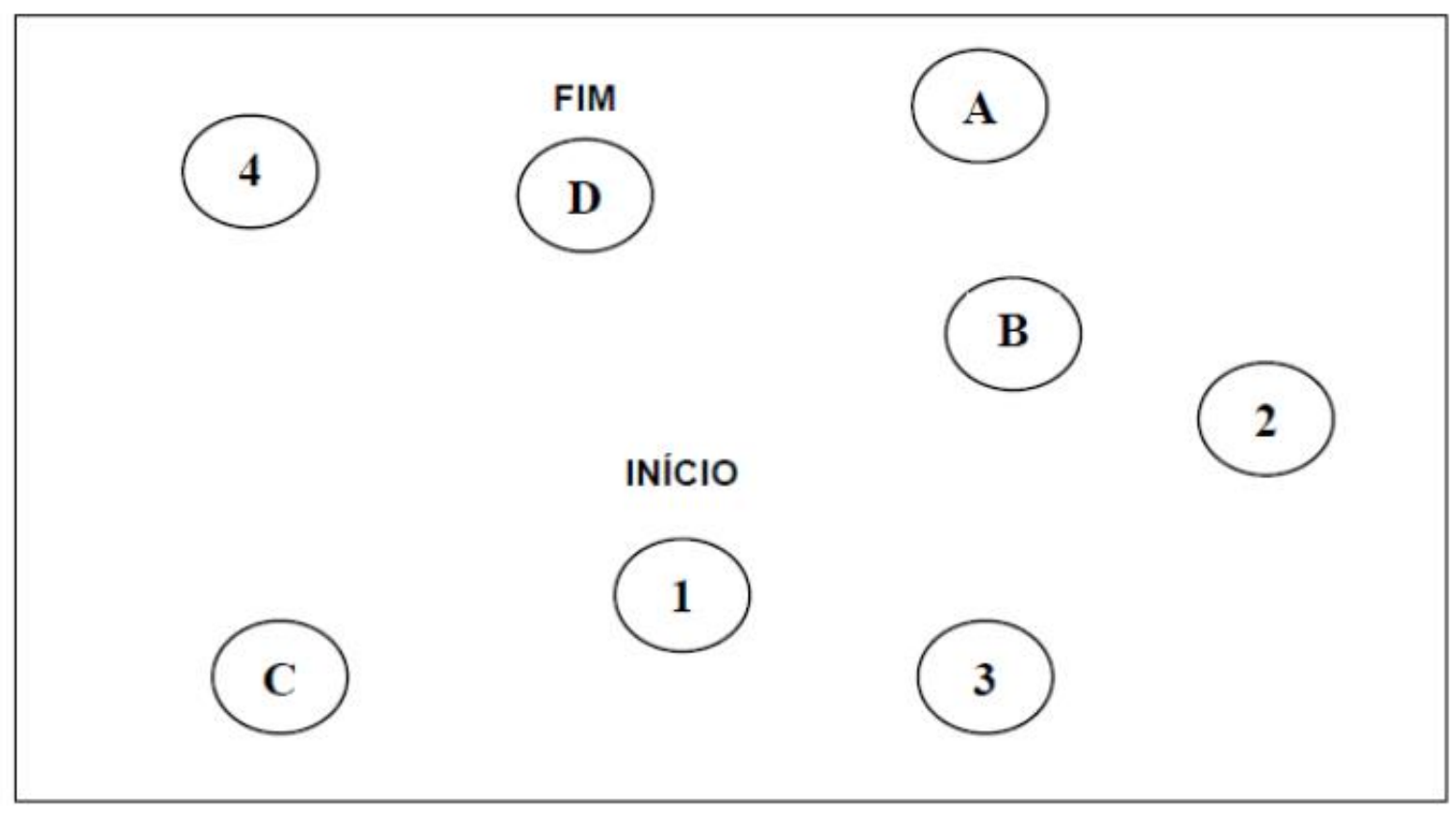




\section{5}

16<smiles>C1=CCCCC1</smiles>

(5)
17

20

(4)

18
13

(7)

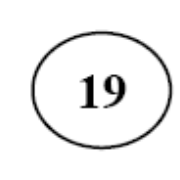

21

22

(6)

INícıo

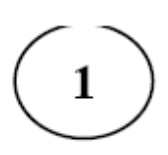

24

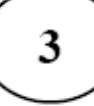

2

FIM

25

11 


\section{FIM}

13<smiles>c1ccccc1</smiles><smiles></smiles><smiles>c1ccccc1</smiles><smiles>c1ccccc1</smiles><smiles></smiles><smiles>C1CCCCCC1</smiles>

\section{5}

\section{3}

\section{H}

INICIO

(1)

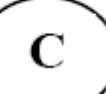

12

G

M

(A)

\section{2}

F

6 


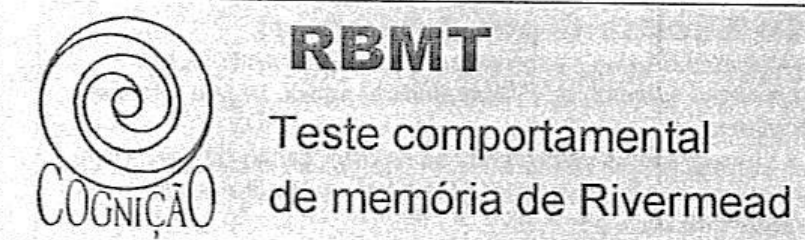

Guia de procedimento e folha de registro Verรaีด $\mathrm{B}$

- Esta folha de registro fornece um sumário do procedimento para assegurar que o teste seja feito consistentemente na ordem correta.

- Por favor, siga as instruções no manual para a orientação detalhada do procedimento e pontuação.
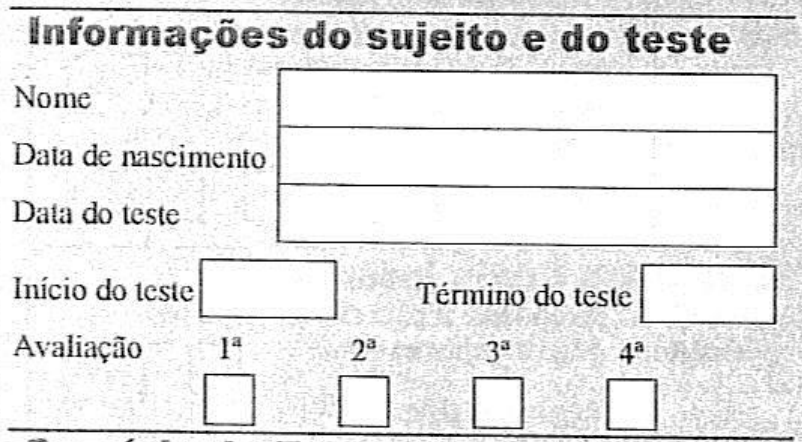

\section{Sumário de Rscores}

$\begin{array}{ll}\text { Escore de Perfil } & \text { Escore de } \\ \text { Padronizado } & \text { Triagem } \\ (2,1 \text { ou } 0) & (1 \text { ou } 0)\end{array}$

1 Nome

2 Sobrenome
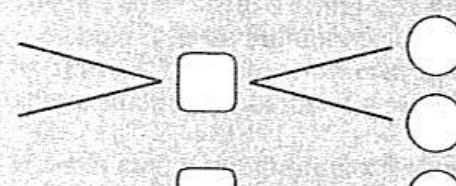

3 Pertence

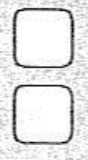

4 Consulta
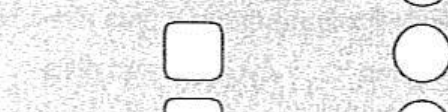

5 Figuras

6a Estória (imediato)

6b Estória (após intervalo)

7 Rostos

8a Caminho (imediato)

8 b Caminho (após intervalo)

9 Recado (imediato e após intervalo)

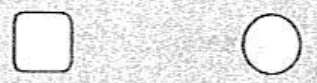

0 Orientação (não incluindo data)
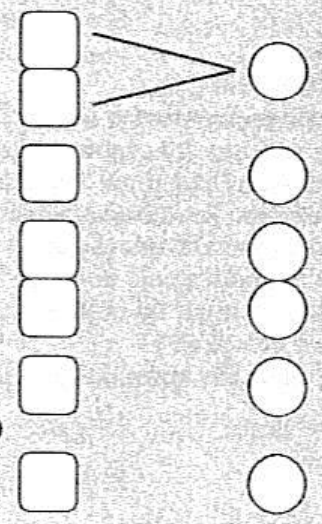

11 Data

Total
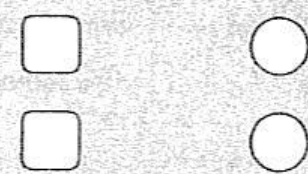

máximo $=2$

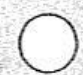

Versão Original

Thames Valley fest Company 7-9 The grean, Flempton

Bury St Fidmunds:

Suftolk IP2861:L. Reino Unido

\section{Versão Traduzida para o Português:}

Editora Cognição LTDA

Rua Mexico 11/1401, Centro

Rio de Janciro, RJ

CEP: 20031-141, Brasil

\section{- 1 e 2 Nome sobrenome}

Apresente a Fotografia e diga: Quero que você guarde na memória o nome desta pessoa. O nome dele é Carlos Machado Você pode repetir o nome? Mais tarde vou perguntar o nome dele.'

\section{- 3 Pertence}

Diga: 'Você pode me emprestar alguma coisa? (objeto não valioso) Agora vou guardar o seu_aqui. Guarde o objeto em um armário e assegure-se de que o sujeito veja onde o objeto é escondido. Quando eu disser "nós

terminamos o teste" quero que você peça seu e diga onde eu o coloquei.'

\section{- 4 Consulta}

Diga: 'Vou programar este despertador para tocar em 15 minutos (demonstre o despertador e programe) Quando tocar, quero que você pergunte quando este teste terminará. Diga algo como: "Quando este teste vai terminar?" ou palavras que transmitam esta idéia.'

\section{- 5 Figuras}

Diga: Vou mostrar algumas figuras para você lembrar. Olhe cada uma cuidadosamente, e diga o nome do que está desenhado. Vou mostrar cada uma por cinco segundos para the dar uma chance de memorizar. Mais tarde vou mostrar mais figuras e quero que você escolha as que vai ver agora." Apresente os desenhos numerados de 1 a 10 , no verso. Se o sujeito nomear incorretamente, dê o nome correto e anote que o sujeito pode ter dificuldades de percepção.

\section{- 6a Estória (imediato)}

Diga: 'Você vai ouvir uma estória curta. Ouça com atenção, e quando tiver terminado diga tudo o que puder lembrar.'

Toque a fita 'estórias - versão B'. Após o término da estória, diga: 'Agora diga tudo o que puder lembrar.' Grave a resposta do sujeito, para pontuar após o teste.

\section{- 5 Figuras}

Diga: Vamos voltar às figuras que the mostrei mais cedo. Para cada figura quero que você diga "sim" se já viu antes, ou "não" em caso contrário.'

Apresente as 20 figuras, numeradas de 11 a 30 no verso, na ordem indicada (As figuras previamente apresentadas são indicadas por números em sobrescrito). Não deve haver intervalos na apresentação. $O$ sujeito deve ser encorajado a adivinhar, se estiver em dúvida. O sujeito não deve ver os números atrás dos cartões.

Registre as respostas: $\mathrm{S}$ para sim, $\mathrm{N}$ para não

$\begin{array}{lllllllllll}11 & 12 & 13 & 14 & 15 & 16 & 17 & 18 & 19 & 20\end{array}$

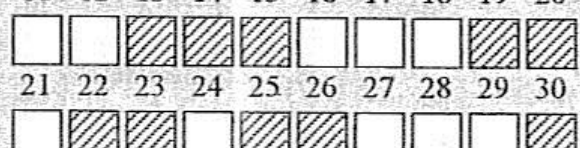

\section{- 7 Rostos}

Diga: Vou the mostrar alguns rostos. Olhe cada um com atençāo e diga se a pessoa é homem ou mulher. Diga também se a pessoa tem mais ou menos de 40 anos. Isto é só para ajuda-lo a se concentrar já que você terá que lembrar deles mais tarde.'

Apresente as 5 fotografias, numeradas de 1 a 5 no verso, na ordem indicada.

Copyright (c) 1991 Barbara Wilson Jantet Cockbum Alan Baddaley reproduzido completo ner em partes en nenhuma forma sem permissão por escrito dos editores. 


\section{- \&a Cantinho (imediato)}

Vou percricr un caminho nesta sala. Quero que você olhe o que estou fazendo e, quando terminar, faça a mesma coisa.' Percorra o caminho descrevendo verbalmente suas ações: 'Vou começar desta porta e fevar este envelope comigo (o envelope deve estar em frente ao sujeito, mas não em um lugar que seja um estágio do caminho), Daqui eu vou para a Janela, e vou deixar este envelope perto da janela. Da janela eu vou para a mesa. Da mesa para a cadeira (use uma cadeira que não seja a do sujeito ou a do aplicador), e vou voltar para a porta.

Pegue o envelope de volta e coloque-o em sua posição original $\mathrm{cm}$ frente ao sujeito e diga: 'Agora quero que comece de onde comecei e siga o mesmo caminho."

Se o sujeito não pegar espontâneamete o envelope, não o deixe continuar o caminho e diga: 'Eu levei aiguma coisa comigo: Você fembra o que foin' Se o sujeito não lembrar, acrescente: 'Foi este envelope. Faça o que eu fiz com ele.' Numere os estágios na ordem executada pelo sujeito. Anote em 'outros' se o sujcito acrescentar estágios.

$$
\text { porta janela mesa cadeira porta }
$$

esperado

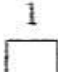

$$
2
$$

$$
3
$$

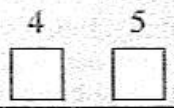

Outros

executado

\section{- Ga Recado (imediato)}

Marque for onde apropriado: S para sim e N para não

Envelope pego espontanemente

$$
\text { pego após pista }
$$

Envelope deixado na janela

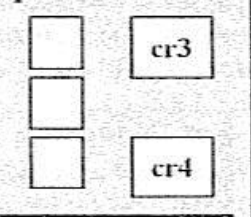

\section{- 7 Rostos}

Diga 'Agora vamos voftar àqueles rostos que lhe mostrei mais cedo. Para cada rosto quero que você diga "sim" se já o viu antes, ou "näo" em caso contrário.' $\mathrm{O}$ sujeito deve ser encorajado a adivinhar se não tiver certeza. Apresente as fotografias numeradas de 6 a 15 no verso (os rostos apresentados previamente estão indicados com números sobrescritos).

Registre as respostas do sujeito: $\mathrm{S}$ para sim e $\mathrm{N}$ para não

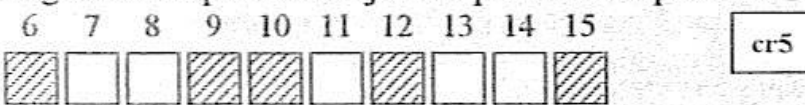

\section{- 10 e 11 Oriertaçáo c data}

Registre as respostas dos sujeitos nos espaços abaixo:

Em que ano estamos?

Em que més estamos?

Qual é a data de hoje?

Que dia da semana è hoje?

Em que cidade estamos?

Que lugar é este?

Qual é a sua idade?

En que ano você nasceu?

Qual é o nome do presidente do Brasil?

Quem é Pelé?

\section{- A Consulita}

Se necessário, converse com o sujeito até o desper- $\quad$ cr7 tador disparar. Se o sujeito não perguntar espontaneamente quando vai saber o resultado do teste, estimule do seguinte nodo: 'O que voce ia fazer quando o despertador tocasse?'. Marqutic onde for apropriado: $\mathrm{S}$ para sim e $\mathrm{N}$ para não

Sujeito faz a pergunta apropriada espontaneamente

$$
\text { depois da pista }
$$

Sujeito lembrou espontaneamente que tinha que perguntar alguma coisa, mas não conseguiu lembrar o que era

\section{- 6b Estória (após intervalo)}

Diga: 'Lembra aquela estória que você ouviu mais cedo? Quero saber quanto vocẽ pode fembrar agora. Diga o máximo que puder.'

Se o sujeito não lembrar nada da estória. então de uma pista: 'Começava assim: Bombeircs e voluntários trabalharam durante todo o dia...'

Grave a resposia do sujeito para avaliar depois do teste.

\section{- Bb Caminho (após intervalo)}

Diga: 'Você lembra do caminho que eu percorri na sala maís cedo? Eu gostaria de saber se você ainda fembra dele. Comece onde comecei e percorra o caminho que percomi.'

Se o sujeito não pegar espontancamente o envelope, não o deixe continuar o caminho e diga: 'Eu fevei algo comigo. Você lembra o que era?'Se o sujeito não lembrar, acrescente: 'Era este envelope. Faça o que eu tĩz com efe.'

Numere os estágios na ordem executada pelo sujeito. Anote cm "outros" se o sujeito acrescentar estágios. porta janela mesa cadeira porta

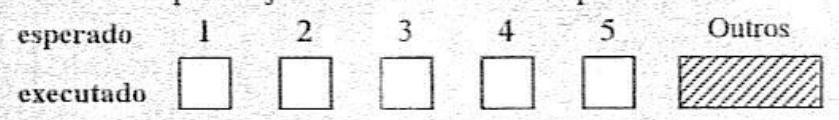

\section{- 9b Recado (apús intervalo)}

Marque onde for apropriado: $\mathrm{S}$ para sim e $\mathrm{N}$ para não Envelope pego espontaneamente

$$
\text { pego após pista }
$$

Envelope deixado na janela

\section{- 1 e 2 Nome e Sobrenome}

Apresente a fotografia e diga: 'Você lembra o nome dele?' Caso o sujeito não lembre ou dê o nome errado, acrescente: 'O nome dele começava coij " $\mathrm{C}$ "?' Caso o sobrenome também não seja lembrado espontaneamente dê a letra inicial.

Marque onde for apropriacio: S para sim e $\mathrm{N}$ para não

$$
\begin{array}{ccc}
\text { Nome } & \begin{array}{l}
\text { evocado sem pista } \\
\text { evocado com pista }
\end{array} \\
\text { Sobrenome } & \square \\
& \text { evocido sem pista } \\
& \text { evoudo com pista }
\end{array}
$$

\section{- 3 Pertence}

Diga: 'Nós temminamos o teste.' Dê uma pausa de 5 segundos para ver se o sujeito espontaneamente pede o seu pertence. Se ele não lembrar, diga: 'Yocé ia me lembrar de devolver uma coisa sua. Você consegue lembrar o que era?'Observe se o sujeito espontaneamente diz onde o objeto foi escondido, observe também se ele conliece a identidade do item. Se ele não indicar o lugar do objeto, diga: 'Você consegue Jembrar onde eu o coloquei?

Marque onde for apropriado: S para sim e $N$ para não

$\begin{array}{ll}\text { Item } & \text { evocado sem pista } \\ & \text { evocado com pista } \\ \text { Lugar } & \text { evocado sem pista } \\ & \text { evocado com pista }\end{array}$




\section{Penteaşa}

Para atribuir pontuação a cada um dos itens remeta-se ao campo de resposta (cr) indicado.

\section{- 1 Nome}

Veja cril.

Escore

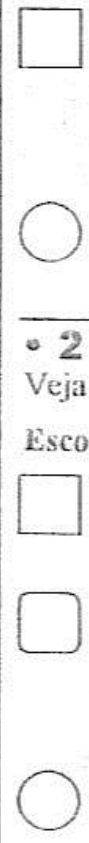

Escore Bruto

Nome evocado sem pista $=2$ evocado com pista $=1$

Escore de Perfil Padronizado

Atribua o escore depois

Escore ale Triagem

Se o sujeito evocou o nome sem pista $=1$ (De outro modo $=0$ )

\section{- 2 Sobrenome}

Veja $\mathrm{cr} 12$.

Escore

\section{Escore Bruto}

Nome evocado sem pista $=2$ evocado com pista $=1$

Escore de Perfil Palronizado

Some us Escores Brutos obtidos no item anterior (1 Wome) e neste ilem.

Escore Bruto $\quad \leq 2 \quad 3 \quad 4$

Escore de Perfil Padronizado $\quad 0 \quad 1 \quad 12$

Escore de Triagem

Se o sujeito evocou o sobrenome sem pista $=1$

(De outro modo $=0$ )

\section{- 3 Pertence}

Para 'item' veja cr13, para 'lugar' veja cr14.

\section{Escore}

\section{Escore Bruto}

Some os escores para 'item' e 'lugar'

'item ${ }^{2}$ lembrado sem pista $=2$ lembrado com pisia $=1$

'Iugar' lembrado sem pista $=2$ lembrado com pista $=1$

\section{Escore de Perfil Padronizado}

Escore Bruto

Escore de Perlil Padronizado

$\begin{array}{ll}\leq 2 & 3 \\ 0 & 1\end{array}$

Escore de Triagem

Se o sujeito evocou espontancamente o item e o lugar onde estava escondido $=1$

(De outro modo $=0$ )

\section{- 4 Consulta}

Veja cr7.

Escore

\section{Escore Bruto}

Pergunta apropriada feita espontaneamente $=2$ após a pista $=1$

Sujeito lembrou espontaneamente que devia perguntar alguma coisa mas não conseguiu lembrar o que era $=1$

Escore de Perfil Padronizado

Escore Bruto

Escore de Perfil Padronizado

$\begin{array}{lll}0 & 1 & 2\end{array}$

Escore de Triagem

Pergunta apropriada feita sem pista, quando despertador disparou $=1$

(De outro modo $=0$ )

\section{- 5 Figuras}

O total de acertos corresponde ao número de quadriculos hachurados marcados com S, em er1.

\section{Total de acerios}

O número de falso positivos corresponde ao número de quadrículos brancos marcados com $\mathrm{S}$, em er1. Número de falso positivos

\section{Escore}

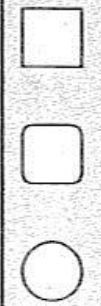

\section{Escore Bruto}

Subtraia o número de falso positivos do número total de acertos.

Escore de Perfil Padronizado

Escore de Triagem

Todos os cinco rostos identificados corretamente sem nenhum falso positivo $=1$

(De outro modo $=0$ )

\section{- Ga Estória (ímediato)}

Registre na Folha de Estória cada uma das 21 'idéias' evocadas corretamente ou parcialmente.

Escore

O escore é bascado nos pontos dados pclas 'idéias'

evocadas corretamente. Logo, os pontos devem ser contados e calculados após o término do teste (Consulte o manual para avaliar as repostas).

\section{Escore Bruto}

Cada 'idéia' evocada literalmene ou usando um sinônimo nuito próximo $=1$

Cada 'idéia' evocada parcialmente, ou evocado com sinônimo aproximando $=0.5$

Escore de Perfil Padronizado

Escore Bruto

$$
\leq 3,5 \quad 4-5,5 \geq 6
$$

Escore de Perfil Padronizado

Escore de Triagem

Atribua escore depois

\section{- Gb Estória (após intervallo)}

Registre na Folha de Estória cada uma das 21 'idéias' evocadas corretamente ou parcialmente.

\section{Escore}

Atribua o escore do mesmo modo que para Estória (imediato) mas deduza um ponto do tolal se o sujeito precisou de pista para começar.

\section{Escore Bruto}

Cada 'idéia' evocada literalmene ou usando um sinônimo muito próximo $=1$

Cada 'idéia' evocada parcialmente, ou evocado com sinônimo aproximando $=0,5$

Escore de Perfil Padronizado

Escore Bruto

Escore de Perfil Padronizado $\begin{array}{llll}0 & 1 & 2\end{array}$

Escore de Tritgem

Se o sujeito evocou pelo menos seis 'idéias' em Estória (innediato) e pelo menos quatro 'idéias' em Estória (após intervalo) = 1

(De outro modo $=0$ ) 


\section{- 7 Rostos}

O total de acertos corresponde ao número de quadriculos hachurados marcados com $\mathrm{S}$, em cr5.

Total de acertos

O número de falso positivos corresponde ao número de quadrículos brancos marcados com $\mathrm{S}$, em cr5. Número de falso positivos

\section{Escore}

\section{Escore Bruto}

Subtraia o número de falso positivos do número total de acertos.

Escore de Perfil Padronizado

Escore Bruto $\leq 3 \quad 4 \quad 5$

Escore de Perfil Padronizado $0 \quad 1$

Escore de Triagem

Todos os cinco rostos identificados corretamente sem nenhum falso positivo $=1$

(De outro modo $=0$ )

\section{- Ba Caminho (imediato)}

O número de estágios evocados na ordem correta corresponde ao número de vezes que a ordem esperada coincide com a ordem executada em $\mathrm{cr} 2$.

Número de estágios evocados na ordem correta

O número de falso positivos corresponde ao número de estágios acrescentados ao caminho pelo sujeito. Veja 'outros' em er2.

Número de falso positivos

\section{Escore}

\section{Escore Bruto}

Subtraia o número de falso positivos do número total de acertos.

\section{Escore de Perfil Padronizado}

Escore Bruto

$\leq 3 \quad 4$

Escore de Perfil Padronizado

0

Escore de Triagem

Todos os cinco estágios do caminho evocados na ordem correta $=1$

(De outro modo $=0$ )

\section{- 8b Caminho (após intervalo)}

O número de estágios evocados na ordem correta corresponde ao número de vezes que a ordem esperada coincide com a ordem executada em cr8

Número de estágios evocados na ordem correta

O número de falso positivos corresponde ao número de estágios acrescentados ao caminho pelo sujeito. Veja 'outros' em er8.

Número de falso positivos

Escore

\section{Escore Bruto}

Subtraia o número de falso positivos do número total de acertos.

Escore de Perfil Padronizado

Escore Bruto $\quad \leq 3 \quad 4 \quad 5$

Escore de Perfil Padronizado $\quad 0 \quad 1 \quad 2$

Escore de Triagem

Todos os cinco estágios do caminho evocados na ordem correta $=1$

(De outro modo $=0$ )

\section{- 9a Recado (imediato)}

Veja cr3 e cr4.

Escore

Escore Bruto

Some os escores para 'pegar' e 'deixar'.

Escore para 'pegar':

Envelope pego espontaneamente $=2$ pego após pista $=1$

Escore para 'deixar':

Envelope deixado no lugar correto $=1$

Escore de Perfil Padronizado

Atribua o escore depois

Escore de Triagem

Atribua o escore depois

\section{- 9b Recado (após intervalo)}

Veja cr9 e $\operatorname{cr} 10$.

Escore

\section{Escore Bruto}

Some os escores para 'pegar' e 'deixar'.

Escore para 'pegar':

Envelope pego espontaneamente $=2$

Escore para 'deixar' pego após pista $=1$

Envelope deixado no lugar correto $=1$

Escore de Perfil Padronizado

Some os Escores Brutos obtidos no item anterior [9a Recado (imediato)] e neste item.

Escore Bruto $\quad \leq 4 \quad 5$

Escore de Perfil Padronizado $\quad 0 \quad 1 \quad 2$

Escore de Triagem

Envelope pego e deixado no lugar certo nas evocações imediata e após intervalo $=1$ (de outro modo $=0$ )

\section{- 10 Orientaçäo}

Veja cr6.

Escore

\section{$\square$ Escore Bruto}

Número total de respostas corretas para as perguntas de Orientação, isto é,excluíndo Data

(Máximo =9)

\section{Escore de Perfil Padronizado}

Escore Bruto $\quad \leq 7 \quad 8 \quad 9$

Escore de Perfil Padronizado $\quad 0 \quad 1 \quad 2$

Escore de Triagem

Todas as nove respostas de Orientação corretas $=1$

(De outro modo $=0$ )

\section{- 11 Daéa}

Veja cr6 (quadriculo hachurado)

Escore

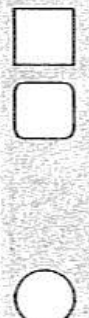

Escore Bruto

Data correta $=1$

Escore de Perfil Padronizado

Escore Bruto $\quad \geq$ Dois dias Um dia Data

Escore de

Perfil Padronizado $\quad 0 \quad 1 \quad 2$

Escore de Triagem

Data correta $=1$

$($ De outro modo $=0$ ) 